This is the version of the article/chapter accepted for publication in ournal of Historical Linguistics, 11 (1). pp. 1-59 published by John Benjamins Publishing

https://doi.org/10.1075/jhl.19021.bod

Accepted version downloaded from SOAS Research Online: http://eprints.soas.ac.uk/34573

(C) John Benjamins Publishing Company, contact publisher for re-use

\title{
The DUHUMBI PERSPECTIVE ON Proto-WeSTERn KHO-BWA ONSETS.
}

TIMOTHEUS ADRIANUS BODT

Postdoctoral researcher, Department of East Asian Languages and Cultures, School of African and Oriental Studies, University of London, United Kingdom.

Associate researcher, Institute for Linguistics, Bern University, Switzerland.

Rosmalenstraat 22,6843 SP Arnhem, the Netherlands.timintibet@hotmail.com 


\title{
The DUhumbi PERSPECTIVE ON Proto-WeStern KhO-BWA ONSETS.
}

\author{
Abstract \\ The eight Western Kho-Bwa varieties are spoken in western Arunachal Pradesh in Northeast \\ India and form a small, coherent sub-group of the Tibeto-Burman (Trans-Himalayan / Sino- \\ Tibetan) language family.
}

This paper presents 96 sound correspondences, mainly between the two Western Kho-Bwa varieties Duhumbi and Khoitam, with additional evidence from other Western Kho-Bwa varieties and other Tibeto-Burman languages whenever deemed illustrative. On basis of these sound correspondences, I propose 282 Western Kho-Bwa proto-forms including a total of 92 onsets. The less common reconstructed Western Kho-Bwa onsets are the uvular onsets and the voiceless nasal and approximant onsets.

A unique innovation of the Western Kho-Bwa languages, and indeed the Kho-Bwa languages in general, is the correspondence of initial ${ }^{*}$ s- in other Tibeto-Burman languages to a vocal onset in Proto-Western Kho-Bwa and its descendent varieties. Another relatively unique innovation is the correspondence between Western Kho-Bwa obstruent onsets *b- and *g$*^{*} \mathrm{k}_{-} \sim *^{*} \mathrm{k}$ - and other Tibeto-Burman nasal onsets *m- and ${ }^{*} \mathrm{y}-$, respectively.

\section{INTRODUCTION}

This introductory section first describes the Kho-Bwa cluster, and the Western Kho-Bwa languages as a coherent sub-group of this cluster. The introduction then describes the nature of the data on which the reconstruction is based and the method in which these data were collected. The introduction ends with an overview of the notational conventions used in this paper.

Northeast India, and in particular Arunachal Pradesh, is a linguistically important region, because of the high density of often endangered languages and language subgroups with unclear affiliations to the other languages of Asia (see, for example, Blench and Post 2014). The Kho-Bwa languages are no exception: they are poorly described, and the only historicalcomparative work on any of these languages is Lieberherr's historical phonology of the Puroik varieties (2015). In combination with the reconstruction of the Proto-Western KhoBwa rhymes (Bodt 2019), this reconstruction of the Proto-Western Kho-Bwa onsets aims to fill an important gap in our knowledge.

The main body of the paper presents a concise overview of the 96 sound correspondences among the initials of the Western Kho-Bwa languages that have been newly identified: plosive onsets $(\S 1-\S 24)$; vocal onsets $(\$ 25-\S 27)$; nasal onsets $(\S 28-\S 33)$; fricative onsets $(\S 34-\S 44)$; affricate onsets $(\S 45-\S 57)$; approximant onsets $(\S 58-\S 66)$ and sound correspondences in loans $(\S 67-\S 73)$. 'Trivial', or unambiguous correspondences, in which all varieties have the same or an easily derivable reflex, are presented first. More complex and unusual correspondences are provided after them. There are in total 282 reconstructions of inherited Western Kho-Bwa proto-forms presented in this paper. These reconstructions are based on the evidence from three or more of the attested Western Kho-Bwa varieties: at least one from either Khispi or Duhumbi, one from the Sartang varieties, and one from the Sherdukpen varieties, unless specifically mentioned otherwise. At the end of the paper, a separate section is devoted to sound correspondences in suspected loan lexemes, followed by a synopsis of the evidence presented in this paper. 
The Kho-Bwa cluster. The first report mentioning that the two small Eastern Himalayan communities 'Sulung' and 'Khowa' speak mutually intelligible languages can be found in Stonor (1952). After a lapse in research caused by geopolitical tensions in the area that lasted three decades, Indian language officers published the first linguistic materials on Puroik (a.k.a. Sulung: Deuri 1982, Tayeng 1990) and Bugun (a.k.a. Khowa, Dondrup 1990), Sartang (a.k.a. Boot Monpa or Butpa, Dondrup 2004) and Sherdukpen (Dondrup 1988). At around the same time, Puroik data were published in China as part of the large-scale survey "TibetoBurman Phonology and Lexicon" (Sūn 1991). Sun $(1992,1993)$ was the first to suggest that Puroik, Bugun, Sherdukpen and 'Lishpa-Butpa' (with data for Lishpa probably derived from the short wordlist in Das Gupta's 1968 description of Central Monpa, i.e. Dirang Tshangla) might belong together as a coherent linguistic group. ${ }^{1}$ This view was adopted by others, such as Rutgers (1999), although Blench and Post (2014) and Post and Burling (2017) expressed scepticism about Puroik being part of this proposed group of languages. ${ }^{2}$

Van Driem (2001) named this group "Kho-Bwa cluster", after his proposed reconstructions for 'water' and 'fire'. Although the current status of research favours the reconstructions *kwa 'water' and *baj 'fire', the name Kho-Bwa has already gained some currency and is not biased toward one language like 'Bugunish' (Sun 1993) or a region like 'Kamengic' (Blench and Post 2014, Post and Burling 2017). In addition, the first root in the name Kho-Bwa evidences the uncommon lexical innovation *kwa 'water' based on Proto-Puroik *kua (Lieberherr 2015), Proto-Western Kho-Bwa *kho (this paper) and attested Dikyang and Rama Bao Bugun $k^{h} O$ (own data and Lander-Portnoy 2013). The second root in the name Kho-Bwa evidences the rather distinct sound correspondence between onset $m$ - in the reconstructed root 'fire' for other Tibeto-Burman languages, *mej (Matisoff 2003), and onset $b$ - in 'fire' for Proto-Puroik *baj (Lieberherr 2015), Proto-Western Kho-Bwa *baj (this paper) and attested Dikyang Bugun boe and Rama Bao Bugun baj (own data and LanderPortnoy 2013). Both features characterise the languages of the Kho-Bwa cluster in respect to other languages of western Arunachal Pradesh and, indeed, in respect to many languages of the Tibeto-Burman language family as a whole.

The Western Kho-Bwa languages. Lieberherr \& Bodt (2017) present evidence for an internal subgrouping of the Kho-Bwa languages in the Puroik varieties, the Bugun varieties, and the eight varieties spoken in the western part of the Kho-Bwa speech area, the Western Kho-Bwa languages. Although the Western Kho-Bwa languages form a distinct sub-group as opposed to both Bugun and Puroik, there is no evidence that Bugun and Puroik belong together as 'Eastern' Kho-Bwa. The eight Western Kho-Bwa varieties are spoken in the valleys of the Gongri and Tenga rivers that administratively belong to West Kameng district of the state of Arunachal Pradesh, India (Bodt 2014a, Bodt 2014b). Lieberherr \& Bodt (2017) present further evidence that the Western Kho-Bwa languages can be sub-divided in two subgroups: Duhumbi (Duh.) and Khispi (Khs.), a.k.a. 'Chugpa' and 'Lishpa', and the 'Sherdukpen' (Shd.) varieties Rupa (Rup.) and Shergaon (She.) and the 'Sartang' (Sar.) varieties Khoina (Khn.), Jerigaon (Jer.), Khoitam (Kht.) and Rahung (Rah.). Sherdukpen and Sartang are considered as distinct ethno-linguistc groups based on historical, ethnological and sociopolitical arguments (Bodt 2014a, Bodt 2014b), but appear to form a dialect continuum based

\footnotetext{
${ }^{1}$ More recent publications, at the time unavailable to Sun, include the Puroik description from China by L $\check{1}$ (2004), the Sherdukpen description by Jacquesson (2015), the Bugun phonology by Lander-Portnoy (2013) and the elicited wordlists of different varieties in the report by Abraham et al. (2018 [2005]).

${ }^{2}$ Nonetheless, all commonly consulted handbooks (Genetti 2016, Post \& Burling 2017) and the online language encyclopaedias Ethnologue (Eberhard, Simons \& Fennig 2019) and Glottolog (Hammarström et al. 2019) mention Kho-Bwa as a (potential) branch of Tibeto-Burman in western Arunachal Pradesh.
} 
on linguistic criteria. The number of speakers merely ranges from 400 (Jerigaon) to 3,000 (Rupa) and all these varieties must be considered endangered.

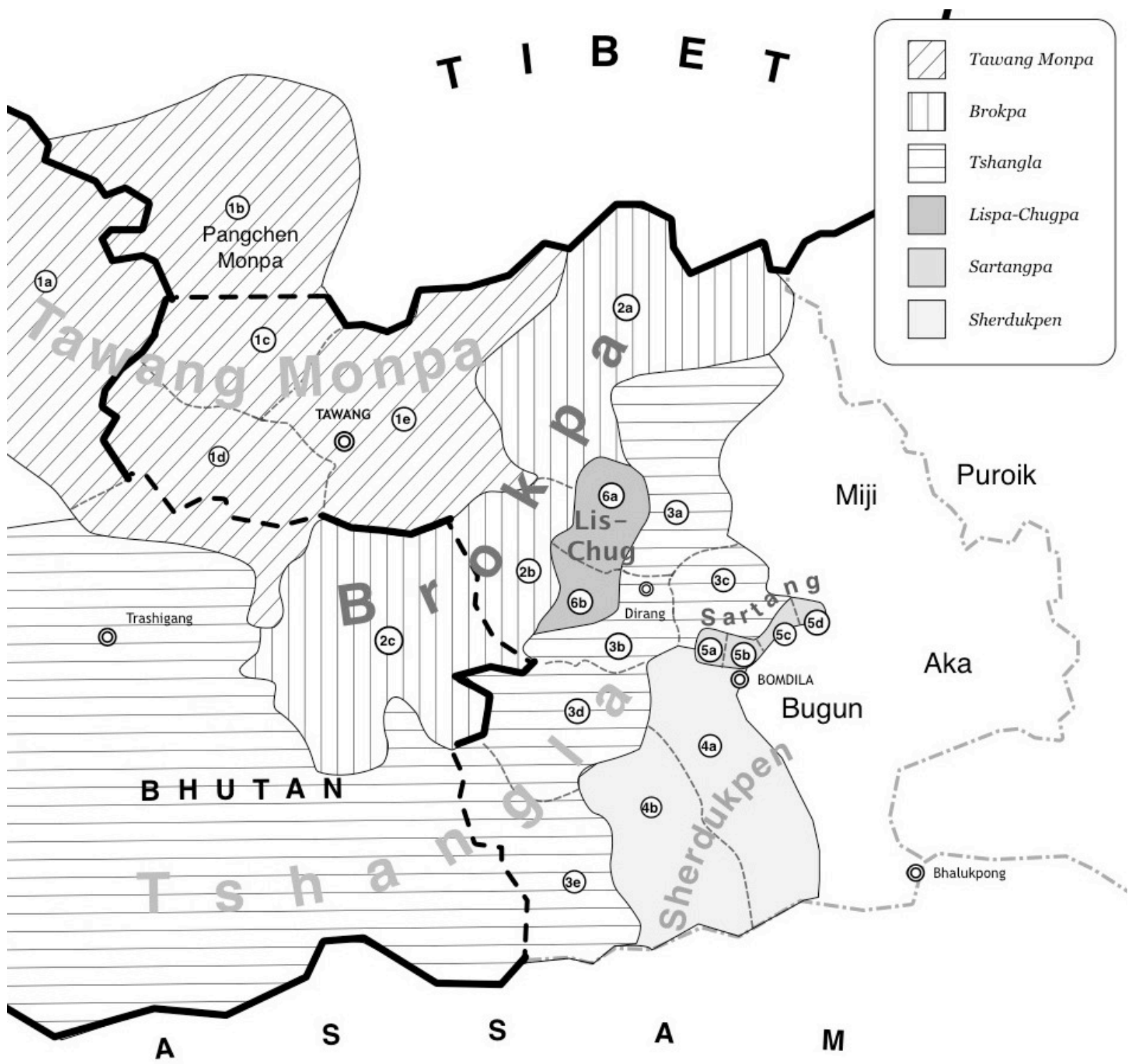

Figure 1. The Western Kho-Bwa varieties (4a: Rupa, 4b: Shergaon; 5a: Rahung, 5b: Khoitam, 5c: Jerigaon, 5d: Khoina; 6a: Duhumbi; 6b: Khispi) and neigbouring languages (from Bodt 2014a).

This paper primarily presents correspondences between Duhumbi and Khoitam. Duhumbi has most conservatively preserved rhymes. Khoitam is representative of the Sartang and Sherdukpen varieties, that have innovated in the rhymes. Khoitam has had less contact influence from Hrusish than Khoina and Jerigaon and less contact with Bodish and Tshangla than Rupa, Shergaon and Rahung. ${ }^{3}$ Wherever the Duhumbi or Khoitam evidence is absent or inconclusive, evidence from one of the other varieties is provided. Of particular significance

\footnotetext{
${ }^{3}$ Contact languages in the western part (influencing mainly Khispi, Duhumbi, Rahung, Rupa and Sherdukpen and to a lesser extent Khoitam and Jerigaon) include Central Bodish Brokpa (Bro.), Chocangaca and Tibetan (Tib.), East Bodish Tawang Monpa (Mon.) and the Dirang variety of Tshangla (Tsh.D.). Contact languages in the eastern part affecting mainly Khoina and Jerigaon are the Hrusish languages Miji (Mij.) and Hruso Aka (Hru.). Linguistic influence of Bugun (Bug.) and Puroik (Pur.), which will be shown to be genetically related in a forthcoming paper, is negligible.
} 
is the evidence provided by Khoina, the variety spoken in what is generally considered the Western Kho-Bwa 'homeland' (Bodt 2014b: 163, 166). Khoina evidences retention of archaic phonemes or unique phonological innovations that are not present in any of the other varieties. A forthcoming monograph on the reconstruction of Proto-Western Kho-Bwa will present the data from all the Western Kho-Bwa varieties.

The data. The Khispi, Duhumbi, Sartang and Sherdukpen data in this paper are all from own data, unless mentioned otherwise. These data were collected between March 2012 and November 2019, with the majority of data collected in May and June 2014, February 2015 and in October and November 2018. Initially, a 556-entry list of concepts was used to elicit the basic data (the "Basic Word List", Bodt 2020). This wordlist contains items from the most commonly used elicitation wordlists, such as the 100 item Leipzig-Jakarta list (Haspelmath \& Tadmor 2009) and the 100-item Swadesh list (Swadesh 1971: 283), but also includes many additional concepts. Examples of these additional concepts are names of flora and fauna characteristic to the region, agricultural crops and culturally significant vocabulary. As far as was feasible under field conditions, the complete elicitation sessions were recorded, and additionally, all wordlists were triple recorded with two speakers for each variety, one male and one female.

The wordlist had been translated into Romanised Hindi and those items for which no reasonable Hindi equivalents could be found had been translated into Tshangla. Tshangla has for long been a lingua franca in the area. Especially the older generation (50 years and above) in Lish, Chug, Rahung, Khoitam, Rupa and Shergaon still has a reasonable to good command of the language. Proficiency in Tshangla is much less among the younger generation in these villages, and absent to poor in all age groups in Khoina and Jerigaon. In addition, a Duhumbi speaker fluent in Sherdukpen came along during the fieldwork in the Sherdukpen and Sartang villages. Communication with this speaker was in Duhumbi, Tibetan, Tshangla and Hindi. Hence, the choice of language in which the data were elicited greatly depended on the background of the respondent.

In addition to the 556-item wordlist, further concepts and short phrases were elicited and recorded from one speaker in Khoitam, Rahung, Rupa and Khispi. The additional concepts elicited in Khoitam and Rahung were based on Dondrup (2004), which had been compared to the lexicon of Duhumbi to find potential cognates. The additional concepts elicited in Rupa were based on Dondrup (1988) and Jacquesson (2015), which had similarly been compared to the lexicon of Duhumbi to find potential cognates. Additional concepts were elicited in Khispi based on the lexicon of Duhumbi.

After the initial analysis described below, missing concepts in the respective varieties were elicited and recorded from a single speaker of each variety and included in the subsequent stages of manual and automated analysis.

Comparative data are provided for attested and reconstructed languages from various sources. These include: Middle and Old Chinese (Chi.) from Baxter \& Sagart (2014) ${ }^{4}$, Mizo (Miz., Lushai) from Lorrain (1940), Proto-Bodo-Garo (PBG) from Joseph \& Burling (2006), ProtoPuroik (PP) from Lieberherr (2015, 2017), Lashi (Las.) from Hill (2019), and Tshangla (Tsh.), Bugun (Bug.), Brokpa (Bro.) and Tawang Monpa (Mon.) from own fieldwork.

\footnotetext{
${ }^{4}$ Several reviewers pointed out the daring nature of many of the correspondences with Chinese. I certainly do appreciate their concerns and reservations and have removed several of the more tentative correspondences, for which evidence remains weak. All remaining correspondences with the Middle and Old Chinese forms should be interpreted as possible cognates pending further research into possible regular sound correspondences and the phylogenetic relationships within the language family.
} 
Tibetan (Tib.) forms are from various sources, including Jäschke (1992 [1881]), Hill (2019) and Zhāng (1993). The sources for other, incidental, comparative data are mentioned with the form.

The methodology. Initially, in a manual analysis, potential cognates were identified, and the sound correspondences were set up. In addition, the data set was converted to a spreadsheet with standardised notations and normalised to a level where it could be automatically processed with the help of the software tools provided by the LingPy Python package (List et al. 2018), post-edited and corrected with help of the web-based EDICTOR tool (List 2017), and used for computer-assisted language comparison following the work flow for the reconstruction of Proto-Burmish (Hill \& List 2017). Depending on the variety, the initial data set was missing between $5 \%$ and $34 \%$ of the concepts. Based on this data set, we then automatically detected cognates and regular sound correspondences (List 2019) which were manually adjusted. In addition, we used this data set to make predictions for the values of the missing concepts. This experiment was registered online (Bodt, Hill \& List 2018) and described in a publication (Bodt \& List 2019), and after elicitation of the missing concepts, the results were presented at an international conference and are currently in preparation for publication.

The number of individual cognate sets attesting to each sound correspondence is robust for most of the sound correspondences described here, i.e. three or more. Wherever there are fewer than three examples of a presumed sound correspondence, this is specifically mentioned. The minor sound correspondences are nonetheless thought to be valid and their specific mention here may facilitate uncovering further cognate sets that attest to them.

This paper does not discuss the actual process of elicitation, cognate identification or setting up sound correspondences, but rather focuses on the results themselves. Elicitation is complicated by factors such as contact language bias and diverse levels of linguistic proficiency of respondents. Cognate identification in multilinguistic environments needs to consider a wide range of methodological issues, such as multiple layers of substrate and superstrate linguistic varieties; language contact, multidirectional borrowing and loans 5 ; semantic chances; multimorphemic roots with distinct reflexes in descendant varieties; lexical and grammatical suffixes; lexical compounding; and multiple roots expressing closely related concepts. A paper discussing several of these methodological issues in elicitation and cognate identification using examples from the reconstruction of Proto-Western Kho-Bwa is in preparation. The complete cognate sets, with the reflexes in all individual varieties in this paper and the corresponding sound files, when available, can be found in the supplementary material on the Open Access website Zenodo (Bodt 2018a, 2018b, 2018c, 2018d).

Notational conventions. In this paper, cognate sets deriving from reconstructed palatalised and labialised onsets are treated on par with simple onsets when these onsets have only resulted in divergent rhyme reflexes. Reconstructed palatalised and labialised onsets and

\footnotetext{
${ }^{5}$ Two of the anonymous reviewers expressed the opinion that several of the reconstructed Proto-Western KhoBwa roots and their attested descendent forms are Bodish (Tibetan) loans. However, the existence of cognates in Tibetan does not necessarily indicate that these are loans from Tibetan. Although Khispi, Duhumbi, Rahung, Khoitam, Rupa and Shergaon have, indeed, witnessed prolongued language contact with Bodish languages such as Brokpa, Central Tibetan and Tawang Monpa, such contact was much less in Khoina and Jerigaon. The Western Kho-Bwa linguistic history described in Bodt (2014b) indicates an early (Old-, Pre- or Proto-?) Bodish contribution to Western Kho-Bwa before the subsequent split in the descendent varieties. Having participated in the Western Kho-Bwa sound changes, these forms with Bodish cognates display regular phonological correspondences, indicating they form part of the inherited Proto-Western Kho-Bwa vocabulary. They may, in fact, form an important criterion for sub-classification of the Kho-Bwa languages, as they most likely lack in the other Kho-Bwa languages, Bugun and Puroik.
} 
rhotic onset clusters are only mentioned separately in case they result in divergent onset reflexes. Every cognate set has a reference to the relevant rhyme correspondence in the paper on Western Kho-Bwa rhymes (Bodt 2019). The evidence is generally presented in the following format:

$\S \#$. Duhumbi onset, Khoitam onset, other relevant onsets. Duhumbi form $<*$ reconstructed Proto-Western Kho-Bwa form 'English gloss', Khoitam form, other relevant Sartang and Sherdukpen forms, other relevant comparative forms (§\# rhyme correspondence)

All forms in italics are attested forms from Western Kho-Bwa languages in IPA notation. English glosses are provided between single quotation marks ("). The symbol $(<)$ indicates that the form before the symbol (usually an attested from) is proposed to derive from the form following the symbol (usually a reconstructed form). A question mark (?) before a reconstructed form either indicates that this reconstruction is tentative, or that it is the reconstruction of a form that was borrowed from a contact language. A single dagger $\left({ }^{\dagger}\right)$ refers to a not (yet) attested but hypothesised form, presented between brackets [] when different from an attested form. An asterisk $(*)$ precedes a reconstructed proto-form in ProtoWestern Kho-Bwa or in another reconstructed proto-language. A tilde $(\sim)$ indicates variant forms such as allophones or allomorphs. A period (.) separates morphemes in a single word, in which single phonemes that are thought to derive from reconstructed syllables with grammatical function (e.g. phonetically reduced prefixes in the Sartang and Sherdukpen varieties, such as $s$. from * ${ }^{\mathrm{j} j a}$. 'animal prefix') are treated as separate morphemes rather than as part of the onset. The short, glottal constricted, creaky voiced and rising pitch open vowels in the contemporary Western Kho-Bwa varieties are transcribed with a superscript glottal stop following the vowel $\left[\mathrm{v}^{2}\right]$, although they would more accurately be transcribed as $\left[\mathbf{v}^{2}\right]$. These short vowels contrast with their long, breathy voiced, level pitch counterparts, which are represented in the Sartang and Sherdukpen varieties with [v:] although they would more accurately be transcribed as $[\overline{\mathrm{V}}: \sim \overline{\mathrm{V}}: \mathrm{i}]$. Additional transcription symbols found in Chinese reconstructions are $\left.{ }^{(}\right)$indicating type A syllables and $\left(^{?}\right)$ indicating pre-glottalised onsets. In Burmese and Tibetan transcriptions, the velar nasal is indicated by $(\dot{\mathrm{n}})$, the palatal nasal by $(\tilde{n})$, the unvoiced and voiced palatal fricatives by (ś, ź) and level tone in Burmese by a macron $\left({ }^{-}\right)$above the vowel.

The Sherdukpen varieties Rupa and Shergaon have distinctive postalveolar affricates [t $]$, [ $\left.\mathfrak{t}^{\mathrm{h}}\right]$ and [d] but no distinctive postalveolar [ $\left.\int, 3\right]$ or palatal fricatives [6, z]. A distinction between the postalveolar affricates and alveolar affricates $[\mathrm{ts}],\left[\mathrm{ts}^{\mathrm{h}}\right]$ and $[\mathrm{dz}]$ is only maintained among older speakers, with younger speakers merging the alveolar affricates with the postalveolar affricates. Similarly, only older Rupa Sherdukpen speakers maintain distinctive palatal stops $\left[\mathrm{c}^{\mathrm{h}}\right]$ and $[\mathrm{f}]$, whereas these have again merged with the postalveolar affricates in Shergaon and among the younger Rupa speakers. ${ }^{6}$ Khispi and Duhumbi have distinctive palatal fricatives [6] and [z] and palatal affricates [t6], [t6 $\left.{ }^{\mathrm{h}}\right]$ and $[\mathrm{d}]$. None of the varieties maintains a distinction between postalveolar and palatal affricates and the exact phonetic value of the affricates in the proto-language is unknown. Hence, the affricates have been reconstructed as $*_{\mathrm{ts}}, *_{t \mathrm{~s}}^{\mathrm{h}}$ and $*_{\mathrm{c}}$ for the alveolar series and $*_{\mathrm{c}}, *^{\mathrm{c}^{\mathrm{h}}}$ and $*_{\mathrm{j}}$ for the postalveolar or palatal series. No such notational convention had to be assumed for the palatal fricatives, even though these vary between [J] and [3] in Khoina and [6] and [z] in Duhumbi and Khispi, because there is

\footnotetext{
${ }^{6}$ I.e. in Rupa, the oldest generation of speakers maintains a phonemic distinction between $t$ - and $t s_{-}, t^{h-}$ and $t^{h_{-}}$, $t^{h^{-}}$- and $c^{h_{-}}, d t_{-}$- and $d t$ - and $d t_{-}$- and $f_{-}$, whereas in the younger generation $t t_{-}$and $t$ - have merged to $t_{-}, t^{h_{-}}, c^{h_{-}}$and $t 6^{h}$ - have merged to $t 6^{h}$ - and $y^{-}$and $d t_{-}$(and often $d t$-) have merged to $d_{t-}$ (as in most other Sartang and Sherdukpen varieties except Khoina). As this is an ongoing phonological process with varying actual realisations as well as significance for the reconstructions, the notation $(\sim)$ was used (e.g. $\left.t^{h} a k \sim t 6^{h} a k\right)$.
} 
hitherto no evidence that these palatal fricatives existed in the proto-language. In the IPA notation, palatal fricatives are transcribed uniformly as [6] and [z], even for Khoina.

Similarly, despite the fact that some varieties have postalveolar rather than palatal affricates, the IPA transcription used in this paper uniformly uses palatal affricates [tc], [t. $\left.{ }^{\mathrm{h}}\right]$ and [t?].

The Sartang and Sherdukpen nasalised vowels are the result of the loss of nasal codas and these nasal codas can invariable be reconstructed as $/ \mathrm{y}, \mathrm{n}, \mathrm{m} /$ on the basis of the retained codas in Khispi and Duhumbi. Some speakers may still realise the nasal coda, whereas others may realise them solely as nasalisation of the preceding vowel. The realisation of the final nasal is not relevant for the reconstruction because the nasalisation of the vowel is sufficient evidence, hence, this variation in realisation is not reflected in the notation (e.g. $t^{h} \tilde{\imath} \eta$ not $t^{h} \tilde{l}:$ $\left.t^{h} \tilde{i \eta}\right)$. In those lexemes where the nasal is lost among all speakers, only nasalisation of the vowel is reflected in the notation (e.g. $t^{h} \tilde{\imath}:$ not $\left.t^{h} \tilde{i} n\right)$.

Detailed phonological descriptions of the Western Kho-Bwa varieties will be provided in a forthcoming monograph on the reconstruction of Proto-Western Kho-Bwa.

\section{Plosive ONSETS}

Voiced plosive onsets in Duhumbi correspond to voiced plosive onsets in Khoitam. Aspirated plosive onsets in Duhumbi correspond to aspirated plosive onsets in Khoitam. All Western Kho-Bwa languages show a marked paucity of the nonetheless distinctive voiceless, unaspirated plosives, especially $p$ - and $k$-. In many cases, voiceless, unaspirated plosives appear to derive from labialised or palatalised voiceless unaspirated onsets or from rhotic onset clusters of voiceless, unaspirated plosives. Presumably, the Western Kho-Bwa languages have regularly aspirated the simple voiceless, unaspirated onsets in most phonotactic environments.

\subsection{TRIVIAL CORRESPONDENCES}

There are eight correspondences in which all varieties have the same reflex.The main absent correspondence is that of the voiceless bilabial plosive $p$ -

§1. Duh. g-, Kht. g-. Voiced velar stops in Duhumbi regularly correspond to voiced velar stops in Khoitam, but the number of attesting cognate sets is very small. Whereas lexemes starting with onset $g$ - are not rare in the contemporary Western Kho-Bwa languages, many of these lexemes appear to be borrowed. Those that are inherited can be shown to derive from onsets such as * gr- $(\S 10),{ }^{*} \mathrm{gr}^{\mathrm{j}}{ }_{-}(\S 51 \mathrm{a})$ or ${ }^{*} \mathrm{gj}_{-}(\S 68)$ or occur as prefix (such as in 'boil (n)' in $\S 69 \mathrm{a}$ and 'sweet buckwheat' in $\S 45)$. Finally, inherited attestations of onset $g$ - in some Western Kho-Bwa varieties often lack cognates in all the Western Kho-Bwa varieties. An example is the lexeme gi: 'pull (at something in a fixed position)', which, though attested in the Sartang and Sherdukpen varieties, does not have a cognate form in Khispi and Duhumbi. The reason for this relative paucity of onset $g$-remains to be explained.

$$
\begin{aligned}
& \text { Duh. gəy <*goy 'fence', Kht. guy }(\$ 39) \\
& \text { Duh. gip }<* \text { gip 'fold (clothes)', Kht. gəp (\$21a) }
\end{aligned}
$$

Characteristic for the Kho-Bwa languages is the correspondence of velar plosive onsets with velar nasal onsets in other Tibeto-Burman varieties, see also $\S 4$ and $\S 7$, in particular with Type A onsets in Old Chinese. Although this is a striking feature of the Kho-Bwa languages, it is beyond the scope of this paper and will be dealt with in a subsequent publication. 
Duh. $g a<*^{*}$ ga 'I', Kht. gu:, Tib. $\dot{n} a$, Bur. $\dot{n} \bar{a}$, Chi. 吾 $n g u<*^{*} \mathrm{y}^{\complement} \mathrm{a}(\S 24)$

$\S 2$. Duh. $d$-, Kht. $d$-. Voiced dental stops in Duhumbi regularly correspond to voiced dental stops in Khoitam.

Duh. $6 a . d s \eta<*$ sja.don 'macaque', Kht. $z . d u \eta(§ 39)$

Duh. $d \varepsilon n<*$ dan 'know', Kht. den, Tib. dran.pa 'remember' $(\S 41)$

Duh. $d \varepsilon m<*$ dem 'lap', Kht. dĩ: $(\S 61)$



Duh. ว.dək<*a.dwak 'big', Kht. a.dək (§16)

Duh. $d u k<*$ duk 'poison', Kht. $d y k$, Tib. $d u g(\S 5)$

Duh. $u . d a<*$ a.da 'son', Kht. $a . d u(\S 24)$

Duh. $d u s<*$ dus 'gather, collect', Kht. dik, Tib. hdus.pa 'gather' (§65)

$\S 3$. Duh. $b$-, Kht. $b$-. Voiced bilabial stops in Duhumbi regularly correspond to voiced bilabial stops in Khoitam.

Duh. buk<*buk 'breath’, Kht. byk, Tib. dbugs $(\S 5)$

Duh. $b u<*$ bu 'carry’, Kht. by:, Tsh. $b u(\S 27)$

Duh. $6 a . b \varepsilon j<*$ s'a.boj 'porcupine', Kht. $z u . b \jmath^{\text {? }}(\S 67 \mathrm{~b})$

Duh. $b e^{\text {? }}<{ }^{*} \mathrm{~b}^{\mathrm{w}} \mathrm{ej}$ 'copula', Kht. $b \varepsilon^{2}(\S 29)$

Duh. bos $<*$ bos 'Curcuma sp.', Kht. be? $(\S 64)$

Characteristic for the Kho-Bwa languages is the correspondence of bilabial plosive onsets with bilabial nasal onsets in other Tibeto-Burman varieties.

Duh. $b \varepsilon j<*$ baj 'fire', Kht. be:, OTib. mye, Tsh. mi, Bur. mīh, Chi. 燬 $x j w e X<*$ maj? 'fire' (§67)

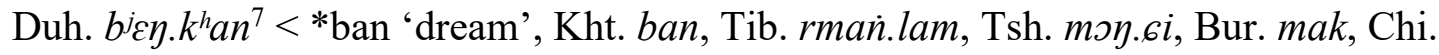
夢 mjuwng $H<*$ C.mən-s $(\S 41)$

Duh. $b a-<*$ ba- 'negative prefix', Kht. bə-, Tsh. $m a-$, Bur. $m a$, Chi. 無 $m j u<*$ ma 'not have' (§31)

Duh. $b e<{ }^{*} \mathrm{~b}^{\mathrm{j}} \mathrm{a}$ 'down ${ }^{8}$, Kht. $b u$; Khs. $b^{j} a$, Tib. smad, Bro. [me: $]^{9}(\S 32)$

The comparative evidence for the examples 'human being prefix' (§17a) and 'name' $(\S 21)$ also illustrates this characteristic Kho-Bwa correspondence of bilabial plosive onsets with bilabial nasal onsets in other Tibeto-Burman varieties.

\footnotetext{
${ }^{7}$ This is a compound of the expected inherited form ${ }^{\dagger} \mathrm{b}$ cn and the agent nominaliser $-k^{h} a n$ (cf. Tibetan -mkhan, Tshangla $-k^{h} c n$ ) with assimilation of the coda to the velar onset of suffix. Palatalisation of the onset before rhymes $-\varepsilon k$ and $-\varepsilon \eta$ in Duhumbi is regular.

${ }^{8}$ A location on a lower plane and usually visible from the point of speaking.

${ }^{9}$ Unlike other cognate sets of the palatalised onset $* \mathrm{~b}^{\mathrm{j}}$ - $(\S 38 \mathrm{a})$, the onset reflexes are all simple $b$ - here, which could be attributed to the open rhyme, see also the example of 'ground level' in $\S 4$.
} 
$\S 4$. Duh. $k^{h_{-}, K h t .} k^{h_{-}}$. Aspirated velar stops in Duhumbi regularly correspond to aspirated velar stops in Khoitam.

Duh. $k^{h} a r^{10}<* k^{\text {har }}$ 'call for', Kht. $k^{h} a n$, Chi. 吅; 諠; 喧; 讙 $x j w o n<* \mathrm{q}^{\text {whar }}$ aclamour, shout' (§66)

Duh. $k^{h} b w<* \mathrm{k}^{\mathrm{h}} \mathrm{O}^{11}$ 'water', Kht. $k^{h} O$; , cf. Tib. kha.ba, Mon. $k^{h} o u$ 'snow', Tib. khu.ba 'broth, soup; semen; liquid', Khaling $k u$ 'water' (Jacques et al. 2015) (§69)

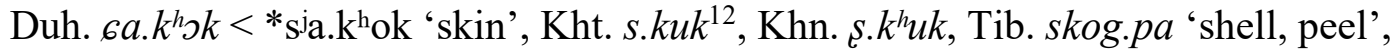
Bur. khok $<*$ 'kuk 'bark (n.)’, Chi. 殼 khaewk $<*\left[\mathrm{k}^{\mathrm{h}}\right]^{\text {' }}$ rok 'hollow shell, hollow' $(\S 4)$

Duh. $k^{h} e<* \mathrm{k}^{\mathrm{hj}} \mathrm{a}$ 'ground level ${ }^{13}$ ', Kht. $k^{h} u$ :, Khs. $k^{h j} a^{14}(\S 32)$

Duh. $k^{h}$ ’k $<* \mathrm{k}^{\mathrm{hw}} \mathrm{ak}^{15}$ 'nest; hive; womb', Kht. $k^{h} \jmath k(\S 16)$

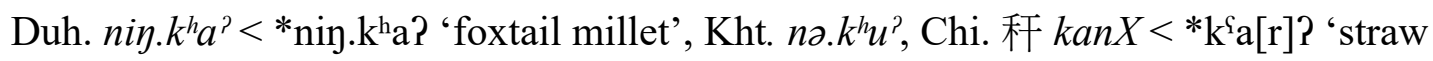
of grain' $(\S 25)$

Duh. $k^{h} \supset w<* \mathrm{k}^{\mathrm{h}}$ aw 'snatch away', Kht. $k^{h}$ o:, Tib. rku.ba 'steal', OBur. khuiw 'steal', Chi. 寇 khuwH $<*[\mathrm{k}]^{\mathrm{h}}(\mathrm{r}) \mathrm{o}-\mathrm{s}$ 'rob; robber' (Hill 2019: 63) (\$69a)

Duh. $-k^{h} \jmath^{?}<{ }^{*} \mathrm{k}^{\mathrm{h}} \mathrm{a}$ ? 'locative suffix', Rah. $-k^{h} \mathrm{~g}^{216}$, Tsh. $-k a$, Chi. 乎 $h u<{ }^{*}{ }_{\mathrm{G}}$ a 'in, at' $(\S 35)$

Duh. $k^{h} u \eta<* \mathrm{k}^{\mathrm{h}}$ uy 'ascend', Kht. $k^{h} y \eta$, Khaling $k^{h} O \eta$ 'come (upwards)' (Jacques et al. 2015) (\$40)

Duh. $k^{h i s}<{ }^{*} \mathrm{k}^{\mathrm{h}}$ is 'hang around the neck', Kht. $k^{h i k}$, Kiranti $* \mathrm{k}[\mathrm{i} \mid \mathrm{e}] \mathrm{k}$ 'tie' (Jacques 2017), Chi. 係 $k e j H<{ }^{*} \mathrm{k}^{\mathrm{e}} \mathrm{ek}-\mathrm{s}$ 'tie (v.)' or 系 $h e j H<*[\mathrm{~m}]-\mathrm{k}^{\mathrm{f}} \mathrm{ek}-\mathrm{s}$ 'bind (v.)' $(\S 63)$

Khs. $k^{h i 6}$ 'to turn back, to return' ${ }^{17}<*($ la. $) \mathrm{k}^{\mathrm{h} i \mathrm{w}}$ 'backwards', Kht. lo. $k^{h} e$ : (§63b)

Again, characteristic for the Kho-Bwa languages is the correspondence of velar plosive onsets with velar nasal onsets in other Tibeto-Burman varieties (cf. $§ 1$ and $§ 7$ ), particularly with Type A onsets in Old Chinese.

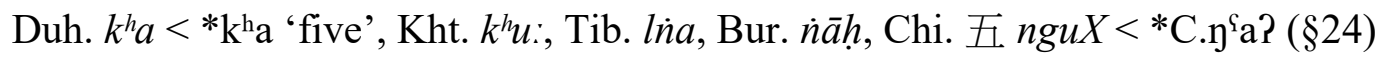

Duh. $k^{h} a m<* \mathrm{k}^{\mathrm{hw}}$ am 'be hungry', Kht. $k^{h} \tilde{u} \eta$, Tib. skom.pa 'be thirsty' < skam.pa 'be dry', Chi. 餓 $n g a H<* \mathrm{y}^{\Upsilon}$ 'aj-s 'be hungry' (§54)

\footnotetext{
${ }^{10}$ The Duhumbi rhyme reflex -ar, not ${ }^{\dagger}-\varepsilon r$ is unexpected and may be attributed to a labialised velar onset or a uvular onset, rather than a simple velar onset, although this would have resulted in the Khoitam rhyme reflex $-\tilde{\jmath}$ : $(\S 70)$.

${ }^{11}$ May be $<* \mathrm{k}^{\mathrm{hw}} \mathrm{a}$.

12 The deaspiration of the onset is conditioned by the unvoiced unaspirated prefix.

${ }^{13}$ As in, the bottom or ground level at a certain location.

${ }^{14}$ Unlike other cognate sets with reflexes of palatalised onset $* \mathrm{k}^{\mathrm{hj}}{ }_{-}(\S 50)$, perhaps the open rhyme here prevents affrication of the onset, see also the example of 'down' in $\$ 3$.

${ }^{15}$ In Bodt (2019) initially reconstructed as * $\mathrm{k}^{\mathrm{hw}}$ ap and assigned to rhyme correspondence $\S 17$.

${ }^{16}$ Khoitam has unexpected reflex $-g y^{\text {? }}$, not expected ${ }^{\dagger}-\mathrm{k}^{\mathrm{h}} \mathrm{o}^{\text {? }}$.

${ }^{17}$ Duhumbi has loan dap 'return; repeat; turn back', cf. Tawang Monpa dap 'again; repeat'.
} 
$\S 5 . D u h . t^{h_{-}}, K h t . t^{h_{-}}$. Aspirated dental stops in Duhumbi regularly correspond to aspirated dental stops in Khoitam.

Duh. $t^{h} a k<*$ thak 'rope', Kht. $t^{\text {hak }}$, Tib. thag.pa $(\S 1)$

Duh. $k^{h} u . t^{h} u \eta<* \mathrm{k}^{\mathrm{h}} \mathrm{a} \cdot \mathrm{t}^{\mathrm{h}} \mathrm{u \eta}$ 'ear', Kht. $k^{h} \cdot t^{h} y y(\S 40)$

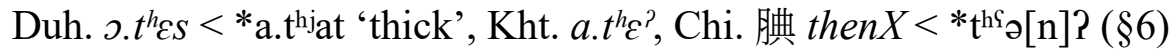

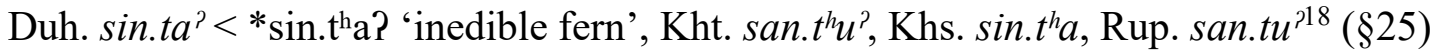

Duh. $t^{h} a-<* t^{\text {ha }}$ - 'prohibitive prefix', Kht. $t^{h} \partial-(\S 31)$

Duh. $t^{h}$ on $<{ }^{*} \mathrm{t}^{\mathrm{h}}$ on 'take', Kht. $t^{h} \tilde{\imath}:(\S 43)$

Duh. tos $\left[{ }^{\dagger} t^{\mathrm{h}} \mathrm{\jmath s}\right]<* \mathrm{t}^{\mathrm{h}} \mathrm{OS}$ 'throw', Kht. $t^{\mathrm{h}} e^{?}(\S 64)$

Duh. $t^{h j} \varepsilon \eta^{19}<* t^{\text {they }}$ 'cover (v)', Rah. $k^{h} a n . t^{h} \varepsilon \eta$ 'cover (n)', Rup. $t^{h} \varepsilon \eta$ 'cover (v)' (§37)

Duh. $t$ s $\left[{ }^{\dagger} \mathrm{t}^{\mathrm{h}} \mathrm{us}\right]^{20}<* \mathrm{t}^{\mathrm{h}} \mathrm{us}$ 'wear (a bracelet)', Kht. $t^{\text {hik }}(\S 65)$

Duh. $t^{h} \varepsilon r<*$ thar 'cane carrying strap', Kht. $t^{h}$ an (§66)

$\S 6$. Duh. $p^{h_{-}, K h t .} p^{h_{-}}$. Aspirated bilabial stops in Duhumbi regularly correspond to aspirated bilabial stops in Khoitam.

Duh. $p^{h} a k<* p^{\text {hak }}$ 'liquor', Kht. $p^{h} a k(\S 1)$

Duh. nam. $p^{h} \supset$ <*nam.p ${ }^{\mathrm{h}}$ on 'night', Kht. nə.p $p^{h} u \eta$, Chi. 昏 $x w o n<{ }^{*} \mathrm{~m}^{\mathrm{f}} \mathrm{u}[\mathrm{n}]$ 'dusk, dark' (\$39)

Duh. $p^{h} \zeta k{ }^{*} \mathrm{p}^{\mathrm{h}} \mathrm{ok}$ 'barley', Kht. $p^{h} u k(\S 4)$

Duh. $p^{h} u s<{ }^{*} \mathrm{p}^{\mathrm{h}} \mathrm{us}$ 'sow ${ }^{21}$, Kht. $p^{h} i k(\S 65)$

Duh. $p^{h} 3 w<{ }^{*} p^{\mathrm{h}}$ Ow 'spread out to dry', Kht. $p^{h} \jmath^{?}(\S 69 \mathrm{~b})$

The following cognate set and the comparative evidence from Chinese indicates that the correspondence between Western Kho-Bwa bilabial stops and other Tibeto-Burman bilabial nasals is not just limited to the voiced bilabials $* b-<* m-(\S 3)$, and may, at least in some cases, derive from an onset *s-m- and be related to Type A syllable initials in Old Chinese, cf. also the footnote with correspondence $\S 32$.

Duh. $p^{h} a m<* p^{\text {hwam }}$ 'lose, be defeated', Kht. $p^{h} \tilde{u} \eta$, Tib. hpham.pa '(be) defeat(ed),

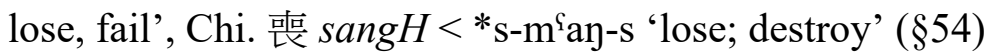

\footnotetext{
${ }^{18}$ The nasal coda of the prefix in this lexeme may condition the variation in aspiration in the Duhumbi, Rupa and Shergaon reflexes.

${ }^{19}$ Palatalisation of the onset before rhymes $-\varepsilon k$ and $-\varepsilon \eta$ in Duhumbi is regular.

${ }^{20}$ Both the Duhumbi unaspirated onset and the rhyme reflex are unexpected. The expected onset and vowel have, however, been preserved in the lexeme $t^{h}$ up.lin 'bangle, bracelet', indicating the rhyme may have been a

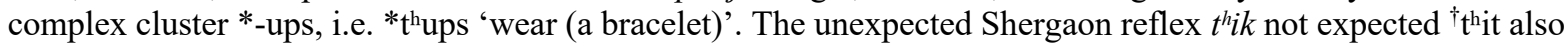
favours the complex rhyme.

${ }^{21}$ This refers to picking small amounts of grains from a full hand or bag and broadcast sowing those seeds in the field.
} 
$\S 7$. Duh. $k$-, Kht. $k$-. There are only limited attestations of voiceless, unaspirated stop $k$ - in the Western Kho-Bwa varieties.

Duh. $k o<*$ kaw 'door', Kht. ks;, Tib. sgo, Chi. 戶 $h u X<* m-q^{\complement} a ?(\S 69 a)$

Again, characteristic for the Kho-Bwa languages may be the correspondence of simple velar plosive onsets with velar nasal onsets in other Tibeto-Burman varieties, in particular with those with Type A onsets in Old Chinese, cf. also $§ 1$ and $\S 4$.

Duh. ${ }^{\dagger} \mathrm{ma} . \mathrm{ku}^{22}<*$ ma.kwa 'forehead', Kht. mo.ko:, Rup. ma.kaw, Tib. $\dot{n} o$ 'face, countenance' $(\S 30)$

Duh. $k a^{\text {? }}<{ }^{*} \mathrm{ka}$ ? 'bite', Kht. $k u^{\text {? }}$, Tsh. yam, Chi. 牙 ngae $<{ }^{*} \mathrm{~m}-\mathrm{G}^{\mathrm{S}}<\mathrm{r}>\mathrm{a}$ 'tooth', also Kiranti *k[r]at (Jacques 2017), Khaling $k a$ 'eat (hard things)' (Jacques et al. 2015) (§25)

$\S 8$. Duh. $t$-, Kht. $t$-. For unvoiced dental plosive onset $t$ - a regular correspondence pattern is better attested than for the other voiceless, unaspirated plosive onsets. In some cases, Khoina has aspirated onsets where the other varieties have unaspirated onsets.

Duh. tom < *tum 'year', Kht. tuך, Mon. tom.rit (§47)

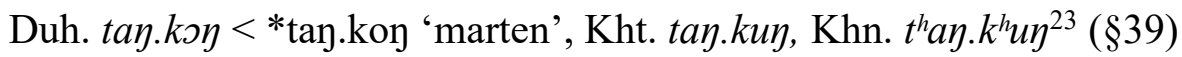

Duh. $t \varepsilon j<*$ tej 'sing', Kht. $t \varepsilon$ ' $(\S 67 \mathrm{a})$

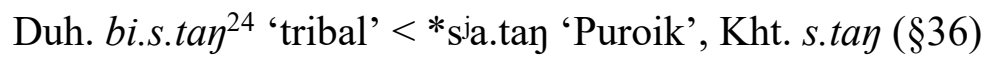

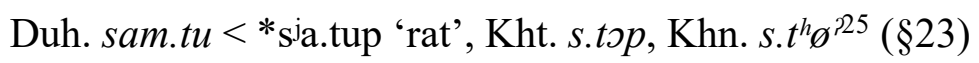

Duh. cip.ta $^{\text {226 }}<{ }^{*}$ sa.ta? 'horse', Kht. s.tu', Tib. rta $(\S 25)$

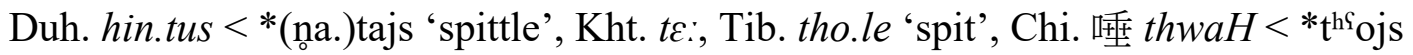
(Hill 2019: 36) (§65a)

Duh. -ta $<*$ tat 'allative ${ }^{27}$, Kht. -tan, Tib. gtad 'direct towards', Tsh. -tat $\sim$-tan, Chi. 達 $d a t<*[1]^{\text {` }}$ at 'arrive at' $(\S 82)$

$\S 9 . D u h . p$-, Kht. $p$-. There are no convincing cognate sets of the simple onset $p$-, although a proto-phoneme * $\mathrm{p}$ - has been reconstructed, cf. correspondence set $\$ 21 \mathrm{a}$.

\subsection{FATE OF RHOTIC ONSET CLUSTERS}

Onset clusters of a velar plosive and rhotic medial are simplified in Duhumbi, Khispi and the Sherdukpen variaties, but become affricates in the Sartang varieties.

$\S 10$. Duh. g-, Kht. dt-. In a cognate set distinct from $\S 1$ (Duh. $g_{-}$, Kht. $g-$-), simple velar stops in Duhumbi correspond to simple velar stops in Rupa and Shergaon but palatal affricate

\footnotetext{
22 Duhumbi has Tshangla loan pa.tวy.

23 The Khoina aspirated onsets are unexpected.

24 The Duhumbi reflex includes the 'human being prefix' (§17a).

25 The Khoina aspirated onset is unexpected.

26 The unexpected prefix is under influence of the honorific Tibetan term chibs.rta 'riding horse', i.e. * sja.ta? > *6a.ta? $>$ cip.ta?

27 The divergent rhyme reflexes and the good comparative evidence indicate, however, that this suffix is most likely a loan.
} 
onsets in Khoitam and the other Sartang varieties, except Khoina which has retroflex affricates. I propose that this correspondence reflects earlier velar plosive and rhotic medial onset clusters * Kr-. This correspondence is best attested for aspirated and unvoiced onsets $(\S 11, \S 11 \mathrm{a}, \S 11 \mathrm{~b})$, but also holds for voiced onsets.

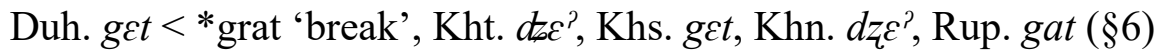

$\S 11 . D u h . k^{h}$, Kht. $t 6^{h}$. In a correspondence comparable to $\S 10$, simple aspirated velar stops in Duhumbi often correspond to simple aspirated velar stops in Rupa and Shergaon but aspirated palatal affricate onsets in Khoitam and the other Sartang varieties, except Khoina which has aspirated retroflex affricates.

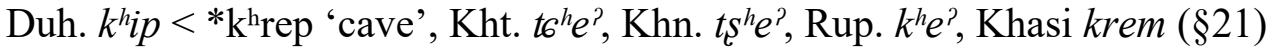

Duh. $k^{h} i p<* k^{\text {hrep }}$ 'cry', Kht. $t^{h} e^{\text {? }}$, Khn. $t^{h} e^{\text {? }}$, Rup. $k^{h} e^{\text {? }}$, Tib. khrab.khrab $<* k r ə p$ 'a person prone to weep' (Hill 2019: 219), Chi. 泣 khip $<*$ k-rəp (§21)


$*_{\mathrm{G}^{\mathrm{w}}} \mathrm{ij}$ 'rope for tying' ${ }^{28}(\S 33)$

Duh. $k^{h j} \varepsilon \eta^{29}<* k^{\mathrm{h}}$ rey 'horn', Kht. $t 6^{h} \varepsilon \eta$, Khn. $t s^{h} a j \eta$, Rup. $k^{h} \varepsilon \eta$, Tib. $r u$ 'horn' and gru 'corner', WBur. khyui, Chi. 觥 kwaeng $<*[\mathrm{k}]^{\mathrm{w}}$ ray 'drinking horn' (Hill 2019: 40) $(\$ 37)$

Duh. $k^{h} i \eta<{ }^{*} \mathrm{k}^{\mathrm{h}}$ rim 'stand up', Kht. $t^{h} \tilde{l}$;, Khn. $t_{s}{ }^{h} \tilde{l}$, Rup. $k^{h} \tilde{l}$, Tib. hgrim.pa 'wander, stroll', Chi. 興 $x i n g<* \mathrm{q}$ (r)əy 'lift, rise’ $(§ 55)$

Duh. $k^{h} i k<{ }^{*} \mathrm{k}^{\mathrm{h}}$ rit 'twist (udder, cane)', Kht. $t^{h} i^{\text {? }}$, Khn. $t_{S^{h}} i^{\text {? }}$, Rup. $k^{h} e^{\text {? }}$, She. $k^{h} r i^{j 30}$, Tib. hkhri.ba 'wind, roll, twist' (§12)

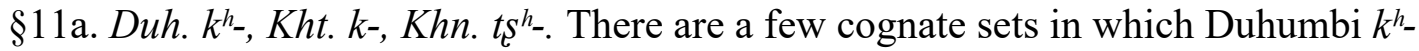
corresponds to Khoina $t_{S}{ }^{h_{-}}$, Jerigaon onset $h$ - and onset $k^{-31}$ in Khoitam and the other varieties. Because of the similarity with correspondence $\S 11$, I propose to reconstruct onset $* \mathrm{kr}-.{ }^{32}$

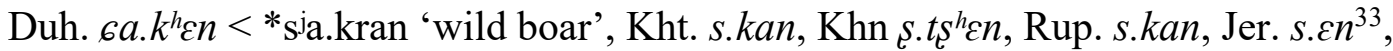
Chi. 豜 $k e n<*[\mathrm{k}]^{\mathrm{\complement}} \mathrm{e}[\mathrm{n}]$ 'pig or boar 3 years old' $(\S 41)$

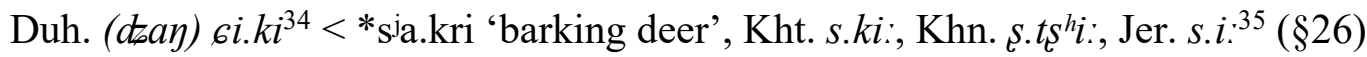

\footnotetext{
${ }^{28}$ According to an anonymous referee, Chi. 維 $y w i j<*_{\mathrm{G}^{\mathrm{w}} \mathrm{ij}}\left(?<*_{\left.\mathrm{G}^{\mathrm{w}} \mathrm{uj}\right)}\right.$ 'rope for tying' (Baxter and Sagart 2014) is an alternative writing of 惟 $y w i j<{ }^{*} \mathrm{G}^{\mathrm{w} i j}$ '(copula); namely' and primarily a verb meaning 'tie', rendering this comparison obsolete, see also Hill (2019: 134, fn. 45).

${ }^{29}$ Palatalisation of the onset before rhymes $-\varepsilon k$ and $-\varepsilon \eta$ in Duhumbi is regular.

${ }^{30}$ Why Shergaon has preserved the rhotic onset is unexplained and may attest to a later Bodish loan in this variety, cf. also $\S 69 \mathrm{~b}$.

${ }^{31}$ The Khoitam and other Sartang and Sherdukpen preservation of the velar onset instead of lenition (affrication, spirantisation and debuccalisation along $\left.*_{\mathrm{kr}-}>*_{\mathrm{kx}}->*_{\mathrm{x}-}>\mathrm{h}-\right)$ as in Khoina and Jerigaon may be attributed to the unvoiced prefix.

32 The comparative evidence from Chinese suggests cognacy with a type A syllable onset $* \mathrm{k}^{\mathrm{\varsigma}}$-.

${ }^{33}$ With intermediate form *s.hen.

${ }^{34}$ The deaspiration of the onset (expected is ${ }^{\dagger} 6 a . \mathrm{k}^{\mathrm{h}} \mathrm{i}$, but cf. the chance cognate Tibetan śa.khyi 'hunting dog') may be attributed to the high open vowel, with subsequent vowel harmony between prefix and root.

${ }^{35}$ With intermediate form * ${ }^{*}$.hi:.
} 
$\S 11 \mathrm{~b}$. Duh. $k^{h}$-, Kht. $k$-, Khn. $x$-. Unlike $\S 11 \mathrm{a}$, in a single set, Khoina has unexpected onset $x$-, not $t_{s}{ }^{h}$, perhaps the result of the vocal prefix.

Duh. $6 a . k^{h} u s<*(\mathrm{a} \sim \mathrm{sia}) . k r u s$ 'bone', Kht. s.kik, Khn. a.xik, Jer. i.hik, Chi. 骨 kwot $<$ ${ }^{*} \mathrm{k}^{\mathrm{\varsigma}} \mathrm{ut}^{36}(\S 65)$

$\S 12$. Duh. $k$-, Kht. t6-. In addition to $\S 7$ (Duh. $k$-, Kht. $k$-), another source of Duhumbi onset $k$ may be onset cluster *kr-, with simple velar stops in Duhumbi, Rupa and Shergaon but palatal affricate onsets in Khoitam and the other Sartang varieties, except Khoina which has retroflex affricates. The Khoitam, Jerigaon and Rahung affricate onsets, rather than the expected simple velar onsets, and the unaspirated, rather than expected aspirated Duhumbi onset, (cf. correspondence $\S 11 \mathrm{a}$ ) may be the result of additional palatalisation of the onset, cf. also $§ 50 \mathrm{a}$ and $\S 51 \mathrm{a}$.

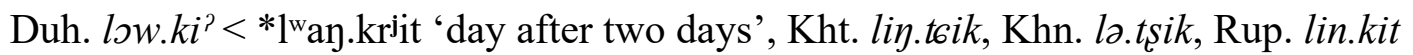
$(\S 34)$

$\S 13$. Duh. $d$-, Kht. $r$-. Unlike the reflexes of the ${ }^{*} \mathrm{Kr}$ - clusters, an onset cluster of a voiced alveolar fricative and a rhotic medial is simplified to $d$ - in Khispi and Duhumbi and to $r$ - in all other varieties, in a correspondence distinct from $\S 2$ (Duh. $d$-, Kht. $d$-), $\S 35$ (Duh. $z$-, Kht. $z$-), $\S 58$ (Duh. $l$-, Kht. $r$-) and $\S 64$ (Duh. $r$-, Kht. $r$-). Stopping of fricative $z$ - to plosive $d$ - is typologically more common, for example, the Written Tibetan onset $z$ - becoming onset $d$ - in spoken Tibetan varieties, such as in zla.ba [da.wa] 'moon', zla.bo [dau] 'companion' and zlog.pa [dok.pa] 'repelling ritual' ${ }^{37}$. Simplification of rhotic onset clusters is also common in the Western Kho-Bwa varieties (e.g. $§ 11{ }^{*} \mathrm{k}^{\mathrm{h}} \mathrm{r}->$ Duh. $k^{h}$ and $\S 10 *$ gr- $>$ Duh. $g$-).

Duh. $d^{j} \varepsilon k^{38}<*$ zrek 'shoot', Kht. $r \varepsilon k$, Chi. 射 zyek $<*$ Cə.1Ak 'hit with bow and arrow', Bug. rak 'arrow' (§2)

Duh. bu.dun <*bii.zrun 'human', Kht. dti.rip, Proto-Puroik *pu.run ${ }^{39}$ (Lieberherr 2015: 38), Bug. b.ran 'human'40, Boḍo bo.ro: 'Boḍo' (§44)

Duh. $d o \eta<*$ zroy 'bind together', Kht. ruy 'assemble (people); pile up (things)' (§39)

Duh. bej.dup < *baj.zrup 'fireplace, hearth', Kht. b.rsp, Tib. thab.ka, PP *rap and Miz. rap 'shelf (over fireplace)' (§23)

The reconstructed Proto-Western Kho-Bwa onset *zr- often corresponds to Chinese dental plosive onsets:

\footnotetext{
${ }^{36}$ Or perhaps, but less likely, Chi. 律 $l$ wit $<*[$ r]ut 'pitch pipe' (Sagart 2014), Tibetan rus 'bone', Old Burmese ruiwh.

${ }^{37}$ This Tibetan evidence actually favours a reconstructed Proto-Western Kho-Bwa onset cluster *zl-, with reflex $d$ - in Khispi and Duhumbi, and simplication to intermediate *1- $>r$ - in the other varieties (cf. §58a). As one reviewer pointed out, *t- to $r$ - could also be explained through sonorising lenition, favouring the reconstruction of simple dental plosive onsets at the proto-level, as is also evidenced by some of the Tibetan and Chinese comparative data.

${ }^{38}$ Palatalisation of the onset before rhymes $-\varepsilon k$ and $-\varepsilon \eta$ in Duhumbi is regular.

${ }^{39}$ With attested varieties p.rin, pu.run, pu.ruik.

${ }^{40}$ Also related to this root is the name of the tribe Bugun [bu.gun] itself. This name may have arrived into English through a linguistic variety where an intervocalic [r] in the likely Puroik source [pu.run] 'human' was realised as voiced velar fricative [8] or voiced uvular stop [G] or fricative [6], perhaps Hruso Aka, which was then transcribed as voiced velar stop $/ \mathrm{g} /$ in the first Anglo-British descriptions in the mid-20 $0^{\text {th }}$ century where the Bugun were called Bugun, instead of by their exonym Khowa.
} 
Duh. $d u<*^{*}$ zru 'push', Kht. ry:, Chi. 推 $t$ hwoj $<*^{\mathrm{h}} \mathrm{h}$ uj 'push away', PP *rui 'pull', Bug. ri: 'pull' (§27)

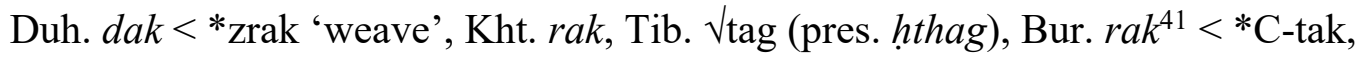
Khroskyabs dây (Lai 2017: 12, 726), Chi. 織 tsyik<*tək, PP *at.rua?, Bug. mə.rok 'weave' $(\S 1)$

Duh. $d i<*$ zri 'roast', Kht. ri:, Chi. 焦 tsjew $<*$ S.tew 'burn, scorch’ $(\S 26)$


$(\S 39)$

Duh. bo.di $<*$ ba.zrəj 'navel', Kht. b.re:, Tib. lte.ba, Chi. 肚 tuX<*t'a? 'belly, stomach', Bug. bu.rui 'navel' (§33a)

$\S 14$. Duh. $b$-, Kht. $b l$-. Finally, another source of Duhumbi onset $b$-can be found in the correspondence between clusters of voiced bilabial plosives and lateral medials in Khoitam and the other Sartang and Shergaon varieties and simple voiced bilabial onsets in Duhumbi and Khispi, with rhotic onset clusters in Rahung. I propose that this correspondence derives from onset clusters of bilabial plosives and rhotic medials *pr- $(\S 16, \S 19 \mathrm{a}, \S 19 \mathrm{~b}),{ }^{*} \mathrm{p}^{\mathrm{h}} \mathrm{r}-(\S 15$, $\S 19)$ and *br- $(\S 14, \S 14 a)$. The reason for reconstructing these onsets, despite the more common reflexes of these onsets as onset clusters of a bilabial plosive and a lateral medial in the contemporary Sartang and Sherdukpen varieties, is that there is no evidence for other onset clusters of a plosive onset and a lateral medial, such as ${ }^{\dagger *} \mathrm{kl}-,{ }^{\dagger *} \mathrm{k} \mathrm{h} l-$ or ${ }^{\dagger *} \mathrm{gl}-$. There is, however, ample evidence for onset clusters of a plosive onset and a rhotic medial, such as *kr- $(\S 11 \mathrm{a}, \S 11 \mathrm{~b}),{ }^{*} \mathrm{k}^{\mathrm{h}} \mathrm{r}-(\S 11)$ and ${ }^{*} \mathrm{gr}-(\S 10)$.

In addition, the modern Western Kho-Bwa languages have a paucity of attestations of onset clusters of a bilabial plosive and a rhotic medial, and most of these attestations may be Bodish loans. Examples include Duhumbi bru 'grain', Khoitam b.ı: 'testicle' and Rupa and Shergaon lak a.bry: 'testicle', but Khispi bu 'grain' and Rahung and Khoina lak a.by:, perhaps all derived from Tibetan hbru 'seed, grain, kernel'.

Nonetheless, the comparative evidence for a number of correspondence sets strongly points towards lateral rather than rhotic onset clusters: $\S 13 *$ zl- not $*$ zr-; $\S 14 *$ bl- not *br-; $\S 15 * p^{\mathrm{h}} 1-$ not ${ }^{*} \mathrm{p}^{\mathrm{h}} \mathrm{r}-; \S 16{ }^{*}$ pl- not ${ }^{*} \mathrm{pr}-; \S 19{ }^{*} \mathrm{p}^{\mathrm{h}} \mathrm{l}-$ not ${ }^{*} \mathrm{p}^{\mathrm{h}} \mathrm{r}$ - before $/ \mathrm{i} / ; \S 19 \mathrm{a} *$ pl- not ${ }^{*}$ pr- before $/ \mathrm{i} / ; \S 19 \mathrm{~b}$ $*$ bl- not *br- before $/ \mathrm{i} /$. This is a matter of future investigation.

Duh. o.bej 'sweet' < *a.broj.da" 'tasty', Kht. a.blo:.du, Rah. a.bro:, Tib. bro.ba 'taste' $(\S 75)$

Duh. nam.ba $a^{43}<*$ nam.bra 'moon', Kht. nam.blu:, Rah. nam.bru: 'moon; frost', Tib. $z l a$, WBur. la 'moon' (§24)

\footnotetext{
${ }^{41}$ As pointed out by one of the anonymous referees, Burmese $r$ - is the result of lenition as in Tangut (Jacques 2014a: 132-133).

${ }^{42}$ In adjectives, Duhumbi (and some other varieties) has regularly lost the nominalising suffix that is reconstructed to *-da. However, Duhumbi preserves this suffix in most adverbs. Cf. also the Khispi reflex o.bej.da 'sweet'.

${ }^{43}$ Also, like related is Duhumbi nam.la 'month': how these two attested forms are etymologically and phonologically derived from a single proto-form is, however, unclear.
} 


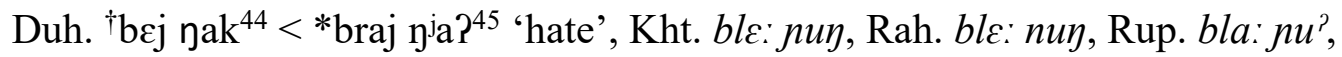
OTib. bla brdol 'speaking frivolously' (Zhāng 1993: 1912) (§67)

$\S 14 \mathrm{a}$. The voicing of the Duh. reflex in the following possible correspondence ( $p$ - not $b$ - as expected of $\S 14)$ is unexpected but may be phonotactic conditioning by the voiceless coda (*brat.da $>*$ bat.da $>$ pat.da). ${ }^{46}$

Duh. pat 'do work' < *brat 'work', Khn. blet, Rup. blat, OTib. rje.blas 'Frondienst' ${ }^{\text {'7 }}$ and myi.blas $^{48}(\S 14)$

$\S 15$. Duh. $p^{h_{-},}$Kht. $p^{h} l_{-}$, Rah. $p^{h} r_{-}$. Unlike $\S 6$ (Duh. $p^{h_{-}}$, Kht. $p^{h_{-}}$), but similar to $\S 14$ (Duh. $b-$, Kht. $b l$-), clusters of aspirated bilabial plosives and lateral medials in Khoitam and the other Sartang and Sherdukpen varieties correspond to simple aspirated bilabial onsets in Duhumbi, with rhotic onset clusters in Rahung.

Duh. $p^{h} a<{ }^{*} \mathrm{p}^{\mathrm{h}}$ ra 'axe', Kht. $p^{h} l u$;, Rah. $p^{h} r u$; , Chi. 鈇 $p j u X<* \mathrm{p}(\mathrm{r}) \mathrm{a}$ ? (§24)

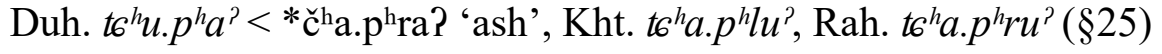

Khs. gan.dti $p^{h} a k<{ }^{*} \mathrm{p}^{\mathrm{h}}$ rak 'forget' ${ }^{49}$, Kht. $p^{h} l a k$, Rah. $p^{h} r a k$, Tib. brjed $<*$ mrjed $<$ *mrlyed 'forget', Tamang ${ }^{2}$ mlet.pa (Hill 2019: 29) (§1)

Duh. $p^{h} a s<{ }^{*} \mathrm{p}^{\mathrm{h}}$ ras 'gift', Kht. $p^{h} l^{\text {? }}$, Rah. $p^{h} r \partial^{\text {? }}(\S 62)$

$\S 16$. Duh. $p^{h_{-}, K h t .} p^{h l-,}$ Rah. $p^{h_{-}}$. Unlike $\S 6$ (Duh. $p^{h_{-}}$, Kht. $p^{h_{-}}$), but similar to $\S 14$ (Duh. $b-$, Kht. $b l-$ ) and $\S 15$ (Duh. $p^{h-}$, Kht. $p^{h l-}$, Rah. $p^{h} r$-), a cluster of an aspirated bilabial plosive and lateral medial in Khoitam, Jerigaon and Khoina corresponds to a simple aspirated bilabial onset in Duhumbi, Khispi, Rahung, Rupa and Shergaon in a single cognate set. Because this correspondence cannot derive from *br- $(\S 14$ or $\S 14 a)$ or ${ }^{*} p^{h} r-(\S 15)$, and in absence of a cognate set that would require reconstruction of onset *pr- except those preceding high vowel /i/ (§19a, §19b), I propose this correspondence derives from onset *pr-.

Duh. le. $p^{h} a<*$ laj.pra 'thigh', Kht. lo.p ${ }^{h} l u$;, Rah. la.p ${ }^{h} u$; Tib. brla (§24)

\subsection{DISTINCT REFLEXES BEFORE/I/}

There are several cognate sets where, when preceding a high vowel /i/ or vowel sequence /ij/ or $/ \partial \mathrm{j} /$, the onset reflexes are distinct from the regular reflexes for the onset.

$\S 17$. Duh. $b$-, Kht. $z$-. The correspondence between Duhumbi onset $b$ - and Khoitam onset $z-$, not expected onset $b$ - $(\S 3)$, is regular when preceding the high front vowel $i$. The comparative evidence indicates that, like with other sets of Proto-Western Kho-Bwa onset *b- (§3), this correspondence set also derives from *m-, via *b- $>z$ -

\footnotetext{
${ }^{44}$ Duhumbi and Khispi have lexical compound / serial verb construction $t^{h} a t$-ba-jay 'think good-NEG-feel like' for 'hate'. Curious is the Duhumbi near-homophonous lexeme bejnoy 'adolescent boy'.

${ }^{45} \mathrm{Cf}$. root $* \mathrm{j} \mathrm{j}$ a? 'language' in $\S 30$.

${ }^{46}$ One of the anonymous reviewers pointed out a possible cognate of the Duhumbi form in Tibetan byed.pa 'do', Japhug pa 'do' (Jacques 2016), also because of the irregular rhyme correspondence. However, the Duhumbi onset merely has unexpected voicing. A Tibetan onset by- would more likely correspond to Duhumbi onset 6-, cf. §38a. Ultimately, however, byed, *brat, .blas may all be etymologically related forms.

${ }^{47}$ From rje 'lord' and blas 'work', cf. Schuessler (1998), Coblin (1991), Uebach \& Zeisler (2008) and Doney (2013).

${ }^{48}$ For the distinction between rje.blas and myi.blas, see Takeuchi (1995: 266-267).

${ }^{49}$ Duhumbi has loan grandta yat 'to forget', cf. Dirang Tshangla grandta yat 'to forget', Bhutan Tshangla yat 'to forget'.
} 


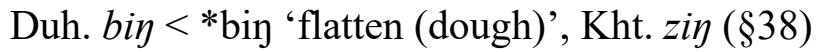

Duh. bis <*bis 'be numb (of limbs)', Kht. zik (§63)

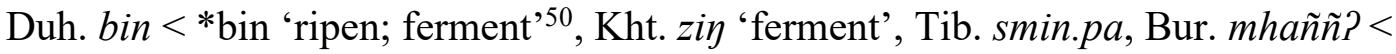
*?min? (Hill 2019: 70) (§42)

$\S 17$ a. Duh. b-, Kht. dt-. There is a small set of homophonous correspondences of Duhumbi onset $b$ - where Khoitam has onset $d t_{-}$, but only before open rhymes with high front vowel $-i$. This correspondence set contrasts with $\S 17$ (Duh. $b$-, Kht. $z$ - before high vowel/i/). The Rupa reflex is $d z$-in older speakers and $d t$ - in younger speakers.

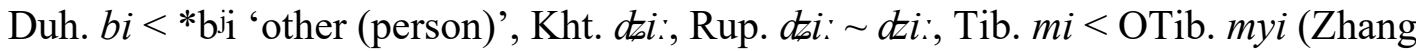
1992: 2128) 'person', Mon. be 'he, she', Tsh. mi 'person' and i.bi 'who', Chi. 人 nyin $<*$ ni[n] '(other) person' $(\S 26)$

Duh. - $b i<*-b$ ji 'reflexive marker'51, Kht. -dtai, Rup. -dtai: - dzi: (§26)

Duh. - $b i<*-b i j i$ 'people of -suffix'52, Kht. -dti:, Rup. -dti: -dzi: (§26)

Duh. $b i-<*$ bij- 'human being prefix', Kht. dtai--, Rup. dti:- $d k i:-(\S 26)$

$\S 18$. Duh. $k^{h_{-}, K h t}$. $6^{h_{-}}$. Like with the reflexes of onset $* \mathrm{~b}^{\mathrm{j}_{-}}(\S 17 \mathrm{a})$, the Duhumbi simple onset $k^{h}$ - can also derive from onset $* \mathrm{k}^{\mathrm{hj}}{ }_{-}$, but only when preceding a high vowel $/ \mathrm{i} /$ or vowel rhyme $/ \mathrm{ij} /$ or $/ \mathrm{j} \mathrm{j} /$. The Sartang and Sherdukpen varieties have the expected affricate reflexes (cf. $\S 50$ ), with the Rupa reflex a palatal stop in older speakers, and a palatal affricate in younger speakers. In all other phonotactic conditions, the Duhumbi and Khispi reflex is also an affricate $(\$ 50)$.

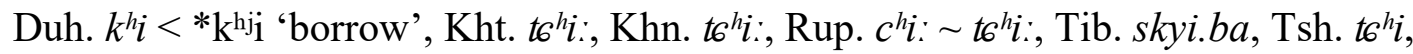
OBur. khiyh (§26)

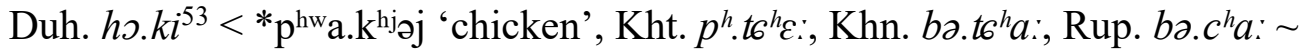
bə.t6ha:, Bur. krak, Chi. 雞 $k e j<*{ }^{\mathrm{f}} \mathrm{e}$ 'fowl, chicken’ (§33a)

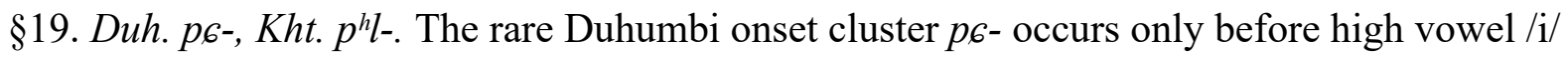
and corresponds to Khoitam onset cluster $p^{h} l$ - in all other Sartang and Sherdukpen varieties including Rahung, which contrasts with the reflexes of the cluster preceding other rhymes $(\S 15)$.

Duh. $p 6 i<{ }^{*} p^{\text {hri }}$ 'needle', Kht. $p^{h} l i$, Rah. $p^{h} l i:(\S 26)$

$\S 19$ a. Duh. p6-, Kht. $p^{h_{-}}$. Duhumbi onset cluster $p_{6}$ - corresponds to Sartang and Sherdukpen simple onset $p^{h}$ - when deriving from onset cluster *pr- and preceding high vowel rhymes, contrasting with the outcomes of the same cluster when preceding other rhymes $(\S 16)$.

\footnotetext{
${ }^{50}$ Duhumbi also has the verb $\min$ 'sleep', which seems to be etymologically related to bin 'ripen; ferment'. A proto-form *s.min 'put to sleep; put / keep to ferment' may have been a causative form of a proto-form *miin 'sleep' (\$32c). The fact that both 'wake up from sleep' and 'be fermented, be ready with fermention (of alcohol or fermenting soybeans)' is expressed in Duhumbi as jow (see $\S 60 *$ jow) is additional evidence for the close etymological relation of these forms.

${ }^{51}$ Used with personal pronouns, e.g. Duhumbi nay.bi 'you yourself'.

${ }^{52}$ Similar to the Tibetan - $p a$ 'people of' suffix, e.g. Duhumbi duhum.bi 'people of Duhum (village)', Tibetan phyug.pa 'people of Chug (village)', also 'rich people'.

${ }^{53}$ Deaspiration of the onset may be conditioned by the prefix, cf. Khispi wa.k $k^{h}$.
} 


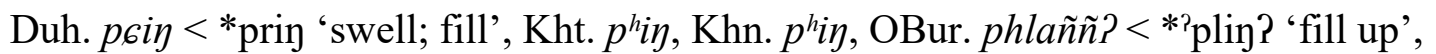

Chi. 不盈 pjuw-yeng <*po-len 'fill' (Hill 2019: 124), 盈 yeng <*ley (<*lin?)

'fill' (Baxter and Sagart 2014) (§38)

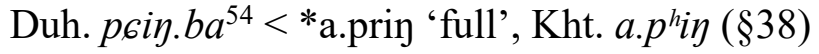

$\S 19$ b. Duh. p6-, Kht. ps-. The divergent reflexes in both Khoitam and Khoina in the following cognate set suggest a palatalised lateral onset cluster, reflecting the correspondence pattern ${ }^{*} \mathrm{~s}_{-} \mathrm{j}_{-}>$Duhumbi $6_{-}$, Khoitam $s^{-}$, Khoina $s^{-}(\$ 22)$. Again, these reflexes only occur before a high vowel rhyme.

Duh. p6i<*prii 'four', Kht. psi,, Khn. psii, Tib. bźi<*blyi (Hill 2019: 14), OBur. liy, Chi. 四 $s i j H<*$ s.li[j]-s $(\$ 26)$

$\S 19$ c. Khs. $p_{6-}$, Kht. $t^{h}$. In a single cognate set, Khispi onset $p_{6}$ - corresponds to Khoitam $t 6^{h_{-}}$, not to $p^{h} l_{-}, p^{h}$ - or $p s-$ as in $\S 19, \S 19 \mathrm{a}$ or $\S 19 \mathrm{~b}$, and I propose this derives from an onset $p s^{-}$, with the biliabial also reflected in the Tibetan prefix *m-. This correspondence pattern reflects the pattern $* \mathrm{~b}_{-}^{j_{-}}>$Duhumbi ${ }_{6_{-}}$, Khoitam $t 6^{h_{-}}$, Khoina $t^{h_{-}}$, Rup. $t^{h_{-}}(\S 38 \mathrm{a})$.

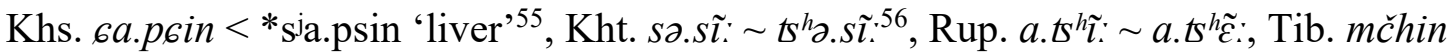

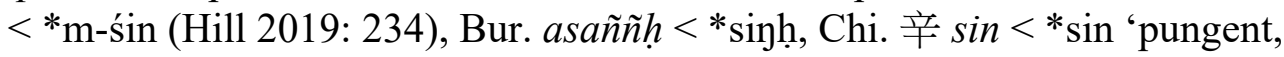
painful' $(\S 51)$

\subsection{MINOR CORRESPONDENCES}

There are nine correspondences with only a few cognate sets in which one or more variaties have unexpected reflexes. For many of these correspondences, I am posulating specific onsets or onsets clusters, in particular, uvular onsets.

§20. Duh. g-, Kht. w-, Rup. j-. In a cognate set distinct from $§ 1$ (Duh. g-, Kht. g-), the following set has distinct reflexes, postulated to derive from onset $* \mathrm{q}^{\mathrm{hw}}$ - (for more reflexes of uvular onsets, see $\S 22, \S 22 \mathrm{a}, \S 43 \mathrm{a}, \S 43 \mathrm{~b}, \S 56$ and $\S 57 \mathrm{a})$. The rhyme reflexes are also irregular, expected would be Khoitam ${ }^{\dagger}$ a.wyy, Rupa ${ }^{\dagger}$ u.jyy (cf. rhyme correspondence $\S 40$ ).

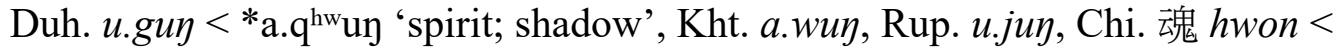
*[m.] $\mathrm{q}^{\mathrm{w}} \partial[\mathrm{n}]$ 'spiritual soul' $(\$ 50)$

$\S 20 a$. Duh. g-, Kht. $j$-. In two cognate sets, Duhumbi and Khispi velar onset $g$ - corresponds to Khoitam and other Sartang and Sherdukpen palatal onset $j$-. This is thought to derive from onset $* \mathrm{q}^{\mathrm{h}}$.

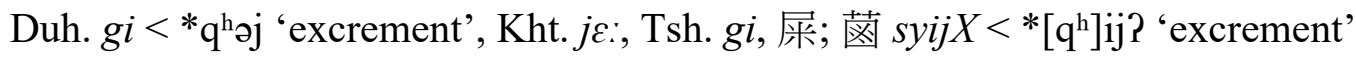
$(\S 33 a)$

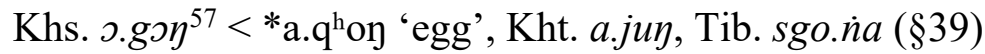

\footnotetext{
${ }^{54}$ Duhumbi here has the Bodish nominalising suffix - $b a$ rather than the Western Kho-Bwa adjective prefix $a$-, cf. also Tibetan phyun.ba 'be in excess, overflow' and Tshangla $p^{h} u \eta . m a$ 'full'.

${ }^{55}$ Duhumbi has lexical innovation $6 a$ tay. $k u$ 'meat dough'.

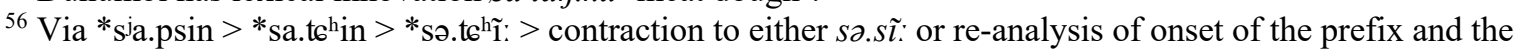
root to th h. $^{h} \tilde{l}$ :

57 The divergent Duhumbi form həj.dto $\eta$, not expected †०.gon is probably not cognate, but rather a compound of hoj 'blood' + dtoว 'bulge', whereas Khispi has the inherited form, cf. also Duhumbi lak.goy 'testicle', literally 'penis' + 'egg'.
} 
$\S 21$. Duh. $b$-, Kht. dt-. A unique correspondence of Duhumbi $b$ - with Khoitam $d_{t-}$, Rupa $z$ and Khoina $d z-$, not $b$ - as expected according to correspondence $\S 3$, that is also contrasting with correspondence $\$ 38 \mathrm{a}$, is postulated to reflect an onset ${ }^{*} \mathrm{~b}^{\mathrm{j}}$ - when preceding the rhyme -

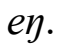

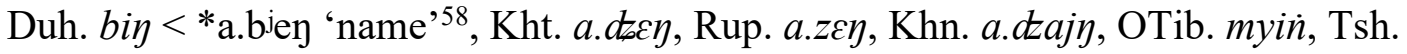

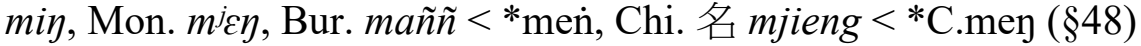

$\S 21$ a. Duh. b-. Kht. $w$-. In the following cognate set, distinct from set $\S 3$ (Duh. $b$-, Kht. $b$-), a reconstructed onset $* b^{w}$ - would result in Duhumbi rhyme reflex - $s k$ and Khoitam rhyme reflex -uk (cf. rhyme correspondence $\S 4 \mathrm{a}$ ). The retention of rhyme -ak may be explained through postulating an onset *p- for this particular correspondence, as this onset has not been used for any other correspondence $(\S 9)$.

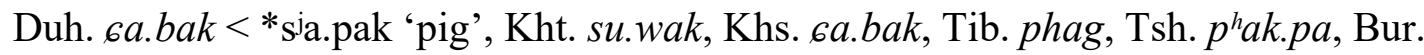
wak $<*$ C-pak (Hill 2019: 287) (§1)

$\S 22 . D u h . k^{h}, K h t . f-, K h n . f$-. There is a unique cognate set in which Duhumbi aspirated velar onset $k^{h}$ - corresponds to fricative $h$ - or $f$ - in all other varieties. I propose this derives from a uvular onset cluster with rhotic medial *qr-.

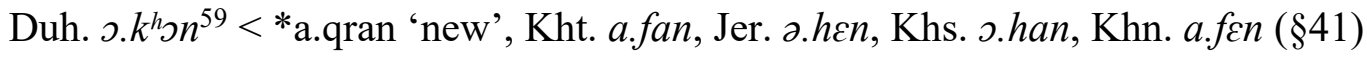

§22a. Duh. $k^{h}$-, Kht. h-, Khn. $x$-. A rhotic onset cluster explains the divergent rhyme and onset reflexes in the following cognate sets, thought to derive from ${ }^{*} \mathrm{q}^{\mathrm{h}} \mathrm{r}-{ }^{60}$

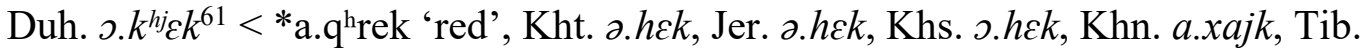
khrag, Mon. $k^{h} r a$ 'blood', Chi. 还 syek $<*\left[\mathrm{q}^{\mathrm{h}}\right](\mathrm{r})$ Ak or 通 $x i k<*\left[\mathrm{q}^{\mathrm{h}}\right](\mathrm{r}) \curvearrowright \mathrm{k}(\S 2)$

Duh. $u . k^{h} a \eta^{62}<* a . q^{h}$ ray 'healthy; strong', Kht. a.hay, Khn. a.xay, Chi. 剛 kang <



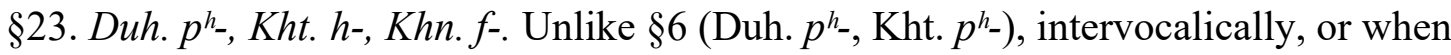
preceded by a prefix with high vowel /i/, Duhumbi onset $p^{h}$ - corresponds to Khoina onset $f$ and onset $h$ - in Khoitam and all other varieties, i.e. ${ }^{*}$ bii.p ${ }^{\mathrm{h}} \mathrm{a}>{ }^{*} \mathrm{~d}$ i. $\mathrm{p}^{\mathrm{h}} \mathrm{u}:>d t a . h u:($ Kht. $) \sim$ dta.fu: (Khn.).

Duh. zo.p $p^{h} a^{63}<*$ bii.p ${ }^{\text {ha }}$ 'man', Kht. dto.hu:, Khn. dto.fui, Bur. -pha $<*$ pa 'male’ (§24)


intervocalically, or when preceded by a prefix with a nasal coda, Duhumbi and Khoitam onset $p^{h}$ - corresponds to Khoina onset $f$ - and Jerigaon and Rahung onset $h$-.

\footnotetext{
${ }^{58}$ Cf. also Lepcha Pá.bryáng (Plaisier 2007) and Nungic Trung $a \eta^{31} b ı \varkappa \eta^{53}$ (Sūn 1991).

${ }^{59}$ Also realised as $2 . q^{h}$. $n$. In Duhumbi, $q^{h}$ - occurs as allophone of $k^{h}$ - intervocalically in a small subset of lexemes, which may in fact be retentions of the Proto-Western Kho-Bwa onset. Based on rhyme correspondence $\S 41$ (earlier exception §59), the expected Duhumbi outcome would be ${ }^{\dagger}$ o. $\mathrm{k}^{\mathrm{h}} \varepsilon \mathrm{n}, \mathrm{Khispi}{ }^{\dagger} \mathrm{o} \cdot \mathrm{h} \varepsilon \mathrm{n}$, and the divergent vowels are unexplained.

${ }^{60}$ To this correspondence may also belong the following set for which the distinctive Duhumbi and Khispi reflexes are missing.

Duh. "u.k'in (attested ra.ba, cf. Bro. ra:, Tsh. ra.tci, Mon. ra.wa) <*a.q'rim 'root', Kht. a.hĩ;, Khn. a.xi:

${ }^{61}$ Also realised as $\supset . h^{j} \varepsilon k \sim \supset . q^{h j} \varepsilon k$. Palatalisation of the onset before rhymes $-\varepsilon k$ and $-\varepsilon \eta$ in Duhumbi is regular.

${ }^{62}$ Also realised as $u . q^{h} a \eta$.

${ }^{63}$ However, Duhumbi prefix $ъ 0-$ not expected †bi- is left unexplained.
} 


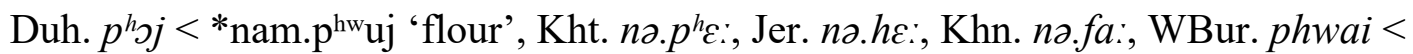
*poi 'chaff, bran' (§68)

$\S 24$. Duh. $t$-, Kht. $n$-. In contrast to $\S 8$ (Duh. $t$-, Kht. $t$-), the following single cognate set resembles the correspondence set of the voiceless dental nasal *n- $(\S 40)$, except that Duhumbi and Khispi have a plosive onset $t$-, not onset $h$-, where the other varieties have a nasal onset $n-$. The denasalisation in Duhumbi and Khispi may be the result of a rhotic medial. ${ }^{64}$

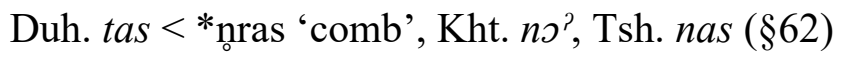

\section{VOCAL ONSETS}

The prefix *a- and its reflexes make vocal onsets relatively one of the most commonly attested onsets in the Western Kho-Bwa languages. In other word classes, vocal onsets are relatively rare, but by no means absent, and their origins are particularly interesting.

$\S 25$. Vocal onsets correspond regularly. Duhumbi vocal onsets correspond regularly to Khoitam vocal onsets, with the ultimate reflex generally following the rhyme correspondences. ${ }^{65}$

Duh. $i r<*$ Pir 'ride (a horse)', Kht. $\tilde{l}:(\$ 71)$

Duh. $a w^{66}<*$ ?o 'itch', Kht. o: $(\S 69)$

Duh. $-\supset^{?}<*-$ Pa? 'agentive / ergative suffix', Kht. $-\rho^{?}(\S 35)$

Duh. $a j<*$ ?oj ‘ok’, Kht. o:, Rup. ว.o: (§74a)

A unique innovation of the Western Kho-Bwa languages, and indeed the Kho-Bwa languages in general, is the correspondence of initial ${ }^{*}$ s- in other Tibeto-Burman languages to a vocal onset in Proto-Western Kho-Bwa and its descendent varieties. ${ }^{67}$


Chi. 殺 sreat $<*$ srat $(\S 19)$

Duh. $a j<*$ ?oj 'see', Kht. o:, Rup. o:, Tib. sad.pa ${ }^{68}$ (§74a)

Duh. $i<*$ ?i ‘die’, Kht. $i$, Tib. Vśi (pres. hçhi), Tsh. $6 i$, OBur. siy (§26)

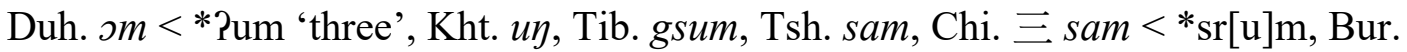
suṃ $(\S 47)$

Duh. is <*?es ‘recognise’, Kht. $\tilde{l}^{\prime}$, Tib. śes.pa, Tsh. se, Bur. si ‘know’ (§63c)

\footnotetext{
${ }^{64}$ Denasalisation of a voiceless nasal is also attested from Chinese as the correspondence between OC voiceless resonants and MC voiceless obstruents, cf. Baxter and Sagart (2014: 111-112).

${ }^{65}$ Proto-Western Kho-Bwa vocal onsets are reconstructed with a glottal onset *?- to indicate their pre-glottalised status, which is relevant in view of rhyme correspondences that often coincide with those of the glottal fricative onset. Although attested reflexes may also have a glottal or pre-glottalised onset, this is not indicated in the transcriptions.

${ }^{66}$ The unexpected Duhumbi reflex aw not "ow is conditioned by the glottal onset.

${ }^{67}$ An incomplete cognate set is Kht. $y$ :, She. $i:<* u t$ 'wipe', cf. Tib. Vśud (pres. śud) 'rub', Bur. sut $<*$ sut 'wipe' (Hill 2019: 56).

${ }^{68}$ Cf. Jäschke (1992 [1881]: 572): sad.pa 'to examine, see, try, test' and Tshe-ring (1997: 569): sad.pa 'examine; slander'.
} 
The following closely related cognate set has a complex phonological history in the descendant varieties.

Duh. wa.ar ${ }^{69}<*$ a.Par 'dry (adj.)', Kht. $y k . .^{.70}$, Khs. .wal s11 $^{71}$ Tib. sro.ba 'dry by exposing to sun rays', Chi. 暵 $x a n H<*\left[\mathrm{q}^{\mathrm{h}}\right]^{\mathrm{S}}$ ar?-s 'dry' $(\S 70)$

In a second set of correspondences, the rhymes of the reflexes do not match the expected outcomes. In several cases, the comparative evidence from Chinese is strongly suggestive of a voiced uvular onset that may underlie these vocal onsets.

Khs. $u n^{72}<*$ ?un 'come', Kht. un, Chi. 栨 yen $<*[\mathrm{G}] \mathrm{a}[\mathrm{n}]$ 'extend; go forward' $(\S 60)$

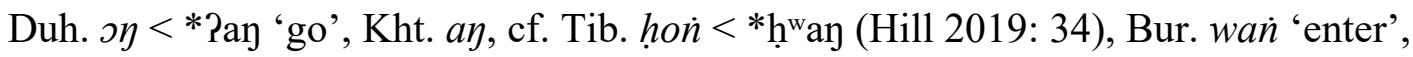
Chi. 往 hjwang $X<*_{\mathrm{G}^{\mathrm{w}}}$ ay? $(\S 56)$

Duh. in $<*$ ?in 'speak', Kht. an, Chi. 誸 hen $<*[\mathrm{G}]^{\mathrm{S}} \mathrm{i}[\mathrm{n}]$ 'speak quickly' $(\S 58)$

Duh. $u k<*$ ?uk 'hide', Kht. $u k(\S 5)$

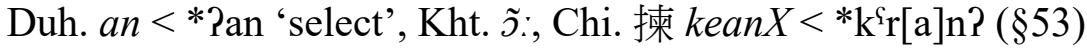

§26. Duh. vocal onset, Khn. $x$-. There is a single, incomplete cognate set where a Duhumbi and Khispi vocal onset corresponds to Khoina fricative onset $x$-. I propose that this set, though data deficient, derives from a voiceless labial onset $*$ w- when preceding a rhyme with a vowel other than /a/, a palatalised onset or a rhotic onset cluster, for which see correspondences $\S 63, \S 65$ and $\S 66 a$. Considering the comparative evidence from Chinese, a uvular onset is also possible.

Duh. $\varepsilon n$ 'spill' < *wen 'spill’, Khs. in, Khn. $x \varepsilon$ :, Chi. 衍, 演 $y e n X<* \mathrm{~N}-\mathrm{q}(\mathrm{r}) \mathrm{an}$ ? 'overflow; flow out, extend' (§57)

$\$ 27$. Duh. vocal onset, $K h t$. $j$-. In a single cognate set, a Duhumbi vocal onset corresponds to a palatal glide in all other varieties. Because the Duhumbi onset reflex $j$ - is expected $(\S 60)$, it is presumed that the palatal onset was elided to avoid both a palatal onset and rhyme.

Duh. aj [†jaj] < *jaj 'fight (n.)', Kht. je: (§74)

\section{NASAL ONSETS}

Correspondences between nasal onsets can be divided in trivial correspondences, in which all varieties have the same reflex, and minor correspondences.

\subsection{TRIVIAL CORRESPONDENCES}

In general, Duhumbi nasal onsets correspond to Khoitam nasal onsets.

\footnotetext{
${ }^{69}$ The Duhumbi outcome is the result of *a.Par $>*$ a.war, an epenthetic labial onset of the root to avoid the phonetically awkward form ${ }^{\dagger}$ a.ar, followed by a re-analysis of the onset of this root to the prefix wa.ar instead of expected outcome ${ }^{\dagger} \mathrm{o}$.ar.

70 The Khoitam outcome is the result of $* \mathrm{a}$. Par $>* \mathrm{a}$. har $>y k . \tilde{\partial}:$, although the reflex of the prefix is irregular, and would be expected to be as in Rupa, o. $\tilde{\text { : : }}$

${ }^{71}$ The Khispi outcome is the result of *a.Par $>*$ a.war, an epenthetic labial onset of the root to avoid the phonetically unpermitted form ${ }^{\dagger}$ a.ar, followed by rhyme *-ar $>-a l$ and vowel harmony of the prefix to the vowel of the root J.wal.

${ }^{72}$ Duhumbi has possible Bodish loan lon, cf. Dzo. lhod 'come', Chi. 沿 ywen <*lon 'go along (a river)'.
} 
$\S 28$. Duh. m-, Kht. m-, Khs. $m$-. Voiced nasal stop $m$ - in Duhumbi regularly corresponds to voiced nasal stop $m$ - in Khoitam. The Khispi evidence is provided for comparison with $\S 32$.

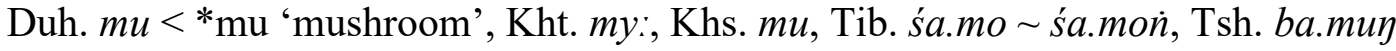
$(\S 27)$

Duh. ग.men <*a.man 'old', Kht. a.man, Khs. ग.men, Tsh. man.ma $(\S 41)$



Duh. mur $<*$ a.mur 'pubic hair', Kht. a.min, WBur. mweh $<*$ muyh $<*$ murlh 'body



$\S 29$. Duh. $n$-, Kht. $n$-. Voiced nasal stop $n$ - in Duhumbi regularly corresponds to voiced nasal stop $n$ - in Khoitam.

Duh. nay <*nay 'thou (2SG)', Kht. nay, Chi. 若 nyak <*nak (§36)

Duh. $n u k<*$ nuk 'sago', Kht. nyk, Tsh. nuך (§5)


$n a$ 'be sick' or sku sñun.ba 'be sick (Hon.)', Bur. nā 'hurt' (\$25)

§30. Duh. $y$-, Kht. $n$-. Duhumbi and Khispi velar nasal $\eta$ - corresponds to simple onset $n$ - in Khoitam and the other Sartang varieties and to $n$ - in Rupa and Shergaon.



Bur. $\dot{n} \bar{a} h$, Chi.魚 ngjo < * ya, PBG *na? (§25)


Chi. 語 $n g j o X<*$ ya? 'speak' $(\S 11)$

Duh. 'yin ${ }^{75}<*$ yin 'silver', Kht. niy, Rup. niy, Tib. dinul, OBur. $\dot{n} u y$, Chi. 銀 ngin < $*_{\mathrm{y}} \mathrm{r}[\mathrm{n}](\S 42)$

$\S 31$. Duh. n-, Kht. n-. A palatal nasal $n$ - in Duhumbi, Khispi and Rupa and Shergaon regularly correspond to $n$ - in the Sartang varieties and derives from a palatalised alveolar nasal onset.

Duh. 6 a.nu 'paneer' <*(s ${ }^{\mathrm{j} a}$./a. $) n^{\mathrm{j} u}$ 'brain', Khs. 6 a.nu, Kht. a.ny:, Rup. a.ny:, Tsh. nok.tay ${ }^{76}$, WBur. nhok, Chi. 腦 $n a w X<{ }^{*} n^{\varsigma} u$ ? (\$27)

Duh. nis 'two' < *nis 'two', Kht. nik, Rup. nik, Tib. gñis, Tsh. nik.tsin, Bur. nhac, Chi. 二 nyijH $<*$ ni[j]-s $(\S 63)$

Duh. $n u t<*$ n'ut 'put on (shoes, pants)', Kht. $n y^{\text {? }}$, She. $n i^{\text {? }}(\S 15)$

\footnotetext{
${ }^{73}$ This is the Chaw (lower class) reflex, the Thong (upper class) reflex is nuy.

${ }^{74}$ I propose this palatalised onset because of the unexpected rhyme reflexes in this lexeme, even though the onset reflexes are regular.

${ }^{75}$ The attested Duhumbi form $\eta \supset j$ is a loan from Dirang Tshangla $\eta \supset j$, in turn borrowed from Tibetan $d \dot{n} u l$.

${ }^{76}$ Whereas Khispi has preserved the inherited lexeme form for 'brain', Duhumbi has borrowed the Tshangla form, although the inherited form survives in the meaning of 'paneer (cheese made by curdling milk with acid buttermilk)'.
} 


\subsection{MINOR CORRESPONDENCES}

There are a few correspondences where one or more of the attested onsets is distinct from the onset that would be expected on basis of the trivial correspondence patterns for the nasal onsets.

§32. Duh. m-, Kht. $m$-, Khs. $p$-. The irregular Khispi reflex $p$ - where the other varieties have onset $m$ - is unexpected and may be evidence for a change *s-m->p-. ${ }^{77}$

Duh. $m \varepsilon n^{78}<*$ man 'medicine', Khs. pen, Kht. men, Rup. man, Tib. sman, Tsh. man $(\S 41)^{79}$

$\S 32$ a. Duh. m-, Kht. m-. Unlike the reflexes in $\S 28$, palatalisation of the Duhumbi reflex and divergent rhyme reflexes could be attributed to a rhotic medial.

Duh. $m^{j} \varepsilon . k a<* a . m r a t ~ ' m a n y '$, Kht. a.me?, Rup. a.mat, Khs. me.ka, Tib. rmad.pa 'excellent, wonderful, marvellous', WBur. mrat 'be excellent, exceed; gain, profit' $(\S 6)$

$\S 32$ b. Duh. $m$-, Kht. $w$-. In a single cognate set, Duhumbi onset $m$ - corresponds to Khoitam

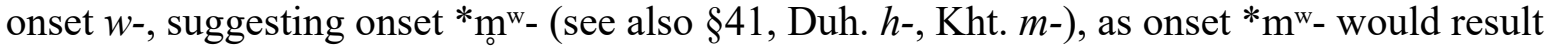
in the rhyme reflexes of rhyme correspondence $\S 16$. Probably, the divergent simplification of onset * ${ }^{*}{ }^{\mathrm{w}}$ - to onsets $m$ - and $w$ - took place before the changes in rhymes as a result of the labialised onset.

Duh. $m a k<{ }^{*} \mathrm{~m}^{\mathrm{w}}{ }^{\mathrm{a}} \mathrm{ak}$ 'beat', Kht. wak $(\S 1)$

\$32c. Duh. m-, Kht. dt-. There is one cognate set with unexpected Duhumbi onset reflex m-, not $b-(\S 17 \mathrm{a})$, and expected Khoitam, Rahung and Jerigaon reflex $d_{6-}$, Khoina, Rupa and Shergaon reflex $d z$ - This set has been assigned to a palatalised onset before high vowel $/ \mathrm{i} / .^{80}$ Note that ${ }^{*} \mathrm{~m}^{\mathrm{j}}$ - simplified to $m$ - in Duhumbi but denasalised to ${ }^{*} \mathrm{~b}^{\mathrm{j}}$ - in the Sartang and Sherdukpen varieties, after which it followed the same sound correspondence $\S 17 \mathrm{a},{ }^{*} \mathrm{~b}_{-}^{\mathrm{j}}->$ Khoitam $d_{t}$ - before high vowel $i$.


sleep' $(\S 42)$

§33. Duh. n-, Kht. n-, Khn. r-. Unlike correspondence $\$ 29$ (Duh. $n$-, Kht. $n$-), in two cognate sets, the Khoina reflex of ${ }^{*} \mathrm{n}$ - or ${ }^{*} \mathrm{n}^{\mathrm{j}}$ - is $r-.{ }^{81}$ As the Khoina reflex $k u . n u^{\text {? }}$ in correspondence set 'be sick' (\$29) shows, the word-internal occurrence of the onset is not the reason for this unexpected alternation.

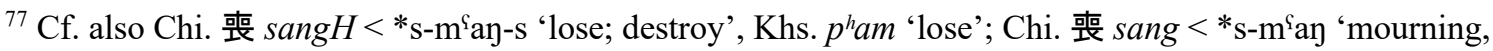
burial', Khs. buy 'bury'; Tib. smin.pa 'ripe', Khs. bin 'to ripen, to ferment'; Tib. smad 'the lower part', Khs. be 'down', cf also $\$ 3$ and $\S 6$.

${ }^{78}$ Duhumbi men not pen may be the result of Bodish contact language influence, where Khispi has preserved the original reflex.

${ }^{79}$ Compare to the reflexes of *a.man 'old' in $\$ 28$ as well as to the following cognate set:

Duh. $m \varepsilon n<*$ man 'potato bean (Apios sp.), Kht. men, Khs. men, Rup. man, Chi. 蔓 mjonH<*C.ma[n]$\mathrm{s}$ 'creep; creeping plant'.

${ }^{80}$ Note how the Old Chinese reconstruction has a Type A onset.

${ }^{81}$ This was initially thought to be a contact-induced (Hrusish) correspondence (see also Bodt \& Lieberherr 2015: 87). But neither Bangru nor Eastern Miji are contact languages for Khoina, the correspondence has not been attested for Hruso, and cognates with Western Miji also have onset $n$-, e.g. no 'ill'.
} 



§3)


*rn̈yil, Chi. 齦 $n g j i n<* y ə[\mathrm{n}](\S 38)$

\section{FRICATIVE ONSETS}

Fricative onsets $s$ - and $z$ - in Duhumbi generally correspond to fricative onsets $s$ - and $z$ - in Khoitam, but whereas Duhumbi has distinctive palatal fricatives, Khoitam does not. There are various sources of the Duhumbi fricative onset $h$-, including distinctive voiceless nasal and lateral onsets.

\subsection{TRIVIAL CORRESPONDENCES}

$\S 34 . D u h . s$-, Kht. s-. Duhumbi fricative onset $s$ - generally corresponds to fricative onset $s$ - in Khoitam.

Duh. nam.sum < *nam.som 'wind', Kht. nə.səm, Tsh. yam.su (§46)

Duh. $s i<*$ səj 'aconite', Kht. se:, Tib. hdzin.pa 'black aconite' (§33a)

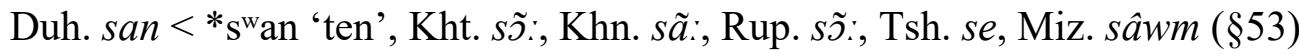

Duh. $s u<*^{*}{ }^{w} a$ 'search', Kht. so:, Rup. saw, Las. 'śo;, Chi. 搜 $s r j u w<*$ sru 'search' $(\S 30)$

§35. Duh. z-, Kht. z-, Khn. z-. Duhumbi fricative onset $z$ - generally corresponds to fricative onset $z$ - in Khoitam and all other varieties.

Duh. zuk 'thorax'<*zuk 'face’, Kht. zyk, Tib. gzugs 'form; body (Hon.)' (§5)

Duh. zum <*zom 'hold', Kht. zom, Tib. hdzoms.pa 'come together, gather' (§46)

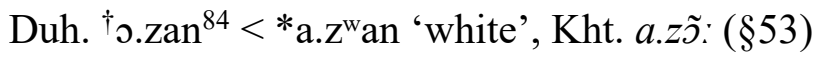

Duh. $6 a . z \varepsilon t<{ }^{*}$ s'a.za? 'langur’, Kht. sə.zu’, Khn. zə.zu’, Khs. $6 a . d b a t^{85}(\S 25)$

$\S 36$. Duh. $h$-, Kht. $h$-. The Duhumbi glottal fricative $h$-regularly corresponds with Khoitam and other Sartang and Sherdukpen glottal fricative $h$-. As the comparative evidence shows, the Proto-Western Kho-Bwa onset *h- often corresponds to other Tibeto-Burman $s^{-}$.

Duh. hin <*han 'one', Kht. han, $\mathrm{PBG} * \mathrm{sV}$, Chi. 壹; — 'jit $<*$ ?i[t] $(\S 58)$

Duh. haj < *haj 'burn', Kht. he:, PBG *sal 'sun; day', Miz. hâl (§74)

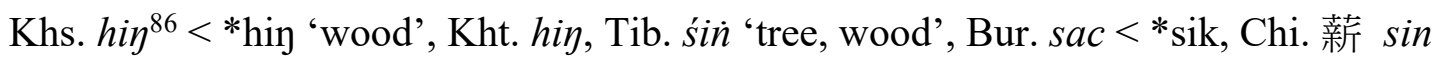
$<* \operatorname{si}[\mathrm{y}]$ 'firewood' (§38)

\footnotetext{
${ }^{82}$ Duhumbi and Khispi have the Bodish loan $n a . t^{h} a$, Tibetan na.tsha 'disease'.

${ }^{83}$ Cf. also Tib sku sñun.ba 'be sick (Hon.)'.

${ }^{84}$ Duhumbi has loan jay.kar cf. Tibetan yan.dkar 'whitewash, lime'.

${ }^{85}$ The palatal affricate in Khispi may be conditioned by the palatal fricative in the prefix, i.e. *sia.zat $>*^{*}$ ca.zat $>$ 6a.dtat.

${ }^{86}$ Duhumbi has $6 i \eta$, due to loan contamination from Bodish cf. Tibetan siin 'tree, wood', Tshangla 6 in 'tree, wood', Brokpa 6 in 'tree'.
} 


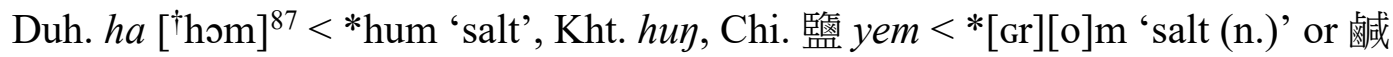
heam $<*$ Cə.[g]' $\mathrm{r}[\mathrm{o}] \mathrm{m}$ 'salty' (§47)

§37. Duh. z-, Kht. z-, Khn. dz-, Khs. dt-. The voiced dental affricate $d z$ - is very rare in the modern Western Kho-Bwa varieties but needs to be reconstructed at the proto-level to account for a few cognate sets that do not fit with other correspondences such as $\S 35$ (Duh. $z$ , Kht. $z$-). There is a single correspondence where Duhumbi and Khoitam both have onset $z$-, but Khoina has onset $d z$ - and Khispi has onset $d t_{-}$. Other sets that derive from onset *dz- are $\S 39 \mathrm{a}$ and $\S 53$.



Khs. $6 a . d t u \eta^{88}<*^{\text {jaa.dzuk 'deer'89 }}$, Kht. dto.zyk, Khn. sy.dzyk (§5)

\subsection{PALATALISED ONSETS}

Distinctive reflexes can be shown to derive from palatalised onsets.

$\S 38$. Duh. 6-, Kht. s-. Duhumbi and Khispi palatal fricative onset 6 - regularly correspond to onset $s$ - in all other varieties except Khoina, which has retroflex reflex $s^{-}$.

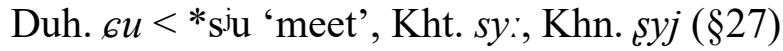

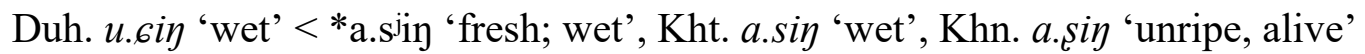
$(\S 38)$

Duh. $n i .6 i<*\left(\right.$ nin./a.)sjiw 'paddy rice', Kht. nə.se:, Rah. t6 ${ }^{h} u$ a.se:, Khn. $\varsigma^{h} u . s e:{ }^{90}$, Chi. 收 syuw $<*^{*}$ s-kiw 'collect; harvest' (§63b)

Duh. cis $<*$ siit 'seven', Kht. sik, Khn. sik, Chi. 七 tshit $<*\left[\mathrm{ts}^{\mathrm{h}}\right] \mathrm{i}[\mathrm{t}](\S 63 \mathrm{a})$

Duh. $6 \varepsilon t<*^{*}$ jat 'exit', Kht. $s \varepsilon^{2}$, Khn. $s \varepsilon$ ?, Tib. gśegs.pa 'come, go’ (§6)



Duh. $6 a-<*^{\mathrm{j}} \mathrm{a}^{-}$'animal prefix', Kht. $s \partial-\sim s-(\S 31)$

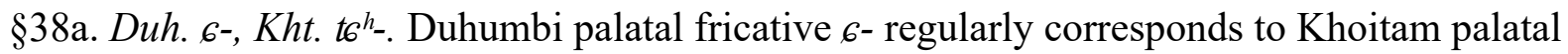
affricates and Khoina dental affricates, with elder Rupa speakers realising a dental affricate and younger Rupa speaker realising a palatal affricate.

Duh. $6 \varepsilon r<*$ bjar 'fly', Kht. $t 6^{h} a n$, Khn. $t s^{h} \varepsilon n$, Rup. t6 ${ }^{h} a n \sim t^{h} a n$, Khaling $b^{h} e r$ (Jacques et al. 2015), Tib. hbyer.ba 'flee, escape', Chi. 飛 $p j+j<*$ Cə.pə[r] $]^{91}(\S 66)$

\footnotetext{
${ }^{87}$ Here, the Duhumbi and Khispi rhyme does not match. Although this is temporarily assigned to an onset *h-, the comparative evidence favours a uvular or velar onset instead.

${ }^{88}$ The nasal coda is unexpected, we would expect ${ }^{\dagger} 6 a . d b u k$, and this reflex is perhaps under influence of Dirang Tshangla douy 'deer'.

${ }^{89}$ On basis of this correspondence, we would reconstruct Duhumbi ${ }^{\dagger} 6 a . z u k$, but Duhumbi has Bodish loan ca.wa, cf. Tibetan śa.ba, Bhutan Tshangla $6 a$.wa.

${ }^{90}$ The Rahung and Khoina reflexes include the root for 'rice', indicating that an adjective *a.siiw originally meant something like 'unhusked, raw'. Khoina has contracted the root for rice with the adjective: * ${ }^{\mathrm{h}} \mathrm{h}$ a.siiw $>$ $*_{\text {tsh }}$ a.se: $>$ ts $u . s e:$.

${ }^{91}$ One of the anonymous referees pointed out that this Chi. form is cognate with Tib. hphur.ba 'fly (v.)' and is probably an ideophone, cf. Jacques (2015).
} 
Duh. $6 a k<*$ bjak 'cliff', Kht. $t 6^{h} a k$, Khn. $t^{h} a k$, Rup. $t^{h} a k \sim t 6^{h} a k$, Tib. brag, Tsh. brak $(\S 1)$

Duh. $6 \varepsilon j<*$ biaj 'buy', Kht. $t 6^{h} \varepsilon$; Khn. $t{ }^{h} a$, Rup. $t 6^{h} a: \sim t{ }^{h} a$, PBG *prai ${ }^{1}$, Chi. 買 meaX $<*^{\text {' }}$ raj? $(\S 67)$

Duh. $6 i<*$ biji 'give', Kht. $t \sigma^{h}{ }^{\prime}$, Khn. $t{ }^{h} i^{\prime}$, Rup. $t \sigma^{h}{ }^{\text {' }} \sim t^{h}{ }^{h}$ ', Tsh. bi, Tib. sbyin.pa,

Chi. 界 pjijH $<*$ pi $[\mathrm{t}]-\mathrm{s}(\S 33)$

Khs. $6 a .6 i^{92}<*\left(\mathrm{~s}^{\mathrm{j}} \mathrm{a} . / \mathrm{a}.\right) \mathrm{b}^{\mathrm{ji}}$ 'gall, bile', Kht. a.t6 ${ }^{h}$ :, Khn. a.tshi: $(\S 26)$

Duh. $60<*$ bjaw 'burst, explode', Kht. $t 6^{h} \mathrm{~J}^{93}(\S 69 \mathrm{a})$

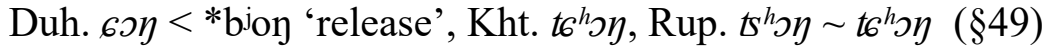

Duh. $6 a<{ }^{*} \mathrm{~b}^{\mathrm{j} a}$ 'precipitate (snow, rain, hail)', Kht. $t 6^{h} u$;, Khn. $t^{h} u$; , Rup. $t s^{h} u: \sim t 6^{h} u$ : $(\S 24)$

$\S 38$ b. Duh. 6-, Kht. t6-. In two cognate sets, Duhumbi palatal fricative 6 - corresponds to Khoitam t6-, with elder speakers realising ts- and younger speaker t6- in Rupa. Similar to correspondence $\S 38 \mathrm{a}$, I propose this set derives from a palatalised bilabial onset, albeit an unvoiced one. ${ }^{94}$

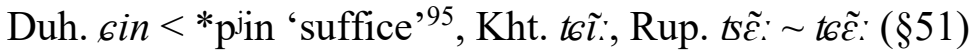

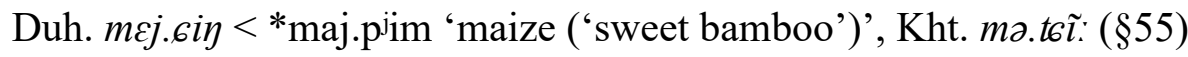

§39. Duh. z-, Kht. z-, Khn. z-. Duhumbi and Khispi onset z- regularly corresponds to onset zin all other varieties except Khoina, which has reflex $z^{-}$.

Duh. $z u<*^{*} \mathrm{Z}^{\mathrm{u} u}$ 'melt', Kht. zy:, Khn. zyj, Tib. źu.ba, Tsh. ju $z u(\S 27)$

Duh. $a . z a<* a . z^{j a}$ 'sister-in-law', Kht. a.zu;, Khn. a.zui, Tib. a.cag 'elder sister; sister-in-law’ (\$24)

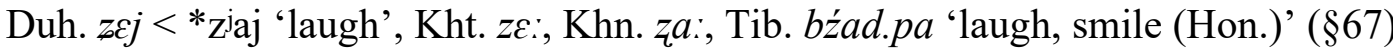

§39a. Duh. z-, Kht. z-, Khn. z-. In the following cognate sets, unlike in correspondence $\$ 39$ Khoina has onset reflex $z$ - instead of expected $z$ - while Duhumbi and Khispi have palatal onset $z^{-}$, hence I propose these derive from a palatalised onset ${ }^{*} \mathrm{c}^{\mathrm{j}-}$ rather than palatalised onset $* \mathrm{z}^{\mathrm{j}-}(\S 39)$ or plain onset $* \mathrm{c} z-(\S 37)$.

Duh. $z i<* d z i$ 'urine', Kht. $z i$, Khn. $z i$, Tib. $z i l<*$ dzil 'dew', Bur. chīh or Tib. gci.ba 'urinate' $(\$ 26)$

Duh. $z \varepsilon t<*$ dzjes 'tear’, Kht. $z e^{?}$, Khn. $z \varepsilon^{2}(\S 20)$

\footnotetext{
92 Duhumbi has Bodish loan $k^{h} r i s$, cf. Tibetan mkhris.pa, Dirang Tshangla $k^{h} r i s$.

${ }^{93}$ But Rupa prok and Shergaon $p o k$ are likely cognate with Tshangla $p^{h} \jmath k$, all 'burst, explode'.

${ }^{94} \mathrm{An}$ incomplete cognate set, the root of which is reflected in the compound for 'maize', that can be added to this correspondence is



${ }^{95}$ E.g. of salt or spices in food.
} 


\subsection{VOICELESS ONSETS}

To account for distinct cognate sets, I propose several distinct voiceless onsets.

$\S 40$. Duh. $h$-, Kht. $n$-. There are a few cognate sets in which, unlike all other varieties, Duhumbi and Khispi have onset $h$ - not $n$ - (§29 Duh. $n$-, Kht. $n$-), justifying positing a voiceless alveolar nasal stop onset.

Duh. has.ta $<*($ a.)nas.da 'slow', Kht. a.no?.du: (\$62)

Duh. hin- hem- hen- ['ha- $]^{96}<*_{\text {na- }}$ 'facial prefix' ${ }^{97}$, Kht. nə-, Mon. 'na:, Dzo. lha.pa [ha.pa], Tib. sna, Bur. nhā 'nose' (§31)

Duh. haj<*a.nojs 'pus', Kht. a.ñ̃', Mon. 'ncp, Dzo. lhabs [hap], Tib. snabs, Bur. nhap 'mucus' (§74b)

Duh. $h a$ 'listen', na 'heed' < *na ? 'listen, heed', Kht. nuך 'listen', Khn. nu' 'listen', Tsh. na 'heed' (\$25)

Duh. ham 'emit smell; putrefy' < *nam 'emit smell', Jer. nan, Tsh. nam, Tib. mnam.pa 'emit smell' and لsnam (pres. snom) 'smell something' (via *smnam $>$ snam (Jacques 2014b: 162)) (§45)

$\S 41$. Duh. h-, Kht. m-, Jer. w-. There is one cognate set that shows distinct reflexes from the voiced bilabial nasal correspondence ( $\$ 28$ Duh. $m$-, Kht. $m$-), justifying a distinctive voiceless bilabial nasal stop *m-.

Duh. hut $<*$ mut 'blow', Kht. mik, Jer. wik, Bur. mhut 'blow away’ (§18)

$\S 42$. Duh. $h$-, Kht. l-. There are several cognate sets where a Duhumbi, Khispi and Khoina onset $h$-corresponds to onset $l$ - in the other varieties. I propose this derives from a voiceless lateral onset *1-.

Duh. hu.ma $a^{98}<{ }^{*}$ lam a.ma ${ }^{99}$ 'path', Kht. lym [†'lam ${ }^{100}$, Khn. ham, Tib. lam, Tsh. lam, Bur. lamh $(\S 45)$

Duh. $h u<*$ lu 'naga', Kht. ly: Tib. klu, Tsh. $l u(\S 27)$

Duh. huk <*luk 'pour', Kht. lyk, Tib. zlug.pa 'pour in', Tsh. luk(§5)

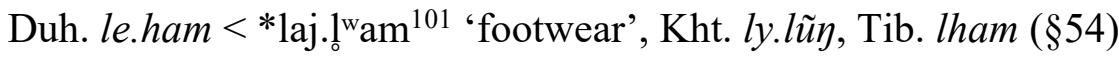

Duh. haj<*1oj 'plant', Kht. lo:, Khn. ha: (\$74a)

\footnotetext{
96 The Duhumbi epenthetic nasal codas are unexpected.

${ }^{97}$ Generally identifying body parts and bodily fluids associated with the lower face, such as 'spittle', 'neck', 'tooth', 'nose' and 'mouth'.

${ }^{98}$ Via *lam a.ma $>*$ ham.ma $(* 1->h$ - and loss of prefix $)>*$ ha.ma (degemination of $\left.-m m-\right)>h u . m a$ (harmonisation of vowels in prefixes with vowels in roots $\{u\}$ prf $+\{a, i, u\}$ root).

${ }_{99}$ A compound of roots *lam 'path' and *a.ma 'mother', with large natural objects in the Kho-Bwa languages regularly expressed as 'X-mother', cf. Duhumbi ca.dtok a.ma 'soybean mother', i.e. 'pod-bearing soybean plant'; Duhumbi $k^{h} \mathrm{\jmath} w . m a<k^{h} \mathrm{~s} w$ a.ma 'water mother', i.e. 'river'; luy a.ma 'stone mother', i.e. 'large solitary rock'; may. $k^{h} a$ a.ma 'walnut mother', i.e. 'nut-bearing walnut tree' etc.

100 The Khoitam rhyme is unexpected and may be the end result of a complex interaction between root and suffix, e.g. *lam a.ma $>*$ lam a.mu $(* 1->l$ - and *-a $>-u)>*$ lam.mu (loss of prefix) $>*$ lum.ma (metathesis of vowel of root and suffix) $>*^{*} \operatorname{lum}($ contraction of root and suffix) and finally $>\operatorname{lym}(*$-uC $>*$-yC after $*$-um $>$ $u \eta)$.

${ }^{101}$ A compound of roots *laj 'leg, foot' and *lawam 'shoe'.
} 
Duh. hor $<*$ lor 'perforate', Kht. $l \jmath^{\text {? }}$, Khn. $h \jmath^{\text {? }}$, Rup. lok (§72)

\subsection{MINOR CORRESPONDENCES}

$\S 43 . D u h . h$-, Kht. $h$-, Khn. $x$-. Duhumbi onset $h$ - corresponds to onset $h$-in all varieties, except Khoina, which has onset $x$ - instead of onset $h$ - as expected from correspondence $\S 36$. I propose this derives from a labialised onset ${ }^{*} \mathrm{~h}^{\mathrm{w}}$ - or rhotic onset cluster $* \mathrm{hr}$-, which is confirmed by the rhyme reflexes. ${ }^{102}$

Duh. $h_{\varepsilon}^{j} k^{103}<*$ hrek 'louse’, Kht. hek, Khn. xajk, Tib. śig, Chi. 蛍 srit $<* \operatorname{sri}[\mathrm{k}](\S 2)$

Duh. həj <*hruj 'blood', Kht. he;, Khn. xa:, OBur. suyh, Chi. 髓 sjweX $<*$ s-loj? 'marrow' (§68)

Duh. hon 'pity'<*hron 'like', Kht. hĩ., Khn. xø:, Chi. 恨 $h o n H<*[\mathrm{~m}-\mathrm{q}]^{\mathrm{f}} \mathrm{\partial}[\mathrm{n}]-\mathrm{s}$ 'regret' $(\S 43)$

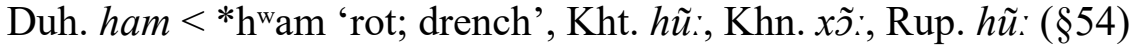

$\S 43 a . D u h . h-, K h t . h-, K h n . x$-, Rup. $k^{h}$. In a single cognate set, Duhumbi onset $h$ corresponds to onset $k^{h}$ - in Sherdukpen and onset $h$ - in all Sartang varieties except Khoina, which has onset $x$-. This set is distinct from both $\S 36$ and $\S 43$, and I propose this derives from a uvular onset *q-.


Japhug tu.NGar 'sputum' (Jacques 2016), Chi. 次 zjen <*s-N-qa[r] ${ }^{104}$ 'saliva; spittle' $(§ 70)$

$\S 43 b . D u h . h-, K h t$. $\varnothing$-. In a single cognate set, Duhumbi and Khispi have onset $h$ - whereas all the other varieties have a vocal onset. I propose this set derives from a labialised uvular onset ${ }^{*} \mathrm{q}^{\mathrm{w}}$-.

Duh. hut $<*^{*} \mathrm{q}^{\mathrm{w} u t}$ 'hand, arm', Kht. $i k$, Chi. 右 hjuwH $<*^{*} \mathrm{~m}-\mathrm{q}^{\mathrm{w}}$ ə?-s $\sim *^{*} \mathrm{~m}-\mathrm{q}^{\mathrm{w}}$ ə?; hjuwX $<*[\mathrm{G}]$ 'ə?? 'right hand'; 肘 trjuwX $<* \mathrm{t}-[\mathrm{k}]<\mathrm{r}>\mathrm{u}$ ? 'elbow' (§18)

$\S 43$ c. Duh. h-, Kht. j-. There is one cognate set, where Duhumbi, Khispi and Shergaon onset $h$ - corresponds to Khoitam and Khoina onset $j$-, with regular rhyme reflexes when following a uvular or glottal onset. This correspondence resembles correspondences $\S 62$ and $\S 65$, but I propose this derives from a palatalised voiced uvular onset. ${ }^{105}$

Duh. hat $<{ }^{*}{ }_{G}^{j}$ at 'split lengthwise (bamboo)', Kht. jo?, She. ho?, Chi. 戌 hjwot $<$ $*[\mathrm{G}]^{\mathrm{w}}$ at 'a kind of axe' (§19)

$\S 43 \mathrm{~d} . D u h . h-, K h t . p^{h}$. In the following cognate set, the onset reflexes in the prefix are distinct from those in roots.

\footnotetext{
102 The comparative evidence for 'louse' and 'blood' indicate that Proto-Western Kho-Bwa onset *hr- may derive from onset *sr-, which would explain the 'gap' in the reconstructed Proto-Western Kho-Bwa onset inventory with $*_{\mathrm{zr}-\text { and }} * \mathrm{hr}$ - present.

103 Palatalisation of the onset before rhymes $-\varepsilon k$ and $-\varepsilon \eta$ in Duhumbi is regular.

104 The Western Kho-Bwa reflexes, like the Japhug reflex, may evidence the N-prefix reconstructed for Chinese.

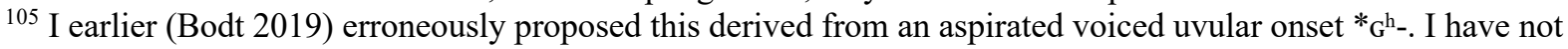
reconstructed any aspirated voiced stop onsets for Proto-Western Kho-Bwa.
} 
Duh. ho- $\sim w a-<* \mathrm{p}^{\mathrm{hw}} \mathrm{a}-$ 'bird prefix' ${ }^{106}$, Kht. $p^{h}$-, Rup. bo-, Khs. $w a-(\S 31)$

$\S 44$. Duh. 6-, Kht. h-. In a single cognate set, Duhumbi onset 6 - corresponds to Khoitam onset $h$-. This is most likely the result of the loss of the second word of the compound in Duhumbi, resulting in a form homophonous with $6 a$ 'meat; animal' (\$38), whereas in Khoitam the root of the second word is contracted to the first word of the compound ( ${ }^{*} s^{j} \mathrm{a}$ a. $\mathrm{p}^{\mathrm{h}} \mathrm{a}>{ }^{*} \mathrm{sa}$ a. $\mathrm{p}^{\mathrm{h}} \mathrm{u}>$ *sa. ${ }^{\mathrm{h}} \mathrm{u}>{ }^{*}$ sə.p $\mathrm{p}^{\mathrm{h}} \mathrm{u}:>$ Rupa s.pu: or further to *sə.hu: $>$ Khoitam $s u:$ ). Alternatively, ProtoWestern Kho-Bwa may have had a distinction between onsets ${ }^{{ }^{j} \mathrm{j}_{-}}$and ${ }^{*} \mathrm{~s}^{\mathrm{h}}$-, but additional evidence for this is hitherto lacking.

Duh. $6 a<{ }^{*}$ sja a.p $^{\text {ha }}$ 'cattle (lit. 'meat male')'107, Kht. hu:, Khn. su:, Rup. s.pu: (§14)

\section{AFFriCATE ONSETS}

Duhumbi (and Khispi, Khoina, Rupa) alveolar affricates regularly correspond to Khoitam (and Jerigaon, Rahung, Shergaon) palatal affricates. Duhumbi palatal affricates generally correspond to Khoitam palatal affricates.

\subsection{TRIVIAL CORRESPONDENCES}

§45. Duh. ts-, Kht. t6-. Duhumbi (and Khispi, Khoina, Rupa) onset ts- regularly corresponds to Khoitam (and Jerigaon, Rahung, Shergaon) onset t6-.

Duh. tsik<*tsik 'pinch', Kht. t6ik, Rup. tsik, Khn. tsik, Kiranti *tsek (Jacques 2017)

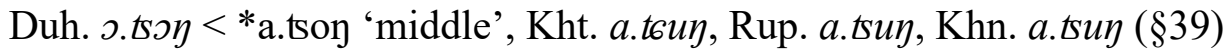

Duh. gun.tsun <*gun.tsun 'sweet buckwheat', Kht. $k^{h i \eta . t 6 i \eta, ~ R u p . ~ g ə . t s i n, ~ K h n . ~ g ə . t s i \eta, ~}$ Tsh. gun.tsun (§44)

Duh. bej.tsi<*baj.tsij 'pine kindle', Kht. ba:.t6i', Rup. ba: bə.tsi', Khn. ba:tsi’ (\$33)

$\S 46$. Duh. $t^{h}{ }_{-}, K h t . t 6^{h}$. Duhumbi (and Khispi, Khoina) onset $t^{h}$ - regularly corresponds to Khoitam (and Jerigaon, Rahung, Sherdukpen) onset $t 6^{h}{ }^{h}$.

Duh. $t^{h} u<*^{*} s^{\text {h } u ~ ' c o u g h ', ~ K h t . ~ t 6 ~}{ }^{h} y:(\$ 27)$

Duh. nam.tsh ${ }^{\text {' }}$ sunshine'<*nam.tsha 'rain', Kht. nə.t6 ${ }^{h} u$ : $(\S 24)$

\$47. Duh. t6-, Kht. t6-. There are two cognate sets in which Duhumbi t6-corresponds to onset t6- in Khoitam and all other varieties. However, the irregular rhyme correspondences and the good Bodish cognates indicate that these lexemes are likely loans in all varieties, rather than inherited lexemes. They can be found as correspondence set $\S 73$, in the section on loans.

$\S 48$. Duh. $t 6^{h_{-}, K h t .} t_{6}^{h}$. Duh. onset $t 6^{h_{-}}$regularly corresponds to Khoitam onset $t 6^{h_{-}}$.

\footnotetext{
${ }^{106}$ E.g. in 'chicken' and 'dog', but also wild bird species such as 'tragopan' and 'partridge'. Note how * $\mathrm{p}^{\mathrm{hw}} \mathrm{a}-$ bears similarity to Tibetan bya 'bird' and Burmese pyāh < *byāḥ 'bee' (Hill 2019: 220).

107 This refers to the common cattle, Bos taurus. Note the semantic distinction with the following correspondence set, which is actually odd considering cattle-mithun cross-breeds are always between a mithun bull and a cattle cow.

Duh. $6 a . m a<*^{*}{ }^{j a}$ a.ma 'mithun (Bos frontalis, lit. 'meat female')', Kht. s.um (via *sa a.mu: > ${ }^{*}$ sə.mu: $>$ s.um), Khn. sa.m, Rup. so.mu:
} 
Duh. u.t6 ${ }^{h} a m<*$ a.čham 'daughter-in-law', Kht. a.t6 ${ }^{h} a m$, Tib. chang.sa rgyag 'marry' $(\S 45)$


chuih $<*$ tsuiwh 'dye', Las. tsha:uH (Hill 2019: 57) and Bur. chu $<*$ 'tsū 'boil', Atsi 'tsu' (Hill 2019: 64) (§69b)

$\S 49$. Duh. $d_{t}-$, Kht. $d_{t}$ - Duhumbi onset $d t$ - regularly corresponds to Khoitam onset $d_{t}-$. The Rupa evidence is added to show the distinction with $\S 51$.

Duh. dtak <*jak 'wait', Kht. dtak, Rup. dtak (§1)

Duh. dtosk.pu<*a.jwak 'fast', Kht. a.dtok, Rup. a.dtok (§16)

Duh. dtow < * jaw 'parch, fry' ${ }^{108}$, Kht. dto:, Rup. dtaw (§69a)

\subsection{PALATALISED ONSETS}

There are a few cognate sets where, based upon distinct onset reflexes in one or more varieties, I propose palatalised onsets.

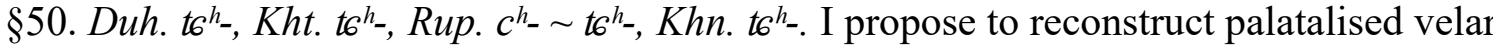
onset $* \mathrm{k}^{\mathrm{hj}}$ - for the following cognate set, in which elderly Rupa speakers realise aspirated palatal stop $c^{h_{-}}$, whereas younger speakers realise aspirated palatal affricate $t^{h_{-}}$, but Khoina has onset $t 6^{h}$, not retroflex $t s^{h_{-}}$(contrasting with correspondence set $\S 52 \mathrm{a}$, Duh. $t 6^{h_{-}}$, Kht. $t 6^{h}$, Rup. $c^{h_{-}} \sim t 6_{-}^{h_{-}}$, Khn. $t s_{-}^{h_{-}}$.

Duh. $t 6^{h} a k<* \mathrm{k}^{\mathrm{hj}}$ ak 'bitter', Kht. $t 6^{h} a k$, Rup. $c^{h} a k \sim t 6^{h} a k$, Khn. $t 6^{h} a k$, Tib. kha, Bur. $k h \bar{a} h$, Chi. 苦 $k h u X<* \mathrm{k}^{\mathrm{hS}} \mathrm{a}$ ? $(\S 1)$


Khispi and Shergaon, unlike Rupa, unexpectedly have affricate onset $t^{{ }^{h}}{ }^{-}$, not expected simple onset $k^{h}-(\$ 11)$, with Khoina having the expected retroflex affricate onset. This cognate set could be the result of additional palatalisation of the onset $* \mathrm{k}^{\mathrm{h}} \mathrm{r}-$.

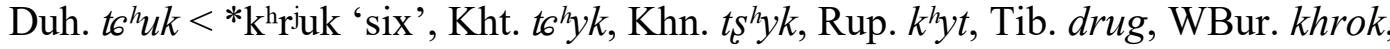
Chi. 六 ljuwk $<*$ k.ruk $(\$ 13)$


speakers realise onset $t^{h^{h}}$ - whereas younger speakers realise onset $t^{h_{-}}$- and Khoina has onset $t^{h}$. Where there are no unexpected rhyme reflexes $(\$ 52, \S 52 \mathrm{a})$, this is explained through onset $*$ ts $^{\mathrm{hj}}$.

Duh. $t 6^{h} \supset p<* s^{\mathrm{hj}}$ op 'fishing net', Kht. $t 6^{h} u k$, Rup. $t^{h} u k \sim t 6^{h} u k$, Khn. $t^{h} u k(\S 22)$

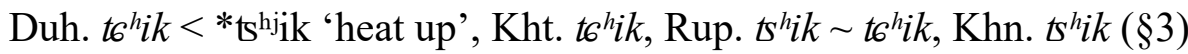

Duh. $t 6^{h} a p . b u<*$ a.tshjap.da 'thin', Kht. a.t6 ${ }^{h} a p . d u$, Rup. a.tsh $a p . d u \sim a . t 6^{h} a p . d u$, Khn. a.tshat.du $(\S 10)$

\footnotetext{
${ }^{108}$ Note how Duhumbi, Khispi and Shergaon make a semantic distinction between *jow 'parch', i.e. 'to parch, toast or roast (e.g. grains) by using dry heat without any oil or grease' and *ziow $\sim$ *zjaw 'fry' (undetermined because the Khoitam reflex is missing), i.e. 'to fry in oil, fat or grease', whereas all the other varieties only have a single lexeme for both. The Duhumbi, Khispi and Shergaon forms are etymologically closely related: Duhumbi and Khispi zow 'fry', doow 'parch'; Shergaon zaw 'fry', dtaw 'parch'.
} 
Duh. $t^{h} \varepsilon t<*$ ts $^{h j}$ es 'need', Kht. $t 6^{h} e^{?}$, Rup. $t s^{h} e^{?} \sim t 6^{h} e^{?}$, Khn. $t^{h} \varepsilon^{?}$, Tsh. $t^{h} a s(\S 20)$

Duh. $t 6^{h} a k<* t^{\text {hjjak }}$ 'taro', Kht. t6 ${ }^{h} a k$, Rup. $t s^{h} a k \sim t 6^{h} a k$, Khn. $t^{h} a k(\S 1)$

§51. Duh. dt-, Kht. dto-, Rup. $\jmath^{-} \sim d_{6-}$. There are a few cognate sets, in which, unlike $\S 49$ (Duh. $d_{t_{-}}$, Kht. $d_{t_{-}}$, Rup. $d_{t_{-}}$), elderly Rupa speakers realise voiced palatal stop $f^{-}$, whereas younger speakers realise voiced palatal affricate $d t$. I propose a palatalised velar onset $*^{\mathrm{g}} \mathrm{j}_{-}$, similar to the correspondence in $\S 50$.





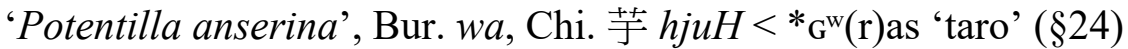

$\S 51$ a. Duh. dt-, Kht. g-, Khn. $d z_{--}$. There is one correspondence set, in which the Duhumbi reflex has affricate $t_{t_{-}}$, not expected simple onset $g$ - ( $\$ 1$. Duh. $g-$, Kht $g-$-), whereas Khoitam has simple onset $g-$, not expected voiced palatal affricate $d_{t-}$ (cf. $§ 10$. Duh. g-, Kht $d t_{-}$). These unexpected reflexes could be the result of additional palatalisation of the onset, like in $\$ 50 \mathrm{a}$.

Duh. dtu <*grju 'swallow', Kht. gy:, Khn. dzyj, Rup. gy: (§27)

\subsection{LABIALISED ONSETS}

There are a few cognate sets where, based upon a combination of distinct onset and rhyme reflexes in one or more varieties, I propose labialised onsets.

§52. Duh. $t 6^{h_{-}}, \mathrm{Kht} . t 6^{h_{-}, \text {Rup. }} \mathrm{s}^{h_{-}} \sim t 6^{h_{-}}$. In a few cognate sets, elderly Rupa speakers realise onset $s^{h}$ - whereas younger speakers realise onset $t 6^{h}{ }^{-}$. Combined with unexpected rhyme reflexes this necessitates the reconstruction of a labialised onset $* \mathrm{~s}^{\mathrm{hw}}{ }_{-}$.



$\S 52 \mathrm{a}$. Duh. $t 6^{h_{-}}, K h t . t 6^{h_{-},}$Rup. $c^{h_{-}} \sim t 6^{h_{-}}, K h n . t s^{h_{-}}$. In a few cognate sets, elderly Rupa speakers realise an aspirated palatal stop $c^{h}$ - whereas younger speakers realise an aspirated palatal affricate $t 6^{h_{-}}$, whereas Khoina has a retroflex affricate $t s^{h_{-}}$. These reflexes are distinct from regular correspondence $\S 48$ (Duh. $t 6^{h}$, Kht. $t 6^{h_{-}}$). Combined with unexpected rhyme reflexes, this necessitates the reconstruction of a labialised aspirated affricate onset ${ }^{*} \breve{c h w}^{\text {- }}$.

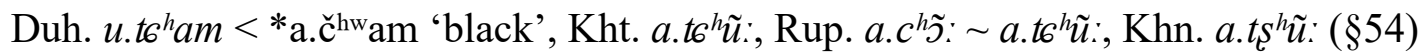

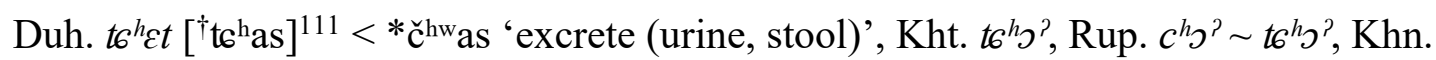
$t_{s}^{h} a^{2}(\S 62)$

§53. Duh. dto-, Kht. dt-, Khn. dt-, Rup. dt- $\sim d t_{-}$. In a few cognate sets, elderly Rupa speakers realise a voiced dental affricate $d z$ - whereas younger speakers realise a voiced palatal affricate $d t$ - and Khoina has voiced dental affricate $d t$-. Combined with unexpected rhyme reflexes this necessitates the reconstruction of a labialised aspirated affricate onset $* \mathrm{k}^{\mathrm{w}}$-.

Duh. dtu $<* \mathrm{dz}^{\mathrm{w} a}$ 'stay, reside, live', Kht. dtos: Rup. dzaw dtaw, Khn. dzo:, Chi. 居 kjo $<* \mathrm{k}(\mathrm{r}) \mathrm{a}$ 'squat; stay, dwell' (§30)

\footnotetext{
${ }^{109}$ A contraction of *gjay a.mu $>*_{\text {gjamu }}>*$ dzamu $>$ dtam, see also fn. 99.

${ }^{110}$ A generic term referring to yams and sweet potatoes, but not taro.

${ }^{111}$ The unexpected Duhumbi reflex and Khispi reflex $t 6^{h}$ at may be under contact language influence, i.e. Dirang Tshangla gi t6 ${ }^{h} c t$ 'to have the urgency to pass stool'.
} 


\subsection{MINOR CORRESPONDENCES}

$\S 54$. Duh. ts-, Kht. t6-. There are several exceptions to $\S 45$ (Duh. ts-, Kht. t6-), where one or more varieties has an aspirated affricate onset instead of an unaspirated affricate onset, or a palatal affricate instead of a dental affricate. The reason for this variation is yet unknown, but in general the dental affricates display greater variation in aspiration between the varieties and among speakers than other onsets. Another example ('mortar') can be found in $\S 72$ in the section on sound correspondences in borrowed lexemes.

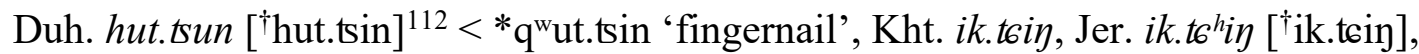

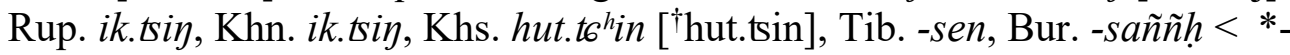
sinh (Wolfenden's law) < *-sinḥ (Hill 2019: 249) (§42)

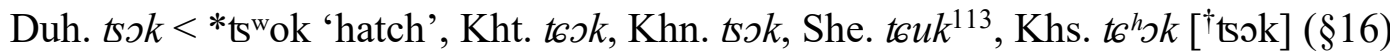

$\S 55$. Duh. ts ${ }^{h_{-}}, K h t$. t6-. Like in $\S 54$, an exception to $\S 46$ (Duh. $t^{h_{-}}$, Kht. $t 6^{h_{-}}$) is the following cognate set, where Duhumbi and Khispi and the Sherdukpen varieties have an aspirated affricate onset, but the Sartang varieties unexpectedly lack aspiration. The reason for this variation is yet unknown.

Duh. o.ts ${ }^{h} \varepsilon n<*$ a.ts an 'cold', Kht. a.t6an ['a.t6han], Rup. a.t6 ${ }^{h} a n$, Chi. 凊 tshjengH< $*\left[\mathrm{ts}^{\mathrm{h}}\right] \mathrm{en}-\mathrm{s}(\S 41)$

$\S 56 . D u h . t_{6}{ }^{{ }_{-},}, K h t . d_{t-}, K h n . d z_{-}$. In the following cognate set, the aspirated Duhumbi onset versus the voiced onsets in the other varieties suggests an aspirated uvular onset, whereas the retroflex Khoina onset suggests a rhotic onset cluster.

Duh. $k^{h i n . t 6^{h}}$ k $<*\left(\mathrm{~s}^{\mathrm{j} a} . / \mathrm{k}^{\mathrm{h}} \mathrm{a}.\right) \mathrm{q}^{\mathrm{h}} \mathrm{r}^{\mathrm{w}} \mathrm{ak}$ 'ant', Kht. say.dtok, Khn. san.dzəo, Tib. grog.mo, Chi. 蚼 $x u w X<* \mathrm{q}^{\mathrm{h} \varsigma}(\mathrm{r}) \mathrm{o}$ ? (§16)

$\S 57$. Duh. dt-, Kht. z-, Jer. dz- $\sim t_{-}-, K h n . z_{-}$. I propose the Duhumbi reflex in the following cognate set to be the outcome of a rhotic onset cluster *dzr-, not from palatalised onset * $\mathrm{z}^{\mathrm{j}}$-, which would result in Duhumbi reflex z- $(\S 39)$, or rhotic onset cluster *zr- which would result in Duhumbi reflex $d$ - (§13). Jerigaon only shows variation between onset $d t$ - and $d z$ - in sets deriving from this reconstructed onset *dzr-. The retroflex fricative in Khoina similarly points to a palatalised onset or a rhotic onset cluster, cf also $\S 11\left({ }^{*} \mathrm{k}^{\mathrm{h}} \mathrm{r}->\mathrm{Khn} . \mathrm{t}^{h-}\right)$.

Duh. dtaik<*dzrik 'ask', Kht. zik, Jer. dzik d dik, Khn. zik, Tsh. dtik, Tib. dri.ba (§3)

Duh. ${ }^{\dagger} \mathrm{d} \not \mathrm{u}^{114}<*$ dzru 'grind', Kht. $z y$; Jer. dzy: zy:, Khn. $z y:{ }^{115}(\S 27)$

\$57a. Duh. dt-, Kht. $j$-. In one cognate set, Duhumbi and Khispi onset $d t_{-}$corresponds to onset $j$ - in all other varieties, which I propose to derive from a palatalised aspirated uvular onset $* \mathrm{q}^{\mathrm{hj}}$, a correspondence closely related to $\S 20 \mathrm{a}$.

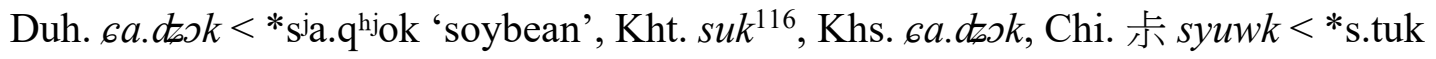
'pulse, beans' (§4)

\footnotetext{
112 The unexpected rhyme ${ }^{\dagger}$-un not -in is perhaps due to vowel harmony with the first syllable of the compound, although the same rhyme is also attested in lej.tsun 'toenail'.

${ }^{113}$ Here the rhyme reflex is unexpected, this is expected to be ttook.

${ }^{114}$ Duhumbi has $k^{h j} \xi \eta$ 'grind'.

${ }^{115}$ Note how, unlike reflexes of rhyme *-u when preceded by a palatalised onset (cf. §38, §39), the Khoina reflex has no epenthetic glide when preceded by a rhotic onset cluster.

${ }^{116}$ A contraction of * ${ }^{*}$.juk, cf. Jerigaon sy.juk.
} 


\section{APPROXIMANT ONSETS}

In addition to several trivial correspondences between approximant onsets, to account for minor cognate sets, I propose the reconstruction of distinct Proto-Western Kho-Bwa voiceless approximant onsets, in addition to their voiced counterparts.

\subsection{TRIVIAL CORRESPONDENCES}

In general, approximant onsets in Duhumbi correspond regularly to approximant onsets in Khoitam and all other varieties.

$\S 58$. Duh. $l$-., Kht. l-. The Duhumbi lateral approximant $l$-regularly corresponds with Khoitam $l$.

Duh. la $<$ *la 'mountain’, Kht. lu: Tib. la 'mountain pass’ (\$24)

Duh. $l \varepsilon j<*$ laj 'leg, foot', Kht. $l \varepsilon:(\S 67)$

Duh. lak <*lak 'penis', Kht. lak, Tsh. loy 'penis’ $(\S 1)$

Duh. lak<*lak 'lick', Kht. lak, Tib. Vldag (pres. ldag) 'lick', Chi. 食 zyik<*mə-lək 'eat' (Hill 2019: 288) (§1)

Duh. loj <*luj 'borrow', Kht. le;, Tib. glud 'ransom' (§68)

Duh. $l y j<*$ luj 'tongue', Kht. $l \varepsilon:$, Tsh. le (\$68)

Duh. $-l \jmath^{?}<*$-la? 'ablative suffix’, Kht. -lo', Tib. -la 'locative suffix' (§35)

Duh. las <*las 'soak in water', Kht. lo', Japhug la (Jacques 2016), Tib. bzhah,ba $<$ *blja 'wet, moist', Khroskyabs causative $s$ - $l i$ ', $s$-li 'drench' (Lai 2017: 537) $(\S 62)$

Duh. u.lis ${ }^{117}<*$ a.liw.da 'beautiful', Kht. a.le:.du, Chi. 修 sjuw $<*$ s-liw 'adorn' $(\S 63 b)$

A major exception to the general correspondence among approximant onsets is the lack of a distinctive phoneme / $\mathrm{r} /$ in Khispi onsets, which is to some extent reflected in Duhumbi (see $\S 64$ Duh. $r$-, Kht. $r$ - for the exceptions).

$\S 58$ a. Duh. l-, Kht. $r$-. In native lexemes, $l$ - in Duhumbi and Khispi corresponds to $r$ - in Khoitam and all other varieties.

Duh. $l \varepsilon t<*$ ret 'have intercourse', Kht. $r \varepsilon^{\prime}$, Chi. 徹 trhjet $<*$ thret 'penetrate' (§7)

Duh. lam <*ram 'be cold', Kht. ram, Chi. 凛 $\lim X<*[\mathrm{r}][$ ○]m? 'cold' $(\S 45)$

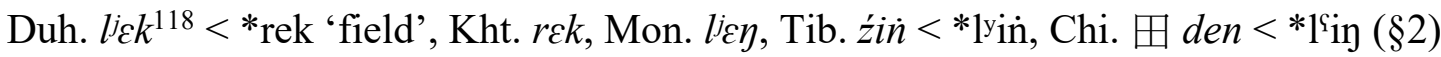

Duh. le $<*$ rej 'do’, Kht. $r \varepsilon^{\prime}$, Chi. 為 hjwe $<*_{G^{w}}(\mathrm{r})$ aj 'make, do, act as’ (§67a)

Duh. $a . l \varepsilon j<*$ a.rej 'brother-in-law’, Kht. $a . r \varepsilon^{?}(\S 67 \mathrm{a})$

\footnotetext{
${ }^{117}$ Note how Duhumbi has lost the adjective suffix, cf. Khispi u.lic.ta.

118 Palatalisation of the onset before rhymes $-\varepsilon k$ and $-\varepsilon \eta$ in Duhumbi is regular.
} 
$\S 59$. Duh. w-, Kht. w-. Duhumbi onset $w$ - regularly corresponds to Khoitam $w$-, but attestations are rare.

Duh. woj 'he / she' <*wuj ${ }^{119}$, Kht. wa: (§76)

Duh. woj ${ }^{120}$ 'plough' < *woj, Kht. wo: $(§ 75 a)$

$\S 60$. Duh.j-, Kht.j-. Duhumbi palatal onset $j$ - regularly corresponds to Khoitam onset $j$-.

Duh. jom $<*$ jum 'ripen’, Kht. juך (§47)

Duh. u.ja $<*$ a.ja 'wife', Kht. a.ju: (§24)

Duh. jet $<*$ jat 'flee', Kht. je', Chi. 逸 yit $<*[1] \mathrm{i}[\mathrm{t}]$ 'flee' $(\S 6)$

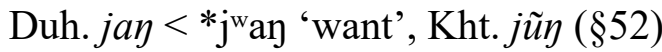

Duh. jot $<*$ jot 'be late', Kht. $j \varepsilon^{?}(\S 8)$



Duh. jow $<*$ jow 'wake up', Kht. jo? $(\S 69 b)$

$\S 60 \mathrm{a}$. There are two cognate sets where a Duh. palatal onset $j$-corresponds regularly to a palatal onset $j$ - in Khoitam and all other varieties. Nonetheless, a labialiased voiced uvular onset for these cognate sets has been reconstructed, because the root in both lexemes is ${ }^{{ }_{G}}{ }^{\mathrm{W}} \mathrm{a}$ 'steal' (cf. §65). In both sets, the irregular Duhumbi onset is conditioned by the prefix. A labialised onset is also warranted by the rhyme reflexes.

Duh. $d \varepsilon j . j u<*$ daj.G ${ }^{\mathrm{w} a}$ 'yesterday', Jer. dky.jo: $(\$ 30)$

Duh. bi.ju $<*$ bii.G ${ }^{\mathrm{w} a}$ 'thief', Kht. dky:.jo: (§30)

\subsection{VOICELESS ONSETS}

There are several distinct cognate sets where, based on the reflexes in one or more of the varieties, I propose voiceless approximant onsets.

$\S 61$. Duh. $l$-, Kht. $r$-. In a few cognate sets distinct from those in $\S 58$ (Duh. $l$-., Kht. $l$-) and $\S 64$ (Duh. l-, Kht. $r$-), Rahung and Khoitam have unexpected reflex $r$ - where all other varieties have $l$. Because the voiceless lateral onset *1- is already assigned to correspondence set $\S 42$, this is explained through positing a voiceless rhotic onset $*_{r}-$ with regular reflexes in all varieties. Nonetheless, the comparative evidence favours a lateral onset *1-.

Duh. luy <*ruy 'stone', Kht. ryy, Jer. lyy, Tsh. luy, PBG* ${ }^{*} \log ^{2}$, Chi. 淥 $l u w k<*[\mathrm{r}]^{\mathrm{c}} \mathrm{ok}$ 'precious stone' $(\$ 40)$

Duh. u.lap $<*$ a.rap 'leaf’, Kht. a.rap, Rup. a.lap, Chi. 葉; 枼 yep $<* \operatorname{lap}(\S 10)$

Duh. $l i<*$ rij 'bow', Kht. ri', Rup. li', OTib. gźi <*glyi (Hill 2019: 16), OBur. liy, Chi. 矢 syijX $X *$ lijp ‘arrow’ $(\$ 33)$

\footnotetext{
${ }^{119}$ Note how in many languages of the region, demonstratives are formed using a root cognate with Old Tibetan $h o \sim h u$ 'this', e.g. Tshangla $u . t^{h} u$ 'this here', o.th $a$ 'that there', Brokpa . $t^{h} i$ 'this here', Monpa $u . t s$ 'this here', $o . t^{h}$ 'that there'.

${ }^{120}$ The Duhumbi rhyme reflex, woj not 'waj wej is unexpected and may point to a complex onset, cf. also PBG *bwail 'plough v.t.', Chi. 禾 $h w a<*[\mathrm{G}]^{\text {'oj }}$ (19-07a) 'growing grain', Tib. gro 'wheat'.
} 
$\S 62$. Duh. j-, Kht. $h$-. A single cognate set where Duhumbi, Khispi and Khoina $j$ - corresponds to $h$ - in the other varieties may attest to a palatalised glottal fricative onset * $h^{\mathrm{j}-}$, in a pattern generally opposite from correspondences $\S 40, \S 41$ and $\S 42$.

Duh. jcj.ba $<*$ hoj.ba 'spicy, pungent', Kht. $h \jmath^{?} . b a(\S 67 b)$

§63. Duh. w-, Kht. h-, Khn. x-, She. h-. ${ }^{121}$ Duhumbi and Khispi are unique among the Western Kho-Bwa varieties in having a voiceless labial approximant $[M]$ or $[\mathrm{w}]^{122}$ in a limited number of lexemes, all preceding back vowel $a$. This unique correspondence justifies positing a voiceless labial approximant $*$ w.

Duh. way <*way 'thread', Kht. hay, Khn. xay, She. hay, Chi. 丸 hwan <*[G] ${ }^{\text {wSar }}$ 'pellet; ball' (§36)

Duh. wa $a^{\text {? }}<*_{\text {wa }}$ ? 'bird', Kht. $h u^{\text {? }}$, Khn. $f u^{\text {? }}$, She. $h u^{\text {? }}$, Miz. va, Mongsen Ao wà.zà? (Coupe 2007), Chi. 烏 ' $u<* q^{\text {`a } a ~ ' c r o w, ~ r a v e n ; ~ b l a c k ' ~(§ 25) ~}$

\subsection{MINOR CORRESPONDENCES}

$\S 64$. Duh. $r$-, Kht. $r$-. Unlike Khispi, which has no distinctive onset $r$-, Duhumbi has preserved onset $r$ - if it goes back to a labialised or palatalised onset $*^{\mathrm{r}^{\mathrm{w}}-}$ or ${ }^{*} \mathrm{r}_{\mathrm{j}}{ }_{-}$, reconstruction of which is based on the divergent rhyme reflexes.

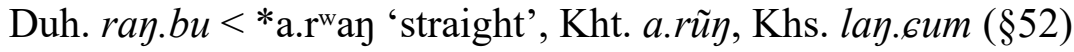

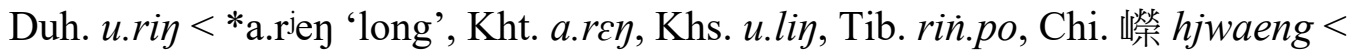

*[G] ${ }^{\mathrm{w}}$ rey 'high, distant' $(\S 48)$



$\S 65$. Duh. w-, Kht. j-. Another source of Duhumbi labial onset $w$-can be found in a few unique cognate sets where, unlike $\S 59$ (Duh. $w$-, Kht. $w$-) all other varieties have palatal onsets. I propose this set derives from a voiced uvular onset ${ }^{*} \mathrm{G}-$, with the need for a labialised variant based on divergent rhyme reflexes.

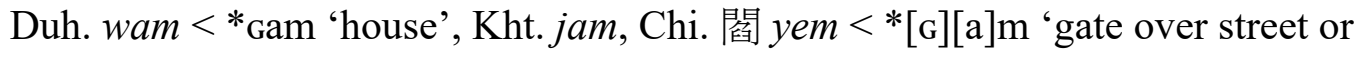
lane $^{123}(\S 45)$

Duh. wat $<*_{\text {Gat }}$ 'clothing', Kht. jo', Tib. gyon.pa $\sim$ gon.pa 'wear', Chi. 褐 hat $<$ $*[\mathrm{G}]^{\text {' }}$ at 'coarse cloth' $(\$ 19)$

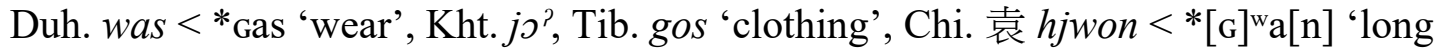
robe' $(\S 62)$

Duh. $w u^{124}<*_{\mathrm{G}^{\mathrm{w}} \mathrm{a}}$ 'steal', Kht. jo; , Chi. 捐 $y w e n *[\mathrm{G}]^{\mathrm{w}} \mathrm{en}$ 'abandon; remove' $(\S 30)$

\footnotetext{
${ }^{121}$ To this correspondence may also belong the following set, for which the distinctive Duhumbi and Khispi cognates are missing, with $*_{\mathrm{w}-}>*_{\mathrm{x}-}>*^{*} f$ - in Khoina because of the vocal prefix.

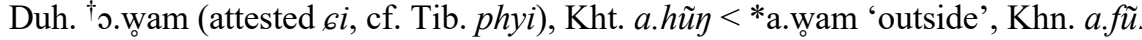

${ }^{122}$ In the Duhumbi phonology and orthography, this phoneme is represented by digraph /hw/.

${ }^{123}$ Here I propose a distinct etymology from the more established Chinese comparanda 窨 $i m H<* \mathrm{q}(\mathrm{r})[$ [ə]m-s 'subterranean room', to which forms such as Tibetan khyim and Burmese im may be related.

${ }^{124}$ Note how, in compound words, the reflex of this root in Duhumbi is $j$-, see examples 'thief' and 'morning' in $\S 60 \mathrm{a}$.
} 
$\S 65 a$. Duh. w-, Kht. $r$-. In a single cognate set that contrasts with both $\S 64$ (Duh. $w$-, Kht. $w$-) and $\S 65$ (Duh. $w$-, Kht. $j$-), Duhumbi and Khispi onset $w$ - corresponds to onset $r$ - in all other varieties. The uvular onset with rhotic medial results in a short rhyme reflex where otherwise Khoitam long reflex †ru: would be expected (cf. the Chinese comparanda and rhyme correspondence $\S 24$ (Duh. $-a$, Kht. $-u$ :)).


'go; at' (§28)

$\S 65 \mathrm{~b}$. Duh. w-, Kht. $h$-, She. vocal onset. In a single cognate set that is largely data deficient, Duhumbi $w$-corresponds to Khoitam $h$ - and a Shergaon vocal onset. I propose this set derives from onset cluster *wr-, which is confirmed by the regular rhyme reflexes.

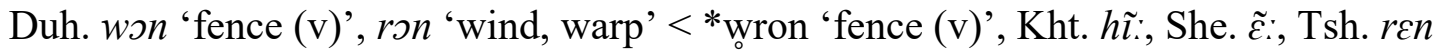
'wind, warp' (§43)

$\S 66$. Duh. j-, Kht. w-, Rup $w$-. In a single cognate set contrasting with correspondence $\S 60$ (Duh. $j$-, Kht. $j$-), Duhumbi onset $j$ - corresponds to Khoitam onset $w$ - and Rupa onset $w$-. I propose this derives from onset ${ }^{*} \mathrm{w}^{\mathrm{j}}$.

Duh. jen $<*{ }^{\text {jan }}$ 'be ashamed', Kht. wan, Rup. wan (§41)

$\S 66$ a. Duh. j-, Jer. j-, Rup. w-. In a single cognate set contrasting with set $\$ 60$ (Duh. $j$-, Kht. $j$ ), Duhumbi onset $j$ - corresponds to Khoitam onset $j$ - but Rupa has onset $w$-. The rhyme reflexes indicate this must derive from a labialised onset, which is proposed to be ${ }^{*}{ }^{w}{ }^{-}$.

Duh. jok $<*_{j}{ }^{w}$ ak 'dig', Jer. jok, Rup. wok $(\S 16)$

\section{SOUND CORRESPONDENCES IN LOANS}

Some interesting observations can be made concerning attested forms that are quite obviously similar in both meaning in form but show unexpected reflexes in one or more varieties. In several cases, the unexpected reflexes can be shown to be the result of borrowing from a contact language. The borrowed form may ultimately be etymologically related to the reconstructed root and the form that can be predicted on basis of the sound correspondences but is, nonetheless, not attested. Another reason may be contact language influence, as a result of which only the onset in one or more varieties does not show the expected reflex, but rather a reflex that is the same as that of the contact language. Some examples are presented in this section.

$\S 67$. Duh. gr-, Kht. dto-. The following irregular cognate set is the result of a later Bodish loan (through Brokpa) replacing the Duhumbi and Khispi reflex we would expect on basis of correspondence $\S 10$.


Tib. granis.ka 'counting' ( $\$ 2)$

$\S 68$. Duh. g- not dt-, Kht. dto-. Influence of the contact languages Tibetan, Brokpa and Tawang Monpa ${ }^{126}$ may be the reason for the simple onset $g$ - in Duhumbi and not the expected

\footnotetext{
125 This was earlier (Bodt 2019) reconstructed as *wra.

${ }^{126}$ Because the local trade and the administration in the region, including the taxation system, was largely conducted by speakers of Tibetan, Brokpa and Monpa, we can discern a certain influence of these languages on the numerals. This also includes the replacement of traditional vigesimal numerals such as Duhumbi
} 
affricate onset $d t$ - in the following set, as would be expected on basis of cognate sets where Duhumbi affricates correspond with Khoitam affricates but palatal stops in elderly Rupa speakers $(\S 51)$.

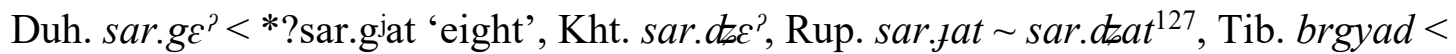
*bryat, Mon. get, OBur. *rhyat (cf. Nishi 1999: 47), Chi. 八 peat $<{ }^{*} p^{\uparrow}$ ret (§6)

$\S 69$. Unlike correspondence $\S 11$, where Duh. onset $k^{h}$ - corresponds to Khoitam onset $t 6^{h}$, proposed to derive from reconstructed onset ${ }^{*} \mathrm{k}^{\mathrm{h}} \mathrm{r}$-, there are several cognate sets where one or more varieties attest an onset cluster $k^{h} r$.

In a single cognate set, Duhumbi rhotic onset cluster $k^{h} r$ - corresponds to onset cluster $k^{h} r$ - in all varieties except Khispi which has typically elided the rhotic medial. Perhaps this lexeme has preserved this onset because it is a relatively recent loan related to the tax collection in the area by the Tibetan administration.

Duh. $k^{h} r o p<*$ ? $\mathrm{k}^{\mathrm{h}}$ rop 'gather, collect (harvest, people, cattle)', Kht. $k^{h} r o p$, Khn. $k^{h} r \varnothing^{\text {' }}$, Rah. $k^{h} r ø p$, Rup. $k^{h} r \supset p$, Khs. $k^{h} \supset p$, Tsh. $k^{h} r \supset p$ 'gather, collect', Tib. sgrug.pa 'collect, gather, pluck, pick' (§77)

$\S 69 \mathrm{a}$. In this respect, also observe how in another lexeme Duhumbi onset $k^{h} r$-corresponds to Sartang and Sherdukpen onset $k^{h}$, again probably because a later loan replaced the inherited lexeme in Duhumbi.

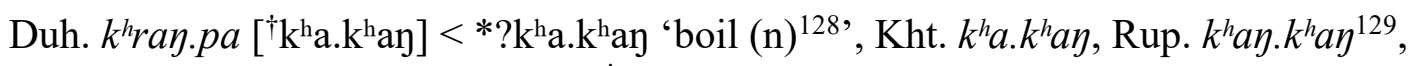
Khn. gə. $k^{h} a \eta$, Khs. $k^{h} a \eta . p a\left[{ }^{\dagger} \mathrm{k}^{\mathrm{h}} \mathrm{a} \cdot \mathrm{k}^{\mathrm{h}} \mathrm{a \eta}\right]$, Tsh.D. $k^{h} r a \eta . p a(\S 36)$

$\S 69 \mathrm{~b}$. In another lexeme, Duhumbi onset $k^{h} r$ - corresponds to Sartang and Rupa onset $t$-, with only Sherdukpen preserving onset $k^{h} r$-. Coupled with the mixed bag of rhyme reflexes, evidencing reflexes of rhyme $*_{-o j}(\S 67 \mathrm{~b}),{ }^{*}$-os $(\S 64)$ and $*_{\text {-op }}$ and $*_{\text {-up }}(\S 22, \S 23)$, this leads to the presumption this lexeme, too, is a later loan, at least in some varieties.

Duh. $k^{h} r j j * * \mathrm{k}^{\mathrm{h}}$ ros 'shell (maize)', Kht. tsp, Rah. $t \varnothing^{\text {? }}$, Khn. $t \varnothing^{\text {? }}$, Rup. təp, She. $k^{h} r e$, Khs. $k^{h} j$, Tib. bgrud.pa 'husk, shell, peel’ (\$37)

The velar plus rhotic onset clusters appear to evidence various layers of inherited lexemes and later Bodish and Tshangla loans, especially related to agricultural practices.

$\S 70$. Duh. $k$-, Kht. $k$-. In a single cognate set, Duhumbi onset $k$ - corresponds to Khoitam onset $k$-, but Khoina onset $k^{h}$ - and Rahung and Shergaon onset $g$-. The voicing and aspiration differences in the onset (see $\S 7$ for regular reflexes of onset $* k-$ ) are indicative that this lexeme is a later Bodish loan.

Duh. kak<*?kak 'halt, stop', Kht. kak, Khn. $k^{h} a k$, Rah. gak, She. gak, Tib. bkag.pa< hgog.pa 'prevent, restrain, stop', Tsh. kak 'halt, stop, prevent from happening or doing' $(\S 1)$

$\S 71 . K h s .6-, K h t . s-$. In the following cognate set, we would expect the Duhumbi and Khispi reflex ${ }^{\dagger}$ sat on basis of correspondence $\S 34$ (Duh. $s$-, Kht. $s$-). Whereas Duhumbi has a distinct

$k^{h}$ cj.nis.day.san (two score and ten) by yap.tcu.t $t^{h} a m . b a$ (Tibetan lina.bcu.thams.pa) 'fifty' and $k^{h} c j . \eta a$ (five score) by dta.hin (Tibetan brgya) 'hundred'.

${ }^{127}$ The rhyme reflex in all varieties suggests that the coda $-r$ was a part of the root, not of the prefix, i.e.

*sa.rgiat.

${ }^{128}$ Referring to a large boil that emits pus.

${ }^{129}$ The velar coda of the prefix is epenthetic, expected would be ${ }^{\dagger} k^{\text {ha }} \cdot k^{\text {han }}$. 
lexeme haw 'to tell', the Khispi form, though apparently cognate, is most likely a loan from Tawang Monpa. A reconstructed form *sjat, which would match with the Khispi onset, would result in divergent rhyme reflexes according to rhyme correspondence $\S 6$ (Duh. $-\varepsilon t$, Kht. $-\varepsilon^{2}$, Rup. -at), cf. example *sjat 'exit'.

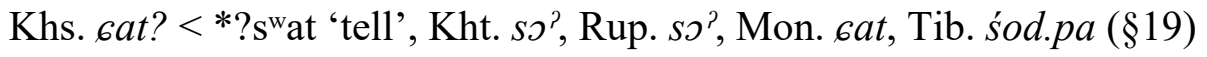

$\S 72$. In the following cognate set, both the variation in the onset (as compared to correspondence \$45) and the variation in rhymes indicates that this lexeme is most likely a loan, even though superficially the forms appear cognate. Whereas Duhumbi and Khispi probably borrowed the term from Tawang Monpa, the likely origin for the Sartang and Sherdukpen varieties is Tibetan or Brokpa.

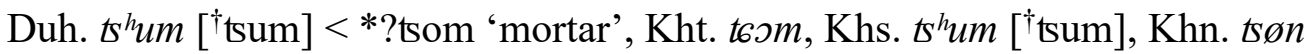
['tsom], Rah. t6øm ['t6om], Jer. t6øn ['t6om], Rup. tsom, Tib. tshon.kho, Mon. $t^{h} u m . k u(\S 47 ?)$

§73. Duh. t6-, Kht. t6-. There are two cognate sets that may in which Duhumbi t6-corresponds to onset t6-in Khoitam and all other varieties. However, the irregular rhyme correspondences and the good Bodish cognates may indicate that these lexemes are loans in all varieties, rather than inherited lexemes.

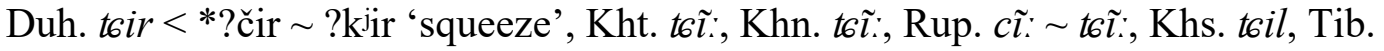
gcir.ba $(\S 80)$

Duh. t6ur $<*$ ?čur 'surround, confine' ${ }^{130}$, Kht. t6or, Rah. t6y:, Rup. t6ur' ${ }^{131}$, Khs. t6ul, Tib. gcur.ba 'pressed into' (§78)

\section{SYNPOSIS}

This paper presents the main onset correspondences between the Western Kho-Bwa varieties Duhumbi and Khoitam, providing reconstructions of the proto-forms based on the current state of knowledge. The paper also provides comparative evidence from the other Western Kho-Bwa varieties and other languages and reconstructed proto-languages where deemed illustrative. The sound correspondences that have been established, the reconstructed protoforms that are based on it, and the comparative evidence from other Tibeto-Burman languages confirm earlier conclusions made for Puroik (Lieberherr 2015) and the Kho-Bwa languages in general (Lieberherr \& Bodt 2017) that the Kho-Bwa languages do indeed form part of the Tibeto-Burman language family, disfavouring earlier hypothesis that these languages, or some of them at least, may represent language isolates (e.g. Blench \& Post 2014).

The following consonants occur as onsets in reconstructed Proto-Western Kho-Bwa: velar plosives $\mathrm{k}, \mathrm{k}^{\mathrm{h}}$, g; uvular plosives $\mathrm{q}, \mathrm{q}^{\mathrm{h}}, \mathrm{G}$; dental plosives $\mathrm{t}, \mathrm{t}^{\mathrm{h}}, \mathrm{d}$; bilabial plosives $\mathrm{p}, \mathrm{p}^{\mathrm{h}}, \mathrm{b}$; nasals $\mathrm{y}, \mathrm{n}, \mathrm{n}, \mathrm{m}, \mathrm{m}$; fricatives s, z, h; alveolar affricates ts, ts ${ }^{\mathrm{h}}, \mathrm{dz}$; palatal affricates $\mathrm{c}^{\mathrm{h}}$, j; and approximants 1, 1, r, r, w, w, j. Furthermore, reconstructed Proto-Western Kho-Bwa has rhotic onset clusters kr, k $\mathrm{k}^{\mathrm{h}}$, gr; qr, q $\mathrm{q}^{\mathrm{h}}$, $\mathrm{Gr}$; pr, $\mathrm{p}^{\mathrm{h}} \mathrm{r}$, br; mr; dzr; zr, hr; nor; wr; onset cluster ps; palatalised onsets k ${ }^{\mathrm{hj}}, \mathrm{g}^{\mathrm{j}} ; \mathrm{kr}^{\mathrm{j}}, \mathrm{k}^{\mathrm{h}} \mathrm{r}^{\mathrm{j}}, \mathrm{gr}^{\mathrm{j}} ; \mathrm{q}^{\mathrm{hj}}, \mathrm{G}^{\mathrm{j}} ; \mathrm{t}^{\mathrm{hj}} ; \mathrm{p}^{\mathrm{j}}, \mathrm{b}^{\mathrm{j}} ; \mathrm{pr}^{\mathrm{j}} ; \mathrm{m}^{\mathrm{j}}, \mathrm{n}^{\mathrm{j}}, \mathrm{n}^{\mathrm{j}} ; \mathrm{s}^{\mathrm{j}}, \mathrm{z}^{\mathrm{j}}, \mathrm{h}^{\mathrm{j}} ; \mathrm{ts}^{\mathrm{hj}}, \mathrm{dz}^{\mathrm{j}} ; \mathrm{r}^{\mathrm{j}}$ and $\mathrm{w}^{\mathrm{j}}$; and labialised onsets k $\mathrm{k}^{\mathrm{w}}, \mathrm{k}^{\mathrm{hw}} ; \mathrm{q}^{\mathrm{w}}, \mathrm{q}^{\mathrm{hw}}, \mathrm{G}^{\mathrm{w}} ; \mathrm{q}^{\mathrm{h}} \mathrm{r}^{\mathrm{w}} ; \mathrm{p}^{\mathrm{hw}}, \mathrm{b}^{\mathrm{w}} ; \mathrm{d}^{\mathrm{w}} ; \mathrm{m}^{\mathrm{w}}, \mathrm{m}^{\mathrm{w}} ; \mathrm{s}^{\mathrm{w}}, \mathrm{z}^{\mathrm{w}}, \mathrm{h}^{\mathrm{w}} ; \mathrm{t}^{\mathrm{w}}, \mathrm{t}^{\mathrm{hw}}, \mathrm{dz}^{\mathrm{w}} ; \mathrm{c}^{\mathrm{hw}}$, $\breve{\mathrm{j}}^{\mathrm{w}} ; \mathrm{r}^{\mathrm{w}}, \mathrm{l}^{\mathrm{w}}$ and $\mathrm{j}^{\mathrm{w}}$. Vocal onsets, alternatively analysable as glottal onsets, include a (Pa), e (?e), i

${ }^{130}$ Esp. said of calves in a fenced surrounding or chickens in a coop.
${ }^{131}$ Expected Sartang and Sherdukpen reflexes would be ttcin. 
( $\mathrm{Pi}), \mathrm{o}(\mathrm{Po})$ and $\mathrm{u}(\mathrm{Pu})$. This reconstructed phonological inventory has some marked 'gaps', where expected onsets have not been reconstructed yet, which could be filled based on the future availability of new cognate sets and the future discovery of new correspondences.

Noted is the fact that whereas onset clusters of a velar plosive and rhotic medial $\left({ }^{*} \mathrm{kr}-,{ }^{*} \mathrm{k}^{\mathrm{h}} \mathrm{r}-\right.$, * gr-) and a bilabial plosive and a rhotic medial (*pr-, ${ }^{*} \mathrm{p}^{\mathrm{h}} \mathrm{r}-,{ }^{*}$ br-) have been reconstructed, there are no correspondence sets that would warrant the reconstruction of dental plosive and rhotic medial onset cluster ${ }^{\dagger *} \operatorname{tr}-,{ }^{\dagger *} \mathrm{t}^{\mathrm{h}} \mathrm{r}$ - and ${ }^{\dagger *} \mathrm{dr}$-. In fact, there are no attestation of these clusters in Khispi and Duhumbi, and only very few attestations of these clusters in the contemporary Sartang and Sherdukpen varieties. Examples include the probably onomatopoetic Jerigaon nə.my: troy 'thunder', Rahung nə.my: dray.druy and Shergaon ni.mi: druy.druy forms for 'thunder', Jerigaon na.trøy.zay and Shergaon tre:.sum 'spider', Rahung tre ' 'big, wide', Khoina, Rupa and Shergaon $t^{h}$ riy 'bracelet' (probably a contraction, cf.


to.rom), Khoina ja.droy 'shoe, footwear' and Khoina dro?.ro: and Rahung dro: (again likely contractions of prefix and root, cf. Duhumbi $d u . l u$ ?, Rupa $d$ o.raw). Note, that none of the Western Kho-Bwa varieties has retroflex dental consonants $/ \mathrm{t}, \mathrm{t}^{\mathrm{h}}, \mathrm{d} /$ in native lexemes.

Of the reconstructed onsets and onsets clusters I postulate for Proto-Western Kho-Bwa in this paper, the more remarkable are the uvular plosives and the voiceless nasals and approximants. I propose an unvoiced uvular plosive $*_{\mathrm{q}}(\S 43 \mathrm{a})$ and voiced uvular plosive $*_{\mathrm{G}}-$ (§65). The uvular plosive has an aspirated ${ }^{*} q^{\mathrm{h}}-(\S 20 \mathrm{a})$, labialised ${ }^{*} \mathrm{q}^{\mathrm{w}}-(\S 43 \mathrm{~b})$, palatalised aspirated $* q^{\text {hj }}$ ( $(\$ 57 a)$ and labialised aspirated $* q^{\text {hw }}$ - $(\S 20)$ counterpart, and also occurs with a rhotic medial $*$ qr- $(\$ 22)$, aspirated with a rhotic medial ${ }^{*} \mathrm{q}^{\mathrm{h}} \mathrm{r}-(\$ 22 \mathrm{a})$ and labialised aspirated with a rhotic medial ${ }^{*} \mathrm{q}^{\mathrm{h}} \mathrm{r}^{\mathrm{w}}-(\S 56)$. The voiced uvular plosive also has a labialised ${ }^{*} \mathrm{G}^{\mathrm{w}}-(\S 60 \mathrm{a}$, $\S 65)$ and a palatalised ${ }^{*}{ }_{\mathrm{G}}^{\mathrm{j}}-(\S 43 \mathrm{c})$ counterpart and occurs with a rhotic medial $*_{\mathrm{Gr}}-(\S 65 \mathrm{a})$. In addition, I reconstruct voiceless nasals $/ \mathrm{m} /(\S 32 \mathrm{~b}, \S 41)$ and $/ \mathrm{n} /(\S 24, \S 40)$ and voiceless approximants $/ \mathrm{r} /(\S 61), / 1 /(\S 42)$ and $/ \mathrm{w} /(\S 26, \S 63, \S 65 \mathrm{~b})$ in addition to their voiced counterparts.

\subsection{NOTABLE SOUND CORRESPONDENCES BETWEEN THE VARIETIES}

There are some notable sound correspondences between the Western Kho-Bwa varieties. These are primarily related to phonological processes involving palatalised onsets, particularly those preceding a high vowel /i/ and high vowel rhymes /ij/ and /əj/, and onset clusters of a velar onset and rhotic medial.

Palatalised velar onsets ${ }^{*} \mathrm{k}^{\mathrm{hj}}$ - and ${ }^{\mathrm{g}} \mathrm{g}$ - resulted in affricate onsets in all varieties except Rupa, where older speakers realise distinctive palatal stops $c^{h}$ and $f^{-}$.

PWKB *k $\mathrm{kj}_{-}>$Duh. $t 6^{h_{-}}$, Khs. $t 6^{h_{-}}$, Khn. $t 6^{h_{-}}$, Jer. $t 6^{h_{-}}$, Kht. $t 6^{h_{-}}$, Rah. $t 6^{h_{-}}$, Rup. $c^{h_{-}} \sim t 6^{h_{-}}$ , She. $16^{h_{-}}(\S 50)$


She. $d t-(\S 51)$

The palatalised bilabial onset ${ }^{*} \mathrm{~b}^{\mathrm{j}}$ - results in a very distinctive set of cognate forms. Whereas Khispi and Duhumbi follow a pattern $* \mathrm{~b}^{\mathrm{j}-}>_{6-\boldsymbol{6}^{-}} \sim$ - also seen in, for example, Tawang Monpa (e.g. Tawang Monpa $z a$, Tibetan bya 'bird'), the Sartang and Sherdukpen varieties all have an aspirated palatal affricate.

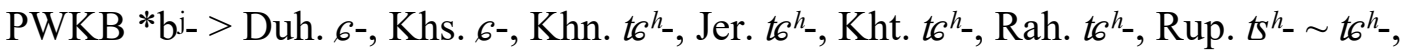
She. $t 6^{h}-(\S 38 a)$ 
Following the lack of aspiration of the reconstructed onset, the Sartang and Sherdukpen reflexes are also unaspirated and unvoiced in the following correspondence.

PWKB *p'- > Duh. 6-, Khs. 6-, Khn. t5-, Jer. t6-, Kht. t6-, Rah. t6-, Rup. t5- $\sim$ t6-, She. t6- $(\S 38 b)$

The main exception to this general correspondence is the homophonous cognate set resulting from palatalised bilabial onsets preceding high vowel /i/, with simplified onsets in Khispi and Duhumbi and palatal affricates in all other varieties except Rupa which shows alternation between a palatal stop and a palatal affricate. ${ }^{132}$

PWKB *b $\mathrm{b}_{-}>$Duh. $b$-, Khs. $b-$, Khn. dt-, Jer. dt-, Kht. $d t_{-}$, Rah. dt-, Rup. dt-, She. $d t_{-}$ $(\S 17 \mathrm{a})$

Closely related is also the following correspondence set, also occurring before high vowel /i/.

PWKB *mj- > Duh. m-, Khs. m-, Khn. dt-, Jer. dt-, Kht. dt-, Rah. dt-, Rup. dt-, She. dte- $(\S 32 \mathrm{c})$

Distinct reflexes can also be found in the few cognate sets deriving from onset clusters of a bilabial plosive and a rhotic medial when preceding high vowel /i/.


$p^{h-}(\S 19 \mathrm{a})$

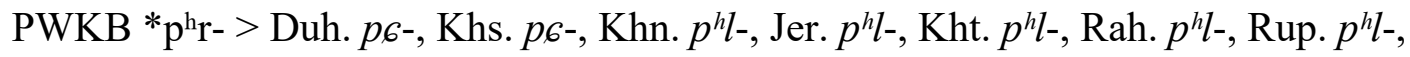
She. $p^{h l}-(\S 19)$

PWKB *prj-> Duh. $p 6^{-}$, Khs. $p 6^{-}$, Khn. $p s^{-}$, Jer. $p s^{-}$, Kht. $p s^{-}$, Rah. $p s^{-}$, Rup. $b s^{-}$, She. $p s-(\S 19 \mathrm{~b})$

Distinct Sartang and Sherdukpen reflexes can be found in a single cognate set.

PWKB *ps- $>$ Khs. $p 6_{-}^{-}$, Khn. $t^{h_{-}}$, Jer. $t 6^{h_{-}}$, Kht. $t 6^{h_{-}}$, Rah. $t 6^{h_{-}}$, Rup. $t^{h_{-}}$, She. $t 6^{h_{-}}$ $(\S 19 \mathrm{c})$

Note, how reflexes of onset clusters of a bilabial plosive and rhotic medial are distinct when the following vowel is not a high vowel $(\S 14, \S 14 \mathrm{a}, \S 15$ and $\S 16)$ and how onset clusters of a nasal $(\S 24, \S 32 \mathrm{a})$ or fricative $(\S 13, \S 57)$ onset and rhotic medial are also different.

Palatalised Proto-Western Kho-Bwa nasal onset * $\mathrm{n}^{\mathrm{j}-}$ has distinct outcomes in Duhumbi, Khispi and the Sherdukpen varieties versus the Sartang varieties. Whereas the latter varieties again lost the palatalisation, they resulted in distinct palatal phonemes in the former varieties.

PWKB *nj- $>$ Duh. $n$-, Khs. $n$-, Khn. $n$-, Jer. $n$-, Kht. $n$-, Rah. $n$-, Rup. $n$-, She. $n$ $(\S 31)$

Palatalised Proto-Western Kho-Bwa fricative onsets $*^{\mathrm{j}} \mathrm{s}^{\mathrm{j}}$ and ${ }^{*} \mathrm{Z}^{\mathrm{j}}$ - have distinct outcomes in Duhumbi, Khispi and Khoina versus the other Sartang varieties and the Sherdukpen varieties. The palatalisation is lost in the latter varieties, whereas they result in distinct palatal phonemes in Duhumbi and Khispi and retroflex phonemes in Khoina.



\footnotetext{
${ }^{132}$ For a related phonological change, cf. Sun's (1993: 93) remark that Proto-Tani *b- became $\check{y}$ - in Western Tani before $* \mathrm{i}$.
} 


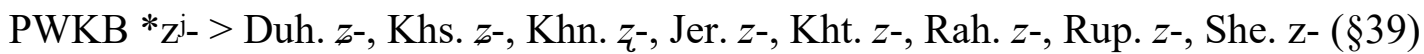

Palatalised affricate onsets also have reflexes slightly different from non-palatalised affricate onsets.

PWKB *dzi- > Duh. z-, Khs. z-, Khn. $z$-, Jer. $z$-, Kht. $z$-, Rah. $z$-, Rup. $z$-, She. $z$ $(\S 39 \mathrm{a})$

PWKB *ts ${ }^{\text {hj- }}{ }_{-}>$Duh. $t 6^{h_{-}}$, Khs. $t 6^{h_{-}}$, Khn. $t s^{h_{-}}$, Jer. $t 6^{h_{-}}$, Kht. $t 6^{h_{-}}$, Rah. $t 6^{h_{-}}$, Rup. $t s^{h_{-}} \sim t 6^{h}$, She. $t 6^{h}-(\S 50 \mathrm{~b})$

Proto-Western Kho-Bwa onset clusters of a velar onset and rhotic medial are regularly simplified in Khispi and Duhumbi and Sherdukpen but become palatal affricates in the Sartang varieties, except Khoina which has distinctive retroflex affricates.

PWKB * $k^{h}{ }_{-}>$Duh. $k^{h_{-}}$, Khs. $k^{h_{-}}$, Khn. $t s^{h_{-}}$, Jer. $t 6^{h_{-}}$, Kht. $t 6^{h_{-}}$, Rah. $t 6^{h_{-}}$, Rup. $k^{h_{-}}$, She. $k^{h}-(\S 11)$

PWKB *gr- > Duh. g-, Khs. g-, Khn. $d z_{-}^{-}$, Jer. dt-, Kht. $d t_{-}$, Rah. dt-, Rup. g-, She. g$(\S 10)$

The only exception is the onset cluster of a voiceless velar onset and rhotic medial, which has simple onsets in all varieties except Khoina.

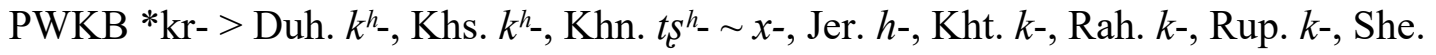
$k-(\S 11 \mathrm{a}, \S 11 \mathrm{~b})$

As with the palatalised versions of the bilabial plosive and rhotic medial clusters, the palatalised versions of the velar plosive and rhotic medials have slightly divergent reflexes, again with characteristic retroflex affricates in Khoina.

PWKB *krj- > Duh. $k$-, Khs. $k$-, Khn. $t^{-}-$Jer. t6-, Kht. t6-, Rah. t6-, Rup. $k$-, She. $k$ $(\S 12)$

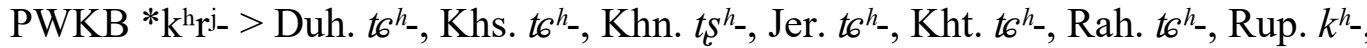
She. $t 6^{h}-(\S 50 a)$

PWKB *grj- > Duh. dt-, Khs. dt-, Khn. $d z_{-}^{-}$, Jer. g-, Kht. g-, Rah. g-, Rup. g-, She. g$(\S 51 \mathrm{a})$

\subsection{NOTABLE SOUND CORRESPONDENCES WITH OTHER TIBETO-BURMAN LANGUAGES}

There are two main sound correspondences that may be characteristic for the Western KhoBwa varieties within the wider perspective of the Tibeto-Burman language family. These were earlier identified as ${ }^{*} \mathrm{~s}->* \emptyset-(\S 25)$ and $* \mathrm{~m}->* b-(\S 3)$.

Regarding the change *s- $>* \varnothing$-, Matisoff (2009: 309) listed Puroik ('Sulong') $j i{ }^{55}$ 'die' as cognate with his reconstructed Tibeto-Burman root*səy. This was observed by Lieberherr (2015: 26-27), who mentioned the apparent regularity of this correspondence and provides additional examples of how Proto-Kuki-Chin *th- corresponds to Puroik vocal onsets. In Bodt \& Lieberherr (2015: 81, 101), we describe how reconstructed Proto-Tibeto-Burman onset *s- has been regularly fortified to onset $t$ - with secondary developments to $t^{h}, t$ - and $d z$ in the Hrusish languages Bangru, Miji and Hruso. This particular correspondence was first described by Shafer (1947: 185) and is one of the defining phonological innovations that Bangru, Miji and Hruso share with the 'Kamarupan' languages (Matisoff 2003: 31-32), including the Kuki-Chin languages (VanBik 2009: 16), the Central Naga languages, the 
Bodo-Garo languages, Karbi and Tangkhulic. In Lieberherr \& Bodt (2017: 40) we provide additional evidence for a regular correspondence between onset $s$ - in several contemporary Tibeto-Burman languages, reconstructed onset $* \mathrm{t}^{\mathrm{h}}$ - in the 'Kamarupan' languages, and the vocal onsets in the Western Kho-Bwa languages.

One of the outstanding questions is why there are also distinct correspondence sets, where onset *s- in other Tibeto-Burman languages corresponds to Western Kho-Bwa onset $s-(\S 34)$ and $h$ - (§36). It is not yet clear which phonotactic conditions resulted in an onset *s- to be retained as $s$-, which phonotactic conditions resulted in further debuccalisation from *s- to $h$-, and why in some cases the onset $* h$ - further debuccalised, resulting in a zero, i.e. glottal or vocal onset.

Like all the Kho-Bwa languages (Lieberherr \& Bodt 2017: 38-39), the Western Kho-Bwa languages show evidence for syllable initial denasalisation. Whereas this is relatively well attested for the bilabial place of articulation (e.g. in $\S 3, \S 6, \S 32$ ), there is also evidence from the velar place of articulation (e.g. in $\S 1, \S 4, \S 7$ ). There is a single candidate for the dental place of articulation, but that only for Khispi and Duhumbi (namely 'comb' in §24).

Denasalisation of initials is a non-trivial change and almost unique in Tibeto-Burman. ${ }^{133}$ The Proto-Western Kho-Bwa plosive onsets where other Tibeto-Burman languages have nasal onsets may be related to Old Chinese Type A syllable initials.

Proto-Western Kho-Bwa nasal onsets, Old Chinese nasal onsets (Type B):

Duh. ya<*ya? 'fish’, Kht. nuy, Chi.魚 ngjo <*ya (§25)

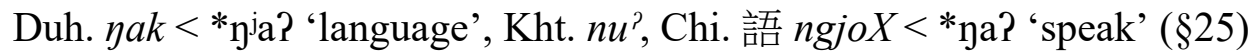

Duh. nay < *nay 'thou (2SG)', Kht. nay, Chi. 若 nyak <*nak (§36)

Duh. ‘yin <* *yin 'silver’, Kht. niy, Chi. 銀 ngin <*yrə[n] (§42)

Duh. nis 'two' <*nis 'two', Kht. nik, Chi. 二 nyijH <*ni[j]-s (§63)

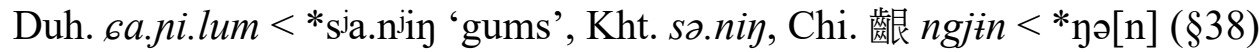

Proto-Western Kho-Bwa stop onsets, Old Chinese nasal onsets (Type A):

Duh. $g a<*$ ga 'I', Kht. gu;, Chi. 吾 $n g u<* \eta^{\mathrm{\Upsilon}} \mathrm{a}^{134}(\S 24)$

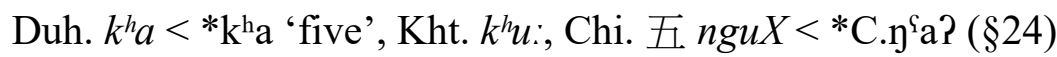

Duh. $k^{h} a m<* k^{\text {hwam }}$ 'be hungry’, Kht. $k^{h} \tilde{u} \eta$, Chi. 餓 $n g a H<* \eta^{\Upsilon} a j-s(\S 54)$

Duh. $p^{h} a m<* \mathrm{p}^{\mathrm{hw}}$ am 'lose, be defeated', Kht. $p^{h} \tilde{u} \eta$, Chi. 茂 $s a n g H<*^{*} \mathrm{~s}-\mathrm{m}^{\mathrm{c}}$ ay-s 'lose; destroy’ $(§ 54)$

\footnotetext{
${ }^{133}$ But see fn. 67 for evidence from Chinese. As one of the reviewers of this paper rightly pointed out, historically we can also observe denasalisation in the development from Old Chinese to Proto-Min and in Sinitic loans in Japanese, for example, from Chi. 五 $n g u X<{ }^{*} \mathrm{C} . \eta^{\varsigma} \mathrm{a}$ ? 'five' to Japanese $g o$ 'five' and colloquial Southern Min [go] 'five' and from Chi. 武 $m j u X<*$ ma? 'military' to Japanese 武道 budō'martial arts' and colloquial Southern Mĩn [bú] 'military'.

${ }^{134}$ As was remarked by one of the reviewers of this paper, there have been several surmises on the relation between a velar nasal and a velar plosive onset for the first person singular pronoun in Tibeto-Burman. See, for example, Benedict (1998) and Jacques (2007). Despite this, I remain of the opinion that both *ka and *ya are ultimately etymologically related, perhaps one having functioned as an independent pronoun, and the other as a dependant morpheme, for example, a lexical prefix or a pronominal marker on pronouns.
} 


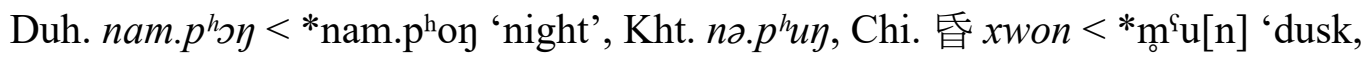
dark' $(\S 39)$

There is, however, also counter-evidence:

Proto-Western Kho-Bwa nasal onsets, Old Chinese nasal onsets (Type A):

Duh. 6 a.nu 'paneer' <*(s ja./a.) n'u 'brain', Kht. a.ny:, Khs. 6 .nu, Chi. 腦 $n a w X<$ ${ }^{*} n^{\varsigma} u ?(\S 27)$

Duh. $\min <*$ min 'sleep', Kht. dtain, Tib. rmi.lam 'dream', Chi. 眠 $m e n<* \mathrm{~m}^{\mathrm{s}} \mathrm{i}[\mathrm{n}]$ 'shut the eyes; sleep' $(\$ 42)$

Proto-Western Kho-Bwa stop onsets, Old Chinese nasal onsets (Type B):

Duh. biy <*a.bjey 'name', Kht. a.dten, Chi. 名 mjieng $<*$ C.men $(\S 48)$

Duh. $b \varepsilon j<*$ baj 'fire’, Kht. $b \varepsilon$;, Chi. 㷐 $x j w e X<*$ maj? 'fire’ $(\S 67)$

Cognates of Tibeto-Burman roots with bilabial nasal onset $* m$ - with bilabial plosive $b$ - are not exclusive to the Kho-Bwa languages. For the Bisoid languages, the correspondence of Bisu stop $b$ - with other Loloish languages $m$ - was reported by Nishida (1966a, 1966b), later mentioned in Matisoff (1972) and Bradley (1977, 1979 and 1985) and also described in Xu (2001: 195). Bradley (1985) described this as an example of consonant denasalistion (Haudricourt 1970) and analysed these examples as reflexes of Proto-Loloish onsets. Compare the following attestions for the root 'name' in several Nungic and Bisoid languages and compare these with the reflexes for the root 'dream' in these languages. ${ }^{135}$ The correspondences of these two roots are seemingly random except for consistent onset *b- in Proto-Western Kho-Bwa: where Trung and related languages have $m$ - onsets, Bisu has $b$ onsets and where Bisu has $m$ - onsets, Trung and related languages have $b$ - onsets.

$$
\begin{aligned}
& \text { PWKB *a.bien 'name', Rawang } b u \eta^{31} \text {, Anong } b u \eta^{31} \text {, Nung } b u \eta^{31} \text {, Trung } \\
& a \eta^{31} \cdot b r u \eta^{53} \text {, Sanglong Bisu } a \eta^{33} \cdot \mathrm{mi \eta}^{55} \text {, Huaipa Bisu } a \eta^{33} \cdot h m e \eta^{55} \\
& \text { PWKB *ban 'dream', Rawang (jup.) } n a \eta^{53} \text {, Anong (ip.) } m a \eta^{55} \text {, Nung } m a \eta^{55} \text {, Trung }
\end{aligned}
$$

For Proto-Hmong-Mien, Ratliff (2010: 38) reconstructs pre-nasalised onsets *mp-, *mp ${ }^{\mathrm{h}}$, *mb- to explain otherwise seemingly random variation between bilabial nasal and bilabial stop onsets in the descendant languages. Hence, Proto-Hmong-Mien 'dream' is *mpeiH and 'name' is *mpouH. Compare this also to Proto-Mon-Khmer *mp[o]? 'dream' (Shorto 2006). In the case of the Bisoid and Nungic languages, this may be an indication of early linguistic contact between Tibeto-Burman, Hmong-Mien and Mon-Khmer speakers. However, the geographic distance with the area where the Kho-Bwa languages are presently spoken make a similar contact language situation less likely, and this perhaps validates the reconstruction of Proto-Tibeto-Burman prenasalised onsets much like they have been reconstructed for other proto-languages in Southeast Asia.

Despite this wider perspective, as we showed (Lieberherr \& Bodt 2017: 39), cognates in all surrounding languages have a nasal continuant onset, and, like the change $*_{s-}>* \varnothing$-, the shared phonological innovation $*_{\mathrm{m}}->*^{*} \mathrm{~b}$-, and perhaps also $*_{\mathrm{y}-}>*^{*} \mathrm{~K}$-, is a strong argument

${ }^{135}$ Forms from Sūn (1991) and Xu (2001). 
for the coherence of the Western Kho-Bwa languages, and indeed the Kho-Bwa languages in general.

\section{ACKNOWLEDGEMENTS}

The research on which this paper is based was funded by the Swiss National Science Foundation Postdoc Mobility grant number P2BEP1_181779. This paper has greatly benefited from the input by Dr. Nathan W. Hill, Yeshy T. Sotrug, Johann-Mattis List and the valuable comments and suggestions by two anonymous referees and the journal editor. The paper has also been updated to include the feedback from three anonymous referees of the corresponding rhymes paper (Bodt 2019). All errors and omissions in this paper are my own.

This research would not have been possible without the patient cooperation of the main language consultants in Arunachal Pradesh: Dorji Choijom, Rincin Buti, Phuntso Tsering and Palden Norbu (Chug); Norbu Dema, Dawa Lhamu, Nima Tsering and Rincin Dema (Lish); Tshering Dolma Nethungji, Geshi Tamu Yamchodu and Phinje Nasidu (Khoina); Sena Phinju Nathongji, Veena Rockpudu and Pema Choijom Yamnojee (Jerigaon); Nima Lhamu Chanadok and Kezang Rokpu (Khoitam); Karma Tsering Ngoimu, Dolma Sarmu and Chomu Sarmu (Rahung); late Dorji Dema Thungdok, Rincin Khandru Karma, Pema Sinchaji and Tashi Sinchaji (Rupa); Prem Khandu Thungon and Dombu Tsering Thongon Lama (Shergaon).

\section{REFERENCES}

Abraham, Binny, Kara Sako, Elina Kinny \& Isapdaile Zeliang. 2018 [2005]. A sociolinguistic research among selected groups in Western Arunachal Pradesh highlighting Monpa. SIL Electronic Survey Reports. https://www.sil.org/resources/publications/entry/75982.

Baxter, William H. \& Laurent Sagart. 2014. Old Chinese: a new reconstruction. New York: Oxford University Press.

Benedict, Paul K. 1998. The first person pronoun in archaic Chinese, with a note on duplex characters. Linguistics of the Tibeto-Burman Area 21:2.1-2.

Blench, Roger \& Mark W. Post. 2014. Rethinking Sino-Tibetan phylogeny from the perspective of Northeast Indian languages. Trans-Himalayan-Linguistics ed. by Thomas Owen-Smith \& Nathan W. Hill, 71-104. Berlin: de Gruyter.

Bodt, Timotheus Adrianus. 2014a. Ethnolinguistic Survey of Westernmost Arunachal Pradesh- a Fieldworker's Impressions. Linguistics of the Tibeto-Burman Area 37:2.198-239. http://dx.doi.org/10.1075/1tba.37.2.03bod

Bodt, Timotheus Adrianus. 2014b. Notes on the settlement of the Gongri river valley of western Arunachal Pradesh. Bulletin of Tibetology 50:1\&2.153-190.

Bodt. Timotheus Adrianus. 2018a. Khispi Lexicon. Zenodo. http://doi.org/10.5281/zenodo.1406887

Bodt, Timotheus Adrianus. 2018b. Duhumbi Lexicon. Zenodo. http://doi.org/10.5281/zenodo.1291599

Bodt, Timotheus Adrianus. 2018c. Sartang Lexicon - Overview file. Zenodo. http://doi.org/10.5281/zenodo.1210131

Bodt, Timotheus Adrianus. 2018d. Sherdukpen Lexicon - Overview file. Zenodo. http://doi.org/10.5281/zenodo.1213719

Bodt, Timotheus Adrianus. 2019. The Duhumbi perspective on Proto-Western Kho-Bwa rhymes. Die Sprache 52:2.141-176. 
Bodt, Timotheus Adrianus. 2020. Proto-Western Kho-Bwa: regionally relevant basic vocabulary elicitation list. Zenodo. http://doi.org/10.5281/zenodo.3608408

Bodt, Timotheus A. \& Ismael Lieberherr. 2015. First notes on the phonology and classification of the Bangru language of India. Linguistics of the Tibeto-Burman Area 38:1.66-124. http://dx.doi.org/10.1075/1tba.38.1.03bod

Bodt, Timotheus A., Nathan W. Hill \& Johann-Mattis List. 2018. Prediction experiment for missing words in Kho-Bwa language data. Open Science Framework Preregistrations October 5. https://osf.io/evcbp/

Bodt, Timotheus A. \& Johann-Mattis List. 2019. Testing the predictive force of the comparative method: An ongoing experiment on unattested words in Western KhoBwa languages. Papers in Historical Phonology 4.22-44. http://journals.ed.ac.uk/pihph/issue/view/253

Bradley, David. 1977. Bisu Dialects, Languages and History in East Asia. Festschrift for Tatsuo Nishida on the Occasion of His 60th Birthday, ed. by Paul K. Eguchi et al., 32-59. Kyoto: Shokado.

Bradley, David. 1979. Historical Sketch of the Bisu Language. Minzu Yuwen 4.35-41. Bradley, David. 1985. Nasality in Bisu and Bisoid. Southeast Asian Linguistic Studies presented to André-G. Haudricourt, ed. by S. Ratanakul et al., 234-263. Nakhon Pathom: Institute of Language and Culture for Rural Development, Mahidol University.

Coblin, Weldon S. 1991. Notes on Old Tibetan rje-blas. Tibetan History and Language: Studies Dedicated to Uray Géza on his Seventieth Birthday (= Wiener Studien zur Tibetologie Buddhismuskunde, Heft 26), ed. by Ernst Steinkellner, 63-110. Wien: Arbeitskreis für Tibetische und Buddhistische Studien.

Coupe, Alexander R. 2007. A grammar of Mongsen Ao (= Mouton grammar library 39). Berlin: Mouton de Gruyter.

Das Gupta, Kamalash. 1968. An introduction to Central Monpa. Shillong.

Deuri, R. K. 1982. The Sulungs. Shillong: Government of Arunachal Pradesh.

Dondrup, Rinchin. 1988. A Handbook on Sherdukpen Language. Itanagar: Government of Arunachal Pradesh.

Dondrup, Rinchin. 1990. Bugun Language Guide. Itanagar: Government of Arunachal Pradesh.

Dondrup, Rinchin. 2004. An Introduction to Boot Monpa Language. Itanagar: Government of Arunachal Pradesh.

Doney, Lewis. 2013. Emperor, Dharmaraja, Bodhisattva? Inscriptions from the Reign of Khri Srong lde brtsan. Journal of Research Institute Kobe City University 51.63-84.

van Driem, George. 2001. Languages of the Himalayas - An Ethnolinguistic Handbook of the Greater Himalayan Region. Leiden: Brill.

Eberhard, David M., Gary F. Simons \& Charles D. Fennig, eds. 2019. Ethnologue: Languages of the World. $22^{\text {nd }}$ ed. Dallas: SIL International. https://www.ethnologue.com

Genetti, Carol. 2016. The Tibeto-Burman languages of South Asia: The languages, histories, and genetic classification. The Languages and Linguistics of South Asia: A Comprehensive Guide, ed. by Hans Heinrich Hock \& Elena Bashir, 130-145. Berlin \& Boston: de Gruyter Mouton.

Hammarström, Harald, Robert Forkel \& Martin Haspelmath, eds. 2019. Glottolog. Version 3.3. Leipzig. http://glottolog.org

Haspelmath, Martin \& Uri Tadmor, eds. 2009. Loanwords in the World's Languages: A Comparative Handbook. Berlin \& New York: Mouton de Gruyter. 
Haudricourt, André-Georges. 1970. Consonnes nasales et demi-nasales dans l'évolution des systèmes phonologiques. Actes du 10e Congrès international des Linguistes, Bucarest, 28 aô̂t-2 septembre 1967 4.105-108. Bucarest: Académie de la République socialiste de Roumanie.

Hill, Nathan W. 2019. The Historical Phonology of Tibetan, Burmese, and Chinese. Cambridge: Cambridge University Press.

Hill, Nathan W. \& Johann-Mattis List. 2017. Challenges of annotation and analysis in computer-assisted language comparison: A case study on Burmish language. Yearbook of the Poznan Linguistic Meeting 3:1.47-76.

Jacques, Guillaume. 2007. A shared suppletive pattern in the pronominal systems of Chang Naga and Southern Qiang. Cahiers de linguistique - Asie orientale 36:1.61-78.

Jacques, Guillaume. 2014a. Esquisse de phonologie et de morphologie historique du tangoute. Leiden: Brill.

Jacques, Guillaume. 2014b. 'On Coblin's Law'. Studies in Chinese and Sino-Tibetan Linguistics, ed. by Richard VanNess Simmons \& Newell Ann Van Auken, 155-65. Taipei: Institute of Linguistics, Academia Sinica.

Jacques, Guillaume. 2015. Le verbe de mouvement 'voler' en sino-tibétain. Panchronica, 16/10/2015, https://panchr.hypotheses.org/443

Jacques, Guillaume. 2016. Dictionnaire Japhug-Chinois-Français, version 1.1. Paris: Projet HimalCo.

Jacques, Guillaume. 2017. A reconstruction of Proto-Kiranti verb roots. Folia Linguistica Historica 38.177-215.

Jacques, Guillaume, Aimée Lahaussois, Dhan Bahadur Rai \& Kumar Yadav. 2015. KhalingNepali-English verb dictionary Version 1.0. Paris: Projet HimalCo.

Jacquesson, François. 2015. An introduction to Sherdukpen (= Diversitas Linguarum Vol. 39). Bochum: Universitätsverlag Dr. N. Brockmeyer.

Jäschke, Heinrich A. 1992 [1881]. Tibetan-English Dictionary, with special reference to the prevailing dialects (to which is added an English-Tibetan vocabulary). London.

Joseph U.V. \& Robbins Burling. 2006. The comparative phonology of the Boro Garo languages. Mysore: Central Institute of Indian Languages.

Lai, Yunfan. 2017. Grammaire du khroskyabs de Wobzi. PhD dissertation. Paris: Université Paris III.

Lander-Portnoy, Maury. 2013. Let Buguns be Buguns: A Preliminary Phonetics, Phonology, and Morphology of the Bugun Language. MA thesis. Swarthmore College.

Lǐ, Dàqín. 2004. Sūlóngyǔ yánjiū [Research on Puroik]. Běijīng: Mínzú chūbăn shè [National Minorities Publisher].

Lieberherr, Ismael. 2015. A progress report on the historical phonology and affiliation of Puroik. North East Indian Linguistics 7, ed. by Linda Konnerth et al., 235-286. Canberra: Australian National University.

Lieberherr, Ismael \& Timotheus A. Bodt. 2017. Sub-grouping Kho-Bwa based on cognate core vocabulary. Himalayan Linguistics Vol. 16:2.2-40. https://escholarship.org/uc/item/4t27h5fg

List, Johann-Mattis. 2017. A web-based interactive tool for creating, inspecting, editing, and publishing etymological datasets'. Proceedings of the $15^{\text {th }}$ Conference of the European Chapter of the Association for Computational Linguistics. System Demonstrations, ed. by Mirella Lapata, Phil Blunsom \& Alexander Koller, 9-12. Valencia: Association for Computational Linguistics.

List, Johann-Mattis. 2019. Automatic inference of sound correspondence patterns across multiple languages. Computational Linguistics 1:45.1-24. 
List, Johann-Mattis, Simon Greenhill, Tiago Tresoldi \& Robert Forkel. 2018. LingPy. A Python library for quantitative tasks in historical linguistics. Jena. http://lingpy.org.

Lorrain, James H. 1940. Dictionary of the Lushai language (=Bibliotheca Indica 261). Calcutta: Asiatic Society.

Matisoff, James A. 1972. The Loloish Tonal Split Revisited (= Research Monograph No. 7). Berkeley: Centre for South and Southeast Asia Studies, University of California.

Matisoff, James A. 2003. Handbook of Proto-Tibeto-Burman: System and philosophy of Sino-Tibetan reconstruction. Berkeley: University of California Press.

Matisoff, James A. 2009. Stable Roots in Sino-Tibetan/Tibeto-Burman. Senri Ethnological Studies 75.291-318.

Nishi, Yoshio. 1999. Four papers on Burmese: Toward the history of Burmese (the Myanmar language). Tokyo: Institute for the Study of Languages and Cultures of Asia and Africa, Tokyo University of Foreign Studies.

Nishida, Tatsuo. 1966a. Bisu Language Research - Preliminary Studies in the Language of the Bisu in Thailand. Southeast Asian Research 4:1.65-87.

Nishida, Tatsuo. 1966b. The Bisu Language System I. Southeast Asian Research 4.3:42-68.

Plaisier, Heleen. 2007. A grammar of Lepcha (=Languages of the Greater Himalayan Region 5). Leiden: Brill.

Post, Mark W. \& Robbins Burling. 2017. The Tibeto-Burman languages of Northeastern India. The Sino-Tibetan Languages, ed. by Graham Thurgood \& Randy J. LaPolla, 213-233. London: Routledge.

Ratliff, Martha. 2010. Hmong-Mien language history. Canberra: Pacific Linguistics, Research School of Pacific and Asian Studies, Australian National University.

Rutgers, Leopold. 1999. Puroik or Sulung of Arunachal Pradesh. Paper presented at the 5th Himalayan Languages Symposium. Kathmandu Guest House: Kathmandu.

Sagart, Laurent. 2014. A note on Tibeto-Burman bone words and Chinese pitchpipes. Studies in Chinese and Sino-Tibetan Linguistics: Dialect, Phonology, Transcription and Text, ed. by Richard VanNess Simmons \& Newell A. Van Auken, 179-83. Taipei: Institute of Linguistics, Academia Sinica.

Shafer, Robert. 1947. Hruso. Bulletin of the School of Oriental and African Studies 12.184196.

Shorto, Harry L. 2006. A Mon-Khmer comparative dictionary. Canberra: Pacific Linguistics, Research School of Pacific and Asian Studies, Australian National University.

Schuessler, Axel. 1998. Another note on Old Tibetan rje-blas. Linguistics of the TibetoBurman Area 21:2.3-4.

Stonor, Charles R. 1952. The Sulung tribe of the Assam Himalayas. Anthropos 47.947-962.

Sūn, Hóngkāi, ed. 1991. Zàng-Miǎn-yǔ yǔyīn hé cíhui [Tibeto-Burman Phonology and Lexicon]. Běijīng: Zhōngguó shèhuì kēxué chūbănshè [Chinese Social Sciences Press].

Sun, Tian-shin J. 1992. Review of Zangmianyu Yuyin He Cihui (Tibeto-Burman Phonology and Lexicon). Linguistics of Tibeto-Burman Area 15.73-113.

Sun, Tian-shin J. 1993. A Historical-Comparative Study of the Tani (Mirish) Branch in Tibeto-Burman. PhD thesis, Berkeley: Department of Linguistics, University of California.

Swadesh, Morris. 1971. The origin and diversification of language. New Jersey: Transaction Publishers.

Takeuchi, Tsuguhito. 1995. Old Tibetan contracts from Central Asia. Tokyo: Daizo Shuppan. Tayeng, Aduk. 1990. Sulung Language Guide. Itanagar: Government of Arunachal Pradesh.

Tshe-ring, rNam-rgyal, ed. 1997. Gǔ zàng wén cídiăn [Old Tibetan dictionary]. Běijīng: Zhōngguó zàng xué chūbăn shè [China Tibetology Publishing House]. 
Uebach, Helga \& Zeisler, Bettina. 2008. rJe-blas, pha-los and Other Compounds with Suffix $-\mathrm{s}$ in Old Tibetan Texts. Chomolangma, Demawend und Kasbek, Festschrift für Roland Bielmeier zu seinem 65. Geburtstag, ed. by Brigitte Huber, Marianne Volkart \& Paul Widmer, 309-334. Halle: IITBS.

VanBik, Kenneth. 2009. Proto-Kuki-Chin: A reconstructed ancestor of the Kuki-Chin languages (= STEDT Monograph 8). Berkeley: University of California.

$\mathrm{Xu}$, Shixuan. 2001. The Bisu language (=Languages of the World/materials 411). München: Lincom Europa.

Zhāng, Yísūn, ed. 1993. Zàng Hàn dà cídiăn [The Tibetan-Chinese Dictionary]. $2^{\text {nd }}$ ed. Běijīng: Mínzú chūbăn shè [National Publishing House]. 